\title{
The capsule of the fungal pathogen Cryptococcus neoformans
}

\author{
Oscar Zaragoza ${ }^{1}$, Marcio L. Rodrigues ${ }^{2}$, Magdia De Jesus ${ }^{3}$, Susana Frases ${ }^{3}$, Ekaterina \\ Dadachova ${ }^{4,3}$, and Arturo Casadevall $3,5,\left(^{*}\right)$ \\ ${ }^{1}$ Servicio de Micología. Centro Nacional de Microbiología. Instituto de Salud Carlos III. Crta \\ Majadahonda-Pozuelo, Km2. Majadahonda 28220. Madrid. Spain \\ 2 Instituto de Microbiologia, Universidade Federal do Rio de Janeiro, RJ, 21941-902 Brasil \\ ${ }^{3}$ Microbiology and Immunology Department. Albert Einstein College of Medicine. 1300 Morris Park \\ Avenue. Bronx, NY 10461 \\ ${ }^{4}$ Nuclear Medicine Department, Albert Einstein College of Medicine. 1695A Eastchester Rd. Bronx, \\ NY 10461 \\ ${ }^{5}$ Medicine Deparment. Albert Einstein College of Medicine. 1300 Morris Park Avenue. Bronx, NY \\ 10461
}

\begin{abstract}
The capsule of the fungal pathogen Cryptococcus neoformans has been studied extensively in recent decades, and a large body of information is now available to the scientific community. Well-known aspects of the capsule include its structure, antigenic properties and its function as a virulence factor. The capsule is composed primarily of two polysaccharides, glucuronoxylomannan (GXM) and galactoxylomannan (GalXM), in addition to a smaller proportion of mannoproteins (MP). Most of the studies on the composition of the capsule have focused on GXM, which comprises more than $90 \%$ of the capsule's polysaccharide mass. It is GalXM, however, that is of particular scientific interest because of its immunological properties. The molecular structure of these polysaccharides is very complex and has not yet been fully elucidated. Both GXM and GalXM are high molecular mass polymers with the mass of GXM equaling roughly 10 times that of GalXM. Recent findings suggest, however, that the actual $\mathrm{Mw}$ might be different to what it has traditionally been thought to be. In addition to their structural roles in the polysaccharide capsule, these molecules have been associated with many deleterious effects on the immune response. Capsular components are therefore considered key virulence determinants in Cryptococcus neoformans, which has motivated their use in vaccines and made them targets for monoclonal antibody treatments. In this review we will provide an update on the current knowledge of the $C$. neoformans capsule, covering aspects related to its structure, synthesis, and particularly, its role as a virulence factor.
\end{abstract}

\section{Introduction}

The adaptation of microorganisms to their environment is often associated with the acquisition of certain attributes that help improve survival in specific ecologic niches. Such adaptations include signal transduction pathways that optimize metabolism to respond to the nutritional environment, stress conditions and interaction with other biological systems, such as other microbes, environmental predators, and symbiotic hosts. In addition, it is common to find morphological changes and the development of specialized structures that provide the microbe with survival benefits during its life cycle. Among these structures, many microbes possess

(*) Corresponding author. Arturo Casadevall. Departments of Microbiology and Immunology and Medicine. Albert Einstein College of Medicine. 1300 Morris Park Avenue. Bronx, New York 10461. Phone + 718430 2811. casadeva @ aecom.yu.edu. 
capsules surrounding their cell body. Microbial capsules are usually composed of polysaccharides although some organisms, like Bacillus anthracis, have capsules composed of polymerized D-glutamic acids. Microbial capsules play important roles in the lives of these microorganisms, providing resistance to stressful conditions (such as dehydration), and playing a key role in the interaction with the environment.

Although capsules are commonly found among bacteria, there are a few encapsulated fungal species. The best characterized fungal capsule belongs to Cryptococcus neoformans. The capsule of this microorganism has been extensively studied because it is the main virulence factor of this pathogenic organism (McClelland et al., 2006). In the environment, the capsule plays a role in the protection of the organism against some stress conditions, such as dehydration (Aksenov et al., 1973). The C. neoformans capsule has some functional similarities to those of encapsulated bacteria such as, Streptococcus pneumoniae and Haemophilus influenzae (De Jesus et al., 2008; Kang et al., 2004). In fact, the cryptococcal polysaccharide is known to share some antigenic determinants with certain pneumococcal polysaccharides (Maitta et al., 2004b; Pirofski and Casadevall, 1996). The capsule is important for virulence, since acapsular mutants do not produce disease in murine models (Fromtling et al., 1982). The definitive experiment establishing the capsule as a virulence factor was accomplished when acapsular mutants were created and shown to be significantly less virulent than wild-type or capsule-reconstituted strains (Chang and Kwon-Chung, 1994). These mutants can survive and replicate in normal laboratory conditions but exhibit a markedly reduced virulence during infection in murine models. Interestingly, acapsular strains can be pathogenic for severely immunocompromised hosts implying a residual pathogenic potential for non-encapsulated yeast cells (Salkowski and Balish, 1991). These studies established that the capsule plays a predominant role in the interaction with the host. Consequently, this structure has been the main focus of attention in many experimental studies. Furthermore, studies have also shown that the capsular polysaccharide has strong immunomodulatory properties and promotes immune evasion and survival within the host (Monari et al., 2006a; Vecchiarelli, 2000). Besides mammalian hosts, studies focused on the capsule have also been extended to include environmental predators such as amoebae, since $C$. neoformans is both a pathogen and an environmental yeast and therefore interacts with multiple types of hosts.

A vast amount of knowledge has been accumulated on the biology, structure and role of the capsule during infection. The purpose of this manuscript is to give an overview of the main aspects of the capsule, including its structure, synthesis, and in particular, its role as a virulence factor.

\section{Section A Capsule components and structure}

The most characteristic feature of $C$. neoformans is a polysaccharide capsule that surrounds the cell body. The capsule is not visible by regular microscopy because it is highly hydrophilic, and due to its high water content it has the same refraction index as the medium. However, it can be easily made visible by several techniques. The classic image of the capsule is that of a halo surrounding the cell made visible by suspending the yeast in India ink preparations. The halo effect is a consequence of the fact that the capsule does not stain with India ink, visible only by a translucent area. It can also be nicely observed by other microscopic techniques, such as scanning electron microscopy and fluorescence. In figure 1 we have collected a series of images in which the capsule is made visible by means of these techniques. The cryptococcal capsule is composed of polysaccharide, causing it to be highly hydrophilic with an extremely high water content of $99 \%$ of the total weight of the capsule (Maxson et al., 2007a). The high hydration of the capsule makes it difficult to study. The polysaccharide capsule confers a strong negative charge by virtue of the glucuronic acid residues on its main polysaccharide component (Nosanchuk and Casadevall, 1997). The polysaccharides that constitute the capsule are found 
in two different locations. The first location is attached to the cell wall, forming the physical structure defined as the capsule. These polysaccharides are also constitutively released by the cell into the surrounding medium and environment, and they can be isolated as exopolysaccharides after certain purification protocols. It is not known whether the capsule's release into the medium is an active phenomenon regulated by the cell, or if it is just an unspecific capsule shedding. It is noteworthy that practically all our information about $C$. neoformans capsular polysaccharides originates from studies of exopolysaccharide components released from cells and recovered from culture supernatants. The field has operated under the notion that exopolysaccharide material is shed capsular polysaccharide and has extrapolated results obtained with this material to infer capsular characteristics. Recent evidence seems to suggest, however, that this assumption may be incorrect and that capsular and exopolysaccharide materials originate from different pools (see below, (Frases et al., 2008)). The exopolysaccharide material contains two major types of polysaccharides (PS), glucuronoxylomannan (GXM) and galactoxylomannan (GalXM). GXM comprises around $90-95 \%$ of the mass, and GalXM around 5-8\%. In addition, a small proportion of mannoproteins (MP) have been identified $(<1 \%)$, but this component has not been studied in detail and its role in capsule architecture, if indeed it has any, remains unknown. The polysaccharides have a complex structure that has not been completely characterized yet. An intriguing finding is that capsule structure is very variable depending on the strain (and on its the environment). It also changes during the course of an infection (Cherniak et al., 1995). Depending on these criteria, five different serotypes (A, B, C, D and AD) have been defined to classify $C$. neoformans strains, depending on the reactivity of the capsule with different rabbit polyclonal sera. Some of these classified serotypes include $C$. neoformans var. grubii (serotype A), C. neoformans var. gattii (serotypes B and C) and C. neoformans var. neoformans (serotypes D and AD). Recently, Cryptococcus gattii serotypes B and C have been proposed as new species because they present significant genetic and biological differences with serotypes A and D (Kwon-Chung and Varma, 2006). The capsular structures of the different serotypes have been studied using a variety of techniques, providing insights on the composition and organization of the capsular polysaccharides. In the next sections we will briefly review the main features of the main capsular components.

\section{A1. Structure of Capsular Components}

1) GXM structure-Based on the analysis of GXM purified from culture supernatants, this component has a high molecular mass with a complex structure. The average $M w$ can range from 1700 to $7000 \mathrm{kDa}$, depending on the strain (McFadden et al., 2006), and it comprises about $90 \%$ of the capsule's mass. There is evidence that the size distribution of the GXM molecules is more complex than initially observed (McFadden et al., 2006; McFadden et al., 2007). Structurally, GXM consists of a linear $\alpha$-(1,3)-mannan main chain with $\beta$ - $(1,2)$ glucuronic acid residues attached to every first mannose forming the basic core, with this unit repeated for all serotypes (Figure 2). Mannosyl residues can also be 6-O-acetylated and substituted with xylosyl units in $\beta$ - $(1,2)$ - or $\beta$ - $(1,4)$-linkages depending on the serotype (Cherniak et al., 1988; Cherniak and Sundstrom, 1994; McFadden et al., 2006; McFadden et al., 2007). Molar ratios of xylose, mannose, and glucuronic acid residues vary depending on the serotype with ratios $1: 3: 1,2: 3: 1,3: 3: 1$, and 4:3:1 for serotypes D, A, B and C, respectively (Cherniak and Sundstrom, 1994).

In contrast to bacterial polysaccharides that have a single oligosaccharide repeating unit, GXM has at least six different structure reported groups (SRGs) identified to date (Cherniak et al., 1998), based on the shift of the anomeric protons and mannosyl residues by ${ }^{1} \mathrm{H}-\mathrm{NMR}$ (Cherniak et al., 1998). These SRGs, classified as motifs 1 to 6 (M1-M6) of GXM, are shown in Figure 2. ${ }^{1} \mathrm{H}-\mathrm{NMR}$ analysis from GXM of $106 \mathrm{C}$. neoformans isolates showed six different chemotypes (Cherniak et al., 1998). A seventh GXM repeating unit was recently described by 
Nimrichter and co-workers (Nimrichter et al., 2007), who characterized a substituted triad in GXM from encapsulated cells that had only been described in polysaccharide fractions from a hypocapsular mutant (Bacon et al., 1996). This structure, called hexasaccharide 1 by Bacon and colleagues (Bacon et al., 1996), is also shown in Figure 2. Later, McFadden et al. found evidence of co-polymerization of different GXM repeating units in one polysaccharide using mass spectrometry (McFadden et al., 2007). In some C. neoformans strains GXM is composed of a single repeating unit whereas in other strains the polysaccharide contains multiple units. Furthermore, those strains that utilize the same set of repeating units often differ from one another by the ratio of those units within the GXM molecule. These differences in ratios result in GXM's compositional similarity while allowing for slight differences in structures that translate into antigenic differences (McFadden et al., 2007).

All the structural studies available to date use exopolysaccharides extracted by cetyl trimethylammonium bromide (CTAB) precipitation as described by Cherniak et al (Cherniak et al., 1998). More recently, a new method of exopolysaccharide extraction based on filtration and the tendency of polysaccharide to self-aggregate has been described (Nimrichter et al., 2007). Using this method, concentration of $C$. neoformans supernatants resulted in the formation of a jellified polysaccharide film providing a one-step procedure for its isolation (Nimrichter et al., 2007). Polysaccharides obtained from the ultrafiltration display differences in the reactivity with GXM-specific monoclonal antibodies when compared with polysaccharides obtained by differential precipitation with CTAB. Viscosity analysis associated with inductively coupled plasma mass spectrometry and measurements of zeta potential in the presence of different ions, strongly suggested that polysaccharide aggregation was a consequence of the interaction between the carboxyl groups of glucuronic acid (GlcA) and divalent cations. The length of a GXM fiber from solution supernatants is shorter than the capsule diameter (McFadden et al., 2006). All these results suggest that capsular assembly in C. neoformans results from divalent cation-mediated self-aggregation of GXM molecules (Nimrichter et al., 2007).

Polysaccharides recovered from culture supernatants have historically provided an ample and convenient source of material for structural and immunological studies. A major assumption in such studies is that the structural features of the exopolysaccharide material faithfully mirror those of the capsular polysaccharide. This remains a mere assumption, and the exact reasons why the polysaccharide is released are still unknown. In fact, it is conceivable that exopolysaccharide differs from capsular polysaccharide in that the former has structural features intended for extracellular release, and thus, the two materials differ in fundamental ways. Suspension of acapsular cells in soluble capsular polysaccharide resulted in the presence of a capsule forming around the cell as was visualized by fluorescence, but the degree of encapsulation was much lower than is commonly seen in regular encapsulated strains. The binding was dependent on the polysaccharide concentration, with high concentrations resulting in non-specific polysaccharide binding to the cell (Kozel, 1977; Kozel and Hermerath, 1984). These findings suggest that a proportion of exopolysacharides retain their ability to form a capsule. The finding that this capsule is much smaller than what is generally found in encapsulated strains, suggests that a significant proportion of exopolysaccharides have different structural features than the polysaccharide that make up the normal capsule in wildtype strains. Structural analysis of the capsular polysaccharides (not exopolysaccharide) has been limited for a long time because of a lack of efficient protocols for separating the capsule from the cell. However, in the last years, different groups have described the exposure of the cells to $\gamma$-radiation or suspension in DMSO resulting in the release of the capsule from the cells (Bryan et al., 2005; Dembitzer et al., 1972; Gates et al., 2004). This has led to the possibility of studying the structural features of the polysaccharide that remain attached to the cell, forming a visible capsule. This approach allowed for the detailed study of different regions of the capsule (inner capsule, medium capsule and outer edge). An additional advantage of stripping 
the capsule with $\gamma$-radiation versus DMSO is that the cells remain viable after radiation treatment (Bryan et al., 2005).

Comparison of exopolysaccharide obtained by two isolation techniques with capsular polysaccharide (PS) stripped from cells exposed to gamma radiation or treated to DMSO, revealed significant differences in glycosyl composition, mass, size, charge, viscosity, circular dichroism spectra and reactivity with monoclonal antibodies (mAbs). This implies that exopolysaccharides and capsular PS are structurally different and originate from different synthetic pools. Hence, the method used to isolate PS can significantly influence the structural and antigenic properties of the product (Frases et al., 2008).

Structural information provided by antibodies to GXM-A large number of monoclonal antibodies (mAbs) that bind to the $C$. neoformans capsule have been obtained (Casadevall et al., 1994; Casadevall et al., 1992; Dromer et al., 1987b; Eckert and Kozel, 1987; Pirofski et al., 1995; Todaro-Luck et al., 1989; van de Moer et al., 1990). Most of these antibodies were obtained after mouse immunization with purified GXM. At present, antibodies differing in affinity, specificity, and isotype are available for the study of the capsule. In addition to immunological studies examining their protective effect during infection, these antibodies have proven to be a useful tool to study the structure and properties of the $C$. neoformans capsule. Studies with mAbs have revealed that the capsule has a very heterogeneous structure, and that several different epitopes are likely to be present in the same GXM molecule (Belay et al., 1997; Todaro-Luck et al., 1989). They have shown that this heterogeneity can be found between different strains, as well as within a population of the same strain (McFadden et al., 2007). Several factors determine the specificity and affinity of the mAbs to GXM, such as acetylation and xylosylation (Kozel et al., 2003; Todaro-Luck et al., 1989). Several genetic screenings have been performed with the aim of obtaining mutants with altered binding to specific $\mathrm{mAbs}$. These mutants were not acapsular, but deficient in acetylation and xylosylation (Kozel et al., 2003), demonstrating the importance of this process for some of the functions associated with GXM. Monoclonal antibodies to the capsule have also been used in immunoblotting experiments, which have shown that the size distribution of the GXM molecules is very complex (McFadden et al., 2006). It has also been shown that the binding affinity of these antibodies varies according to the different capsule regions (Maxson et al., 2007b). This confirms that capsule structure is very heterogeneous, not only at the level of a single GXM molecule, but also in terms of the spatial and structural organization of the capsule.

2) GalXM structure and localization in the capsule-GalXM constitutes about $8 \%$ of the capsular mass (Bose et al., 2003; Vaishnav et al., 1998) and has an $\alpha-(1 \rightarrow 6)$-galactan backbone containing four potential short oligosaccharide branch structures (Figure 3). The branches are 3-O-linked to the backbone and consist of an $\alpha(1 \rightarrow 3)$-Man, $\alpha(1 \rightarrow 4)$-Man, $\beta$ galactosidase trisaccharide with variable amounts of $\beta(1 \rightarrow 2)$ - or $\beta(1 \rightarrow 3)$-xylose side groups (Bose et al., 2003; McFadden et al., 2006; Vaishnav et al., 1998). The GalXM backbone consists of galactopyranose and a small amount of galactofuranose (Vaishnav et al., 1998), unlike GXM, which contains only mannopyranose (Bose et al., 2003). Compositional analysis of GalXM was confirmed by gas chromatography/mass spectrometry of the per- $O$ -

trimethylsilyl derivatives of the monosaccharide methyl glycosides produced from the sample by acidic methanolysis. The analysis revealed that the molar percentage for GalXM were as follows: xylose, 22\%; mannose, 29\%; and galactose, 50\% (De Jesus et al., 2008; Vaishnav et al., 1998). GalXM is very sensitive to oxidation with sodium periodate, which destroys the integrity of most of the carbohydrats. Xylose residues are completely eliminated and two-thirds of galactose and mannose residues oxidized (Cherniak, 1982). To elucidate the proposed structure of GalXM repeats, proton nuclear magnetic resonance spectrum analysis was used to determine the anomeric region of the galactan building unit. The results showed the anomeric region to be between 5.4 and $4.3 \mathrm{ppm}$ in a one-dimensional ${ }^{1} \mathrm{H}$ spectrum recorded at $600 \mathrm{MHz}$ 
and $56^{\circ} \mathrm{C}$ (De Jesus et al., 2008; Vaishnav et al., 1998). Although the GalXM from serotypes $\mathrm{A}, \mathrm{C}$ and $\mathrm{D}$ all contained galactose, mannose and xylose, it has been shown that the molar ratios are not identical, suggesting that there may be more than one GalXM entity. GalXMs are thought to be a group of complex closely related polysaccharides (James and Cherniak, 1992; Vaishnav et al., 1998).

A recent study showed that GalXM is significantly smaller than GXM $\left(1.7 \times 10^{6} \mathrm{Da}\right)$, with an average mass of $1 \times 10^{5} \mathrm{Da}$ (McFadden et al., 2006). Additionally, the radius of gyration $\left(\mathrm{R}_{\mathrm{g}}\right)$, defined by the average distance between the center to the outer edge of the molecule, was measured for both GXM and GalXM. The results revealed that for GXM different strains showed differences of $68-208 \mathrm{~nm}$ while GalXM isolated from the acapsular strain cap67 was 1.4-fold smaller than GXM with an $\mathrm{R}_{\mathrm{g}}$ of $95 \mathrm{~nm}$ (McFadden et al., 2006). Attempts to image GalXM by scanning transmission electron microscopy (STEM) were unsuccessful, possibly because the molecule was too narrow to be detected (McFadden et al., 2006). GalXM is the most abundant polysaccharide in the capsule based on its molar mass, since GalXM has a comparatively smaller molecular weight, with 2 to $3.5 \mathrm{~mol}$ of GalXM for each mole of GXM. The widespread assumption that GXM was the most abundant molecule was based on the total amount of material that was recovered from the culture supernatant (McFadden et al., 2006). It is noteworthy that all studies of GalXM used material obtained from non-encapsulated strains that failed to secrete GXM. This is due to an absence of adequate methods available that are able to separate GalXM from GXM in exopolysaccharide preparations to yield GalXM of sufficient purity for structural studies. However, given that non-encapsulated strains often have secretion defects (Garcia-Rivera et al., 2004), this introduces the conundrum that the GalXM so obtained may not be in its native state.

While GXM seems to be distributed throughout the capsule, the exact location of GalXM is not known as there is no visualization method available to help determine this (such as an antibody to GalXM). Experiments aimed at purifying GalXM revealed that supernatant fractions following homogenization of cell walls derived from the acapsular strain cap67 contained both GalXM and mannoproteins. It was demonstrated that GalXM and MP do not form a part of the cell wall matrix since they are not covalently bound to glucans within the cell wall (James and Cherniak, 1992). GalXM and MP can be separated using Concanavalin A affinity chromatography which binds MP, with the eluate containing GalXM (James and Cherniak, 1992; Vaishnav et al., 1998).

Capsular studies by Bryan et al. noted the absence of galactose in the fraction removed by radiation alone, which represents the outer most section of the capsule (Bryan et al., 2005). This was interpreted to indicate an absence of GalXM in the outer layers of the capsule. The compositions of the outer layer of the capsule removed by either DMSO or radiation alone were similar. This result was consistent with the observation that both DMSO and radiation removes the same part of the capsule. Neither radiation nor DMSO removed the portion of the capsule in the region closest to the cell wall. This can be explained by the fact that the inner radiation- and DMSO-resistant capsule and the outer radiation- and DMSO-susceptible regions have differences in terms of their chemical compositions, branching or the density of molecules packed. In these studies it was also noted that GXM protects against radiation with a possibility that GalXM in the inner capsule also contributed to the effect of radioresistance observed by that layer (Bryan et al., 2005).

Another study utilized low doses of gamma radiation to investigate the structure of the $C$. neoformans capsule (Maxson et al., 2007b). The authors prepared two different fractions of the capsule by irradiating C. neoformans H99 strain for 20 minutes, enough time to allow for the lower density part of the capsule to be stripped. The second part of the experiment included washing and irradiating for another 20 minutes, which stripped away the higher density region 
of the capsule. The results revealed no differences in terms of the carbohydrate composition. However, the occurrence of galactose was found with both strippings, which was interpreted to signify that GalXM is present throughout the capsule (Maxson et al., 2007b).

Structural information provided by antibodies to GaIXM-In the early 1990's, van de Moer et al. generated six mAbs against spheroplast lysate of $C$. neoformans serotype A. MAb CN6 of the IgM isotype was reactive with GalXM. The CN6 antibody binding was blocked by the presence of GXM but the acapsular mutants were able to bind the antibody (James and Cherniak, 1992; van de Moer et al., 1990). Immunogold transmission electron microscopy and a microagglutination assay demonstrated through epitope recognition by the monoclonal antibody CN6 that GalXM was located within the cytoplasm and the cell wall in acapsular strains (Vaishnav et al., 1998). Unfortunately, the antibodies were not used again for any subsequent studies and are apparently no longer available.

Mannoproteins-Classically, mannoproteins (MP) have been considered as minor components of the capsule, but their role in capsule architecture has never been established. Their presence was identified in culture filtrates by ${ }^{13} \mathrm{C}-\mathrm{NMR}$ analysis of the GXM-free portion of the GalXM-enriched fraction (Murphy, 1988; Reiss et al., 1985). Very little is known, however, about their function and the role they play in the capsule. Some articles have investigated the location of MP on cryptococcal cells and concluded that they are mainly found in the inner cell wall, and not associated with GXM or GalXM (Vartivarian et al., 1989). It has been shown that mannoproteins are highly immunogenic during infection, which will be discussed in a different section.

\section{A.2.- Capsule dynamics}

In this section, we will review an important aspect of the capsule that has important implications for the virulence of the organism, namely the ability of Cryptococcus neoformans to modify the size and structure of its capsule in response to various stimuli. Since the capsule is presumably the first fungal structure that interacts with host cells, the capability for multiple combinations of capsule size and structure makes this a very versatile structure. Changes in capsule size are typical features among $C$. neoformans strains during the interaction with the host, and are considered an early morphologic response during infection. Capsule enlargement occurs after a few hours of infection in murine models (Feldmesser et al., 2001). Moreover, it is also observed to occur during C. neoformans intracellular parasitism. This phenomenon has been elegantly illustrated using live imaging techniques (see supplemental movie 1 in (Ma et al., 2006)). In addition, during the course of infection, the immunogenic properties of the capsule can change, a finding that is also considered as an adaptation phenomenon to survive in the host.

Capsular enlargement-The size of the capsule is very variable, not only among strains, but also between individual cells of the same strain, to such an extent that a given strain can exhibit large differences in capsule size depending on the specific environmental conditions. There are many different conditions that lead to capsule enlargement in natural environments. In laboratory conditions there are several factors that are known to influence capsule size.

In the late 1950s, it was Littman who described for the first time that capsule size in $C$. neoformans could be modulated in vitro by placing the cells in different growth conditions. He described several minimal media in which he observed a significant increase in capsule size (Littman, 1958). The inducing factors in that media still remain unknown. In 1985, carbon dioxide was described as a factor that had an influence on capsule size. In that work, Granger et al. found that when the cells were placed in a $\mathrm{CO}_{2}$ enriched atmosphere (5\%) the capsule manifested a significant enlargement (Granger et al., 1985). These authors also isolated mutants 
defective in capsule growth in the presence of $\mathrm{CO}_{2}$, and demonstrated that it had reduced virulence in murine models, which provided the first evidence that the phenomenon of capsular enlargement played a role in the pathogenesis of the microorganism. Consistent with these findings it was found that strains which differed in terms of their capsule size also differed in their virulence and in their effects on macrophages. The strain with reduced virulence was not able to increase capsule size in the presence of $\mathrm{CO}_{2}$. During infection, the strain unable to induce capsule size elicited a rapid inflammatory response in the host and was efficiently cleared from the lungs (Blackstock et al., 1999; Blackstock and Murphy, 1997). These reports provided strong evidence that capsule enlargement is a process that plays an important role during infection. Several studies have found, however, that virulence is not correlated with in vitro capsule size (Clancy et al., 2006; Dykstra et al., 1977; Littman and Tsubura, 1959). This lack of correlation is most probably due to the fact that in vitro capsule size does not predict the degree of encapsulation of a strain during infection seen in vivo. Furthermore, $C$. neoformans has multiple virulence factors that contribute to the overall virulence phenotypes and it is possible that differences in non-capsular virulence factor expression affect the overall virulence potential to obscure a correlation with capsule size (McClelland et al., 2006). In 1993, iron limitation was shown to result in capsule enlargement (Vartivarian et al., 1993). The fact that both $\mathrm{CO}_{2}$ and iron limitation influenced capsule size is particularly interesting because these conditions mimic some situations that the microorganism encounters during lung colonization. In addition, capsule size during infection varies according to the organ infected, the lung being the place where higher capsule size is found, which indicates that microenvironments during infections have a great impact on capsule size (Rivera et al., 1998). Iron is an essential nutrient for the life of the yeast whose concentration in the host is normally very low, so the yeast must compete with iron binding proteins from the host such as transferrin. It is not known why $C$. neoformans responds to iron limitation by enlarging its capsule, but it has been suggested that the capsule might contribute to iron uptake (Vartivarian et al., 1993). Therefore, capsule growth could increase the iron concentration available to the yeast.

More recently other media that induce capsule growth have been described. In the context of media that mimic infection situations, mammalian serum was found to induce in vitro capsule growth in the absence of $\mathrm{CO}_{2}$ (Zaragoza et al., 2003a). Those studies also established that the incubation media had a major determinant effect on the efficacy of inducing factors, such as serum or $\mathrm{CO}_{2}$. Furthermore, results showed that the behavior of different strains varies and that the optimal conditions to obtain capsule growth should be standardized for every strain.

The signals that induce capsule growth are very heterogeneous (iron concentration, $\mathrm{CO}_{2}$, serum), and it is not clear if they induce capsule enlargement through different pathways and whether there is a common element to all of these factors that the cell senses as a capsuleinducing factor. In all the media described that are known to induce capsule growth a significant decrease in the growth rate of the yeast has been observed. It is therefore believed that capsule growth occurs under certain conditions where yeast grows very poorly. Accordingly, media which contain low nutrient concentrations, such as diluted Sabouraud buffered at a neutral $\mathrm{pH}$, induced a significant increase in capsule size (Zaragoza and Casadevall, 2004), supporting the hypothesis that capsule growth is probably inversely related to the growth rate of yeast. While a slow as opposed to a rapid growth rate of yeast appears to be a requirement for induction of capsule growth, this is apparently not sufficient, since conditions have been observed in which the yeast grows slowly that do not lead to capsule enlargement.

Physical factors that affect capsule size-Capsule size also changes in the presence of certain factors that affect its structure or its packing without affecting the amount of polysaccharide accumulated in the capsule. One such factor is the effect of the osmotic pressure of the medium. Addition of a high $\mathrm{NaCl}$ concentration produces a reduction in capsule size 
(Dykstra et al., 1977). The same effect is produced by glucose concentrations over 10\%, a finding that has been correlated to an increase in osmotic pressure of the medium. There are several explanations for these findings. It is possible that a high osmotic pressure produces an effect whereby a significant part of the water content of the capsule is lost in these conditions, which in turn, results in an increase in the packing of the polysaccharide fibers and thereby a decrease in capsule size. Concerning glucose effect, it has also been described that growth of the cells in high glucose concentration produces a higher polysaccharide release to the growth medium (Cleare and Casadevall, 1999), which suggests that carbon metabolism might be an important factor in capsule synthesis. Another element that has been reported to influence capsule size is the binding of monoclonal antibodies. Cleare and Casadevall reported that appearance of the cells by scanning electron microscopy was affected by the presence of $\mathrm{mAb}$ 2H1 (Cleare and Casadevall, 1999). Later on, it has been described that binding of a high amount of mAb 18B7 to the capsule produces a drastic decrease in capsule size (Zaragoza and Casadevall, 2006). Monoclonal antibodies tend to bind to each other through interactions of the constant regions, which could feasibly produce a force within the capsule resulting in a compaction of the polysaccharide fibers toward the cell body. Moreover, capsule size decreases in the presence of monoclonal antibodies can result not only in a diminished capsular size, but also in one with irregular edges, in which the morphology changes and the capsule loses its characteristic spherical shape (Zaragoza and Casadevall, 2006).

However, recent findings suggest new explanations for the different packing of the polysaccharide fibers in different conditions. Capsule enlargement is facilitated under alkaline conditions (Zaragoza and Casadevall, 2004), which is consistent with the view that capsule growth requires the acidic groups of glucuronic acid (GlcA) residues to be ionized, possibly so that they can react with divalent cations for capsule assembly (see below). It is noteworthy that mammalian physiological fluids are usually slightly alkaline. In addition, since the finding that high $\mathrm{NaCl}$ concentration blocks capsule growth does not generally apply to other solutes, it has been proposed that capsule growth could be inhibited in the presence of $\mathrm{Na}^{+}$by univalent neutralization of negatively charged GlcA residues (Nimrichter et al., 2007).

In plant cell walls, galacturonans can be cross-linked by insertion of $\mathrm{Ca}^{2+}$ ions between the unesterified carboxyl groups of the uronosyl residues (Vincken et al., 2003). The same property was recently described for GXM which self aggregates through a divalent metal-mediated process (Frases et al., 2008; McFadden et al., 2006; Nimrichter et al., 2007). The efficacy of this association depended on water removal and increased polysaccharide concentration (Nimrichter et al., 2007), which allowed an efficient interaction between GXM fibers and divalent ions at neutral and alkaline $\mathrm{pH}$ (pK of glucuronides, $\geq 3$ ). Accordingly, carboxylreduction of GXM, as well as its treatment with EDTA, monovalent ions and excessive concentrations of $\mathrm{Ca}^{2+}$ impaired self-aggregation (Nimrichter et al., 2007). These observations suggested that divalent metals could regulate the aggregation of GXM fibers.

The cultivation of cryptococci in the absence of divalent ions was associated with smaller capsules and a concomitant increase in the concentration of GXM in supernatants, presumably as a result of incomplete assembly (Nimrichter et al., 2007). In contrast, the addition of increasing concentrations of $\mathrm{Ca}^{2+}$ to the culture medium resulted in augmented capsule expression that was associated with decreased levels of soluble GXM in fungal cultures. Finally, high concentrations of $\mathrm{Ca}^{2+}$ caused a decrease in capsule sizes (Nimrichter et al., 2007). Interestingly, dead C. neoformans cells incorporated exogenous GXM in the presence of varying $\mathrm{Ca}^{2+}$ concentrations. A possible explanation for these findings is based on the stoichiometric ratio between divalent cations and glucuronic acid residues. According to this model, divalent ions would be expected to positively modulate capsule assembly by forming ionic bridges between glucuronic acid residues in different GXM fibers. In this context, metal ion concentrations compatible with a 1:2 metal ion-GlcA ratio in cryptococcal cultures would 
promote capsule growth, while the capsule would be reduced when the metals were provided in excess. These results are consistent with and support the notion that divalent cation-mediated aggregation of GXM is involved in capsule enlargement.

Recent findings suggest that capsule size and packing depends on the interaction of its basic components, GXM and GalXM. Mutants that cannot synthesize GalXM manifest larger capsules than the isogenic wild-type strains, suggesting that GalXM plays an important structural role in maintaining a certain capsule size, and in turn, structure and density. It could also suggest that in the absence of GalXM the cell responds by overproducing GXM molecules, resulting in a higher capsule size (Moyrand et al., 2007).

Physical changes associated with capsule growth-Capsule growth is achieved by addition of polysaccharide to the capsule, which implies that capsule enlargement is a high energy consuming process. Addition of new polysaccharide to the capsule leads to an increase in the density of the polysaccharide, especially in the regions closer to the cell wall. This has been proven by different groups using different approaches, based on microscopy, immunogenic properties and direct polysaccharide measurement in different capsule regions (Gates et al., 2004; Maxson et al., 2007b; Pierini and Doering, 2001). A characteristic feature of the encapsulated cells is a very high negative zeta potential value due to the high number of glucuronic acid residues in the capsular polysaccharide of cryptococcal cells. Different studies suggest that capsule enlargement is associated with a decrease in the zeta potential value consistent with larger negative surface charges (Maxson et al., 2007b; Nosanchuk and Casadevall, 1997). It has been reported that the binding of mAbs to the capsule changes its permeability, a phenomenon that is correlated with a phenomenon known as quellung reaction (MacGill et al., 2000; Mukherjee et al., 1995a). Yoneda and Doering (2007) observed in immunoblotting experiments that the size distribution of exopolysaccharide GXM varied when the capsule enlargement was induced (Yoneda and Doering, 2008), which suggests that in these conditions, the GXM fibers that are produced and incorporated in the capsule are different, at least in size.

Capsule growth model-The mode of polysaccharide accumulation on the capsule has been the subject of many different studies. For this purpose, different methods have been used to label the capsule prior to induction and trace the label once the cell triggers the signals to increase capsule size. The first study used a monoclonal antibody and radioactive xylose (Pierini and Doering, 2001). This approach revealed that the marker moved to the edge of the capsule after induction, an observation that was interpreted as indicating that the capsule grows by accumulation in the inner part of the capsule, displacing the old capsule to the edge.

However, since antibody binding is not covalent and antibody-antigen interactions are prone to dissociation and association, there was some concern that the antibody was not a stable capsule geographical marker. More recently a similar approach was employed, using a marker that covalently binds to the capsule (Zaragoza et al., 2006b). This marker was provided by proteins from the complement systems, which bind to the polysaccharide capsule fibers through covalent bonds. Using this approach, it was shown that the old polysaccharide fibers remained in a position close to the cell wall after capsule induction, suggesting that capsule growth was achieved by addition of the polysaccharide fibers at the capsule edge (Figure 4A). The authors confirmed this result by giving a pulse of radioactive mannose prior capsule induction, and then establishing the localization of the radioactive label in different regions of the capsule obtained after gamma radiation treatment of the cells. Consistent with this last model, Charlier et al. found that during infection, there is a difference in the binding pattern of specific antibodies to the capsule after capsular enlargement during infection (Charlier et al., 2005). These investigators infected mice with a $C$. neoformans strain that reacted to $\mathrm{mAb}$ E1 which is specific for serotype A. After 6 hours of infection, they observed that a new area surrounding the E1-binding region appeared which was not reactive to this antibody anymore, but to another 
mAb named CRND-8, raised against serotype D strains. These findings suggest that new polysaccharide is added at the capsule edge such that capsular enlargement proceeds by apical growth.

Capsule rearrangements during budding-Capsule growth poses a problem for the cell because during budding, the new cell has to traverse the width of the parental capsule to separate from the mother cell. Theoretically, the presence of a dense net of polysaccharide fibers around the cell wall could interfere with bud migration and separation. However, the fact that a cell buds successfully implies the existence of mechanisms to ensure bud separation. Several lines of evidence have suggested the existence of a mechanism for this phenomenon. 1) When a $C$. neoformans cell is coated with a mAb and then placed in a medium that induces budding, the mAb does not migrate to the bud (Pierini and Doering, 2001; Zaragoza et al., 2006b); 2) the binding of mAbs to the capsule over the bud is different from the binding to the capsule of the mother cell, which suggests that the capsules does not mix during budding (Zaragoza et al., 2006b); 3) when budding cells with large capsule are incubated with complement, immunoflourescence staining for complement proteins is not observed in the regions that separate the bud and the mother cell (Zaragoza et al., 2006b); 4) when cells with large capsule start budding, it is possible to observe some rearrangement at the regions of the capsule of the mother cell where the bud is forming. Furthermore, it is possible to observe a dimple on encapsulated budding cells which suggests that the capsule disappears at the region where the bud will appear. In cells coated with complement it is also possible to observe some rearrangements in the capsular region of bud emergence. This suggests that during budding, the capsule of the mother cell opens, leaving an empty space for the bud to migrate through; 5) the region of the capsule where the bud is going to emerge becomes highly permeable to India Ink (Pierini and Doering, 2001); 6) when budding cells with large capsule are placed in the presence of serum for a very short time period, thus allowing complement deposition, complement proteins accumulate in the region between the bud and the mother cell, suggesting that in the capsule region where the capsule is going to pass there are not fibers, which would facilitate the migration of the bud; 7) scanning electron micrographs have shown a physical separation between the capsules of the mother cells and the bud (Zaragoza et al., 2006b).

All these observations led us to propose a model to explain how the bud crosses the capsule of the mother cell without being retained, or entangled, within the polysaccharide fibers of the mother cell (see Figure 4C). We hypothesized than when the bud emerged from the mother cell, there are some rearrangements in the region where the bud has to pass, which produce the formation of a tunnel in the capsule, creating a physical space that allows the bud to migrate through the capsule. The description of bud scars in the capsule supports this idea (Cleare and Casadevall, 1999). The presence of chitin-like structures in the cell wall which are projected into the capsule have been recently described (Rodrigues et al., 2008a). Staining for this structure is particularly abundant in the neck around the bud, which suggests that these structures could be involved in the migration of the bud through the mother's cell capsule.

Capsule degradation-An interesting feature that has hardly been addressed is how the capsule is degraded and how the cells diminish their capsule size in adaption to the environment. For example, after passage through hosts, the capsule of the C. neoformans cells reverts to a small size. During budding, the creation of the tunnel described above could imply the degradation of the polysaccharide fibers in the budding area of the capsule. However, despite these situations in which a reduction or degradation of capsule size seems to be required, no capsule degrading enzymes have been described so far in C. neoformans. Moreover, preliminary findings indicate that when cells with a large capsule are shifted to a medium where the capsule is small, the cells do not degrade the capsule, and they retain a considerable capsule size (Zaragoza et al., 2006b). Although the cells initially placed in the new medium remain with an enlarged caspule, the buds that emerge in the new medium have a small capsule, which 
suggests that when C. neoformans is shifted to a medium which does not require a large capsule, the adaptation mechanism cause the cells to invest their cellular energy in producing buds with the proper capsule size, and not in degrading the capsule (figure 4B). It also seems to suggest that during budding, a mechanism of capsule release occurs in the budding area without actual capsule degradation. Since budding implies cell wall degradation, and the capsule is linked to the cell wall, it is believed that the capsule fibers are released by rearrangements in cell wall, rather than through direct capsular polysaccharide degradation. This issue remains a key point in the cryptococcal biology that needs to be further examined.

Capsule structural changes in vitro and during infection-In addition to capsule growth, several other phenomena indicate that the capsule is dynamic, which is related to an inherent ability of $C$. neoformans cells to alter their capsular structure. As mentioned above, not only are physical changes observed in terms of density, but also alterations with regards to the structure of the polysaccharide fibers. Turner et al. found that capsule structure from different strains from within the same serotype (serotype A) differed in their structure as shown by chemical analysis and ${ }^{13} \mathrm{C}$ NMR spectroscopy (Turner et al., 1992). Different groups have found that even within the same population, there are significant changes in the immunoreactivity of $C$. neoformans cells to specific mAbs (Garcia-Hermoso et al., 2004; McFadden et al., 2007). This heterogeneity is also a characteristic feature of these cells seen during infection (Garcia-Hermoso et al., 2004).

Structural changes are relevant during the course of infection, especially during the interaction with phagocytic cells. Addition of purified capsular polysaccharide isolated from different serotype A strains to acapsular mutants produces different effects on phagocytosis, for example (Small and Mitchell, 1989). Furthermore, C. neoformans phagocytosis by amoeba is influenced by the incubation medium, a phenomenon that has been related to differences in capsule structure in accordance with the surrounding environment (Zaragoza et al., 2008b). Finally, capsule structure changes have been implicated in dissemination (Charlier et al., 2005). These implications will be discussed in more detail in the coming sections.

Capsule and phenotypic switching-As is seen in other fungi (such as Candida albicans), $C$. neoformans undergoes macroscopic changes, determining different phenotypic morphologies, through a process known as phenotypic switching (Goldman et al., 1998). Two different variants have been defined, smooth and mucoid. These variants manifested different virulence, and it was later shown that they differed in terms of their capsular structure (Fries et al., 1999; McFadden et al., 2007). Similar findings have recently been reported for Cryptococcus gattii (Jain et al., 2006). Although it has not been demonstrated that capsule changes are responsible for phenotypic switching, this phenomenon and its correlation with capsule variation is a clear example of how $C$. neoformans can produce dynamic capsule changes in correlation to variations in phenotypes and related to virulence.

\section{Section B Capsule synthesis in Cryptococcus}

\section{B.1) Genes, enzymes and signaling pathways}

The CAP genes-During the last decade, different genes involved in capsule biosynthesis have been identified. The first one, CAP59, was cloned by complementation of an acapsular mutant isolated by uv random mutagenesis (Chang and Kwon-Chung, 1994). The gene was deleted by homologous recombination and resulted in an acapsular phenotype associated with loss of virulence in an animal model of cryptococcal infection. The restoration of virulence by complementation of the acapsular phenotype represented the first molecular evidence for the capsule as a virulence factor of $C$. neoformans. At the time of the study by Chang and KwonChung (Chang and Kwon-Chung, 1994), no sequences similar to that found in the CAP59 gene had been reported, More recently, CAP59 sequence presents homology with a cryptococcal 
$\alpha$-1,3-mannosyltransferase (Sommer et al., 2003). Cap59p has a putative transmembrane domain, and it was further suggested to play a role in capsule secretion (Garcia-Rivera et al., 2004). Interestingly, CAP59 was considered to be related to the $L 27$ gene (Chang and KwonChung, 1994), which encodes for a ribosomal protein that is present in secretory vesicles carrying capsular polysaccharides in C. neoformans (Rodrigues et al., 2008b; Rodrigues et al., 2007).

Following the molecular characterization of $C A P 59$, three other $C A P$ genes were identified. CAP64 was the second capsule-related gene described in C. neoformans (Chang et al., 1996). The gene demonstrated similarity to the gene encoding the yeast proteasome subunit, PRE1. Deletion of CAP64 resulted in an acapsular strain that was avirulent in mice. As with CAP59, complementation of the cap64 mutation restored both capsule expression and virulence. Interestingly, the CAP64 gene from a serotype D isolate complemented the acapsular phenotype of a serotype A strain, indicating that the gene product of CAP64 did not contribute to serotype specificity of $C$. neoformans polysaccharides (Chang et al., 1996).

The third gene required for capsule formation was CAP60 (Chang and Kwon-Chung, 1998), which is closely linked to a cellulose growth-specific gene from Agaricus bisporus, CEL1. CAP60 is located on the same chromosome as CAP59 but, although similarity exists between Cap59p and Cap60p, the gene products cannot functionally substitute each other by direct complementation or by domain swap experiments. Immunogold labeling localized Cap60p at the nuclear membrane, although antibody reactivity was also detected in both the plasma membrane and the cell wall (Chang and Kwon-Chung, 1998). Deletion of CAP60 resulted in acapsular cells that were moderately virulent in mice and complementation of the mutation restored capsule expression and virulence (Chang and Kwon-Chung, 1998).

CAP10 was the fourth characterized gene required for capsule formation and virulence in $C$. neoformans (Chang and Kwon-Chung, 1999). The gene sequence shows homology with a gene encoding a cryptococcal xylosyltransferase (Klutts et al., 2007). Cap10 mutants were unable to produce fatal infection in mice, as demonstrated with other acapsular strains such as cap59, cap60, and cap64 (Chang and Kwon-Chung, 1994, 1998, 1999; Chang et al., 1996).

Complementation of the cap10 mutation restored capsule and virulence (Chang and KwonChung, 1999). The construction of Cap10p as a green fluorescence protein-conjugate revealed that the product of $C A P 10$ is distributed in patches within the cytoplasm of yeast cells, in cluster formations resembling vesicles.

Cryptococcal enzymes involved in GXM biosynthesis-The connections between the building units of GXM require the activity of different glycosyl transferases. The activity of glycosyltransferases involves the transfer of a monosaccharide from an activated sugar phosphate to an acceptor molecule. Most commonly, sugar nucleotide derivatives are used as glycosyl donors and, in the case of GXM, these basic building units consist of UDP-glucuronic acid, UDP-xylose and GDP-mannose. Some of the genes encoding for the enzymes responsible for the synthesis of these activated sugar donors have been characterized in C. neoformans and shown to have key roles in capsule biosynthesis and function, as detailed below.

Mannose is the most abundant sugar unit in GXM, and its incorporation into the polysaccharide depends on the synthesis of GDP-mannose. The GDP-mannose biosynthesis pathway is initiated by the cytosolic conversion of fructose-6-phosphate into mannose-6-phosphate by phosphomannose isomerase (PMI). Mannose-6-phosphate, the product of the reaction catalyzed by PMI, is then sequentially converted into mannose-1-phosphate and GDP-mannose by the enzymes phosphomannomutase and GDP-mannose pyrophosphorylase, respectively. The C. neoformans gene encoding for PMI, the enzyme responsible for the first step of GDPmannose biosynthesis, was characterized (Wills et al., 2001). This gene, denominated 
MAN1, was disrupted and the resulting mutant had a poor ability to form a capsule. The mutant also produced reduced levels of exopolysaccharide and, in comparison with wild-type and reconstituted cells, had attenuated virulence in both rabbit and mouse models of cryptococcosis (Wills et al., 2001).

GDP-mannose is used as a mannose donor for polysaccharides, but also for glycolipids and glycoproteins. As mentioned above, this activated sugar is produced in the cytosol, although the process of mannosylation generally occurs within different organelles. GXM synthesis, for example, is thought to occur in Golgi-related structures (Yoneda and Doering, 2006). The activity of GDP-mannose transporters is therefore required for the transfer of nucleotideactivated mannose from the cytosol to the organelles in which mannosyl transfer to acceptor molecules will occur. The occurrence of two functional GDP-mannose transporters (Gmt1 and Gmt2) has been recently reported in C. neoformans (Cottrell et al., 2007). Interestingly, this study demonstrates that deletion of GMT1 generates poorly encapsulated cells that are not responsive to capsule induction conditions. In contrast, deletion of GMT2 does not affect capsule expression. This observation clearly indicates that the transporters have distinct roles, some of them apparently relevant for capsule biosynthesis, while others are probably related to mannosylation of other glycoconjugates.

Glucuronic acid is the second sugar unit of GXM. Its addition to the polysaccharide requires the synthesis of UDP-glucuronic acid, which occurs via oxidation of UDP-glucose by UDPglucose dehydrogenase in the cytoplasm. The gene encoding for the enzyme (UGDI) was cloned and expressed in Escherichia coli (Bar-Peled et al., 2004), revealing that the cryptococcal enzyme is a dimer whose activity is regulated by its NAD ${ }^{+}$- and UDP-glucosebinding sites. Igd1p showed membrane localization. The result was unexpected since there is no signal in the polypeptide sequence typical of membrane association or anchorage, which suggested the indirect association with the membrane via interactions with other proteins. Two independent studies revealed that disruption of $U G D 1$ results in acapsular cells with alterations in cell integrity, morphological defects at the bud neck, lack of growth in an animal model of cryptococcosis, and enhanced sensitivity to temperature, detergent, $\mathrm{NaCl}$, and sorbitol (Griffith et al., 2004; Moyrand et al., 2004).

Xylose is the third monosaccharide component of GXM. It is used by fungal glycosyltransferases in the form of UDP-xylose, which is synthesized from the decarboxylation of UDP-glucuronic acid by UDP-glucuronic acid decarboxylase. The subcellular location of UDP-glucuronic acid decarboxylase is uncertain. In plants, UDP-xylose synthesis occurs both in the cytosol and in membranes (Reiter, 2002), and it is currently not known which source of UDP-xylose the different Golgi-localized xylosyltransferases (described later in this section) are utilizing. UDP-xylose and UDP-glucuronic acid transporters, supposedly present at the Golgi apparatus membrane, are also probably required for GXM synthesis in C. neoformans. As expected, mutant cells that had UGD1 disrupted and, consequently, lacked UDP-glucuronic acid synthesis, failed to produce UDP-xylose (Griffith et al., 2004; Moyrand et al., 2004). The cryptococcal gene encoding for UDP-xylose synthase (UXS1) was also characterized and deleted, but uxs $1 \Delta$ strains were encapsulated and grew at $37^{\circ} \mathrm{C}$ (Kozel et al., 2003). These results suggest that xylose incorporation into GXM is not essential for capsule formation, although it is clearly relevant for biological functions (Klutts and Doering, 2008).

Nucleotide-activated sugar donors are used by cryptococcal glycosyltransferases to form GXM. Considering that the polysaccharide consists of an $\alpha-1,3$ mannan backbone containing $O$-acetyl, $\beta-1,2 / \beta-1,4$ xylosyl- and $\beta-1,2$ glucuronyl substitutions, proteins like $\alpha 1,3$ mannosyltransferase, $O$-acetyltransferase, $\beta-1,2$ glucuronyltransferase, and $\beta-1,2$ and $\beta-1,4$ xylosyltransferase are expected to occur in $C$. neoformans. In fact, both early and more recent studies describe characterization of some of these enzymatic activities (Jacobson, 1987; Klutts 
and Doering, 2008; Klutts et al., 2007; Klutts et al., 2006; Moyrand et al., 2004; Sommer et al., 2003; White et al., 1990; White and Jacobson, 1993). In several cases, the genes encoding these enzymes were characterized, as described below.

An $\alpha$-1,3-mannosyltransferase that catalyses the transfer of mannose from GDP-mannose to $\alpha-1,3$-linked mannose disaccharides has been described (Sommer et al., 2003). The related gene, $C M T 1$, was shown to be homologous to CAP59, a cryptococcal gene involved in capsule synthesis by participating in the process of GXM export (Garcia-Rivera et al., 2004). $C$. neoformans cells in which CMT1 expression was affected by RNA interference or genetic deletion had no 1,3-mannosyltransferase activity (Sommer et al., 2003). Interestingly, the product of CMT1, Cmt1p, co-purifies with a protein (Cas31p) that is homologous to the $C A P 64$ gene. Cas31p is required for xylosylation and $O$-acetylation of GXM (Moyrand et al., 2004). As discussed by Sommer and co-workers (Sommer et al., 2003), the co-purification of two CAP protein homologues suggests that these polypeptides might normally be associated. In addition, the hypothesis that Cmt1p is a mannosyltransferase could suggest the product of CAP59 also acts in the synthesis of different glycans, since mannosylation is a common feature of different cryptococcal glycoconjugates (Gutierrez et al., 2007; Heise et al., 2002).

The analysis of capsular phenotypes revealed that approximately 50\% of the cells in which expression of the putative mannosyltransferase (Cmt1p) was blocked were acapsular (Sommer et al., 2003). The remaining population, however, presented modified capsules, with lower density and shorter fibers than wild-type cells. Therefore, paradoxically, at least some of the cmtl mutant cells had no mannosyltransferase, but were encapsulated. A hypothesis raised by the authors is that, since fungi have a propensity to have multiple enzymes of overlapping specificity involved in glycan synthesis, other enzymes could compensate for the loss of $\mathrm{Cmt} 1 \mathrm{p}$. However, the hypothesis that Cmt1p is not directly related to GXM synthesis cannot be ruled out.

Once the $\alpha$-1,3-mannan is synthesized, $O$-acetyl, glucuronyl and xylosyl residues are added to the growing polysaccharide. Cryptococcal protein fractions containing xylosyltransferase and glucuronyltransferase activities were described by White and co-workers (White et al., 1990). Potential acceptor molecules were investigated and, interestingly, $O$-acetylated mannan served as an acceptor for glucuronyl residues but xylomannan did not. In addition, glucuronomannan served as an acceptor for xylosyl residues, although acetylated mannan did not. These observations led to the conclusion that, during GXM synthesis, mannan is first assembled and then $O$-acetylated. Glucuronate is then added to the polysaccharide, followed by xylosyl residues.

Janbon and co-workers described for the first time a capsule synthesis gene, CAS1, coding for an enzyme that is apparently required for GXM $O$-acetylation (Janbon et al., 2001). The gene product, Cas1p, had no homology with any known protein putatively involved in protein or polysaccharide $O$-acetylation, but sequence analysis using a program designed to find putative protein families when querying a new sequence that has failed identification using alignment methods classified Cas 1p as a putative glycosyltransferase. Mutant cells in which CAS1 had been deleted synthesized regular GXM, except that it lacked $O$-acetyl groups. Strikingly, cas1 mutant cells were more virulent than the parental strain (Janbon et al., 2001). Further studies revealed that $O$-acetylation is important for recognition of GXM by monoclonal antibodies, complement activation, tissue accumulation of GXM and interference with neutrophil migration, although it had no relevance on phagocytosis by neutrophils (Kozel et al., 2003). The relationship between the hypervirulent phenotype of casl mutants and the properties described above remain unclear. It is noteworthy that antibody selection was used to isolate a spontaneous O-acetylation deficient variant that was hypovirulent (Cleare et al., 1999b). Another gene (CAS3) necessary to complete $O$-acetylation of the capsule was 
described by Moyrand et al (Moyrand et al., 2004). The product of CAS3, Cas3p, shares homology with five other putative proteins, named Cas31p, Cas32p, Cas33p, Cas34p, and Cas35p. Mutational analysis of the related genes demonstrated that a cas 31 mutant produces GXM with the same $O$-acetylation as that of the parental strain, while the polysaccharide from a cas 3 mutant strain had a $70 \%$ loss of $O$-acetylation. Interestingly, GXM from a cas 3 -cas 31 double mutant was completely de- $O$-acetylated. Cas $31 \mathrm{p}$ and Cas $3 \mathrm{p}$ were demonstrated to have very similar sequences, suggesting that they correspond to proteins that have similar functions and different regulatory mechanisms (Moyrand et al., 2004).

Klutts and co-workers (Klutts et al., 2007) have recently described a $\beta 1,2$-xylosyltransferase activity that transfers xylose to an $\alpha 1,3$-mannose dimer. The corresponding gene, $C X T 1$, was cloned and successfully expressed in Saccharomyces cerevisiae, which normally lacks endogenous xylosyltransferase activity. Interestingly, the product of $C X T 1, \mathrm{Cxt} 1 \mathrm{p}$, is homologous to Cap10p, a product of the capsule-related gene CAP10. The characterization of Cxt1p represented the first $C A P$ gene homolog whose product had a defined biochemical function, and this homology suggests that $C A P 10$ and its homologs (CAP1, -2, -4 , and -5) encode glycosyltransferasaes that are likely to be involved in capsule synthesis. The cryptococcal xylosyltransferase is not homologous to any related enzyme in mammalian or plant cells, so its characterization defined a novel family of glycosyltransferases. This family includes $C$. neoformans Cap10p and its homologs and is exclusive to fungi. Cas31p, described above to be involved in capsule $O$-acetylation, is also required for xylosylation (Moyrand et al., 2004), suggesting that at least some of the proteins involved in capsule assembly are multifunctional.

CXT1 deletion did not affect in vitro growth of the mutant cells or the general morphology of their capsules, as concluded from India ink staining and immunofluorescence with mAbs to GXM (Klutts and Doering, 2008). This result was in agreement with findings by Moyrand and Janbon (Moyrand et al., 2004), showing that mutant strains that lost the ability to form UDPxylose are still encapsulated. Structural analysis of GXM and GalXM measured by NMR from cxt1 mutants prepared on encapsulated or acapsular backgrounds revealed that the enzyme is involved in the synthesis of both polysaccharides (Klutts and Doering, 2008). However, NMR structural analysis of GXM and GalXM, revealed that both polysaccharides were missing $\beta-1,2$-xylose residues. A $30 \%$ reduction of $\beta-1,2$-xylose was noted in the abundance of this residue in GXM as compared to wild-type strains. In the mutant strains GalXM was almost completely devoid of $\beta$-1,2-linked xylose and $\beta$-1,3-linked xylose residues. Interestingly, fungal burden in the lungs of mice infected with the $c x t l$ strain was significantly reduced compared to wild-type strains, indicating that deletion of $C X T 1$ results in an attenuated virulence (Klutts and Doering, 2008). Recently, Cxt1p has been involved in the addition of xylose residiues to glycosphingolipids (Castle et al., 2008), a fact which could contribute to the reduced virulence observed.

According to Doering and colleagues, at least twelve glycosyltransferases would be required for GXM synthesis (Doering, 2000; Klutts et al., 2006). It is clear, therefore, that several of these enzymes remain yet to be characterized, including key molecules such as xylosyltransferases forming $\beta-1,4$ linkages with mannose, as well as glucuronyltransferase.

Cryptococcal enzymes involved in GalXM synthesis-Recently, GalXM mutant strains were generated for a putative UDP-glucose epimerase (Uge-1) and a putative UDPgalactose transporter (Ugt1p). The study revealed that galactose metabolism plays a central role on the virulence of $C$. neoformans (Moyrand et al., 2007). The UGEl gene encodes a putative UDP-glucose epimerase, an enzyme that converts UDP-glucose and UDP galactose. The UGTI gene encodes a putative Golgi UDP-galactose transporter. In infection studies, ugel mutants are cleared from the brain and lungs. The ugtl mutant is found in a significantly 
lower burden in the brain, lung and spleen. Over time C. neoformans is completely eliminated in the brain and lung with diminished levels in the spleen. Carbohydrate composition analysis revealed that the mutants do not secrete GalXM although their capsule size is larger than the isogenic wild-type strain. Both mutants had a growth defect at $37^{\circ} \mathrm{C}$ that was suppressed by $1 \%$ galactose addition to the medium, which suggested that absence of these enzymes also produced a cell wall defect. To date, the reason why GalXM deficiency results in disminished brain dissemination is unknown, and it is unclear if the effect is due to a reduction in fungal replication in the brain, or because of an impairment in crossing through the blood- brain barrier. Further studies are required to clarify the role of GalXM in dissemination.

Signaling pathways involved in capsule synthesis-The particular cellular distribution of the CAP genes in $C$. neoformans suggests that capsule formation is a complex and finely coordinated biosynthetic pathway. In fact, different compounds and environmental conditions have been shown to regulate capsule size by affecting the expression of $C A P$ and other genes. Analyses of capsule size and quantitative real-time PCR indicated that, under capsule-inducing conditions, the expression of CAP genes is increased (Okabayashi et al., 2005). In contrast, capsule-repressing conditions, such as supplementation of culture media with high glucose concentrations, results in the concomitant decrease of capsule size and $C A P$ gene expression (Okabayashi et al., 2005). The functions of these genes have not been clearly described, however. Since homologs of the $C A P$ genes have been identified in fungal species that do not produce capsules (Janbon, 2004), their roles are probably not exclusively related to capsule production. Components of the cyclic AMP signal transduction pathway, as well as mechanisms that regulate $\mathrm{pH}$ and $\mathrm{CO}_{2}$ sensing, utilization of carbon, nitrogen, serum components and iron, are also relevant to capsule expression in C. neoformans, as summarized in Table 1 and discussed below.

Iron sensing and capsule synthesis in C. neoformans-As stated above, iron concentration is one of the main environmental factors that influence capsule synthesis. Recently, genes encoding high affinity iron permeases (CFT1 and CFT2) were shown not to be involved in capsule size regulation. SAGE and Northern blot analyses demonstrated that iron limitation results in elevated transcripts of the CAP60 gene (Lian et al., 2005). The ironresponsive transcription factor Cir 1 was also demonstrated to be a requirement for elaboration of the capsule, since $\operatorname{cirl}$ mutants of both the serotype D and serotype A strains were acapsular (Jung et al., 2006). The cirl mutants also failed to form polysaccharide capsules in the presence of elevated $\mathrm{CO}_{2}$ concentrations. Microarray analysis allowed the evaluation of the potential targets of Cir1 regulation resulting in the loss of capsule (Jung et al., 2006). The only gene that had its regulation altered in the cirl mutants was CAS32, which belongs to a family (CAS) of genes that are homologs of CAP64 (Moyrand et al., 2004). The CAS genes are involved in insertion of xyloxyl substitutions and/or $O$-acetylation of GXM (Moyrand et al., 2004).

Therefore, it was not clear whether transcriptional changes in capsule-related genes caused the capsule defect in the $\operatorname{cirl}$ mutants. It has therefore been speculated that Cirl could be necessary for capsule formation through the regulation of genes needed for sensing iron and $\mathrm{CO}_{2}$ levels (Lian et al., 2005).

Signaling cascades involving cAMP regulation control capsule synthesis in $\boldsymbol{C}$. neoformans_Elements of the cyclic AMP (cAMP) dependent pathway control melanin and capsule production in C. neoformans (D'Souza and Heitman, 2001). Strains in which the cryptococcal gene encoding for adenylyl cyclase $(C A C 1)$ was disrupted lost the ability to synthesize capsule and melanin (Alspaugh et al., 2002). Consequently, the mutants were unable to cause disease in animal models of cryptococcosis. Exogenously added cAMP suppressed the capsule defect of adenylyl cyclase mutant strains (Alspaugh et al., 2002). The reintroduction of the $C A C l$ gene in the mutant strains reverted the $c a c l$ phenotype to wild-type phenotypes. 
An upstream regulatory element of adenylyl cyclase, Aca1 (for adenylyl cyclase-associated protein 1) was further demonstrated to regulate capsule production via the Cac1-cAMP-protein kinase A pathway (Bahn et al., 2004). In addition, the activity of Cac1 is stimulated by $\mathrm{HCO}_{3}{ }^{-}$, produced through hydration of $\mathrm{CO}_{2}$ by carbonic anhydrase 2 (Can2) (Mogensen et al., 2006), which is consistent with the well-described ability of $C$. neoformans to increase capsule size in response to $\mathrm{CO}_{2}$ (Granger et al., 1985; Zaragoza et al., 2003a).

The gene encoding the major cAMP-dependent protein kinase catalytic subunit in $C$. neoformans (PKAl) was identified and disrupted (D'Souza et al., 2001). Pkal strains failed to produce melanin or capsule and were avirulent as a result. Interestingly, disruption of the gene encoding for the protein kinase A regulatory subunit $(P K R l)$ in mutant strains which have a constitutively activated pathway resulted in overproduction of capsule. These mutant strains were hypervirulent in animal models (D'Souza et al., 2001). Pka1 catalytic subunit acted downstream of the Pkr1 regulatory subunit, since the phenotype of a pkrl-pkal double mutant was similar to that observed in single pkal mutants (D'Souza et al., 2001).

The cAMP pathway is highly regulated by the cell, and genes involved in this regulation have been identified. An early study (Alspaugh et al., 1997) revealed that the $\alpha$-subunit 1 of the cryptococcal $\mathrm{G}$ protein (Gpa1), which in other species is necessary to activate adenylate cyclase, regulates capsule expression in $C$. neoformans in response to environmental signals. The impaired ability of mutant cells lacking Gpa1 to produce capsule and melanin led to an attenuated virulence in animal models of cryptococcosis. Exogenous cAMP restored mating, melanin, and capsule production in gpal mutant strains (Alspaugh et al., 1997). This observation supported the hypothesis that cAMP-dependent signaling proteins were involved in capsule formation. Indeed, it has been further demonstrated that Gpa1 transcriptionally regulates at least nine genes that are known or presumed to function in capsule synthesis or assembly, including $C A P 10, C A P 59$, and $C A P 64$ and genes encoding for $O$-acetyltransferase and UDP-xylose synthase (Pukkila-Worley et al., 2005). Gpa1 is apparently under the control of the $\mathrm{G}$ protein-coupled receptor Gpr4, which engages amino acids in the cAMP-PKA pathway involved in the regulation of capsule formation (Xue et al., 2006). Recently it has been shown that disruption of $C R G 2$, encoding a G-protein, results in increased cAMP levels and capsule enlargement, which suggests that $\mathrm{Crg} 2$ negatively regulates the Gpa1-cAMP pathway (Shen et al., 2008).

Using a gene microarray approach, Cramer and co-workers (Cramer et al., 2006) demonstrated that the expression of NRG1, a gene encoding for a homolog of the Candida albicans Nrg1 and Saccharomyces cerevisiae $\mathrm{Nrg} 1 / \mathrm{Nrg} 2$ family of transcription factors regulated in response to carbohydrate availability, is altered in a gpal mutant of $C$. neoformans. Nrg1 is under transcriptional control of the cAMP pathway (Liu, 2001). In fact, glucose and intact cAMP are required for wild-type levels of transcription of the cryptococcal NRGl gene (Cramer et al., 2006). Disruption of the $C$. neoformans NRG1 gene by homologous recombination resulted in hypocapsular mutants with attenuated virulence. The reduced ability of $n r g l$ mutants to form a capsule was probably associated with an effect on the expression of $U G D 1$, which encodes a UDP-glucose dehydrogenase that is required for capsule formation (Moyrand et al., 2004). Interestingly, the Nrg1 protein contains a consensus sequence for phosphorylation by the cAMP-dependent protein kinase (PKA) that is required for its full function (Cramer et al., 2006).

Intracellular cAMP concentrations depend on the activity of the low- and high-affinity phosphodiesterases (PDEases), Pde1 and Pde2, respectively. In C. neoformans, mutational analysis revealed that Pde2 has no apparent role in regulating intracellular cAMP levels. In contrast, Pde1 is clearly relevant to cAMP-dependent signaling pathways regulating capsule formation (Hicks et al., 2005). Intracellular cAMP levels are elevated in a pde1 mutant. In 
addition, deletion of the PDE1 gene restored the ability of gpal mutants to form capsule (Hicks et al., 2005). Measurements of cAMP intracellular content revealed that the levels of this second messenger in a double pde1-pkal mutant strain is approximately 15-fold higher than the cAMP content in a pkal single mutant strain. In addition, a mutation in a consensus Pka phosphorylation site reduces Pde1 function. These results clearly indicate the occurrence of a feedback regulation system controlling cAMP levels, via its degradation by Pde1 (Hicks et al., 2005).

\section{B.2.- GXM traffic in C. neoformans}

Microbial polysaccharides are usually polymerized at the outer layer of the plasma membrane or even at the extracellular space. Bacterial capsular polysaccharides, for instance, are synthesized by plasma membrane glycosyltransferases whose active sites face the extracytoplasmic environment (Raetz and Whitfield, 2002; Whitfield, 2006; Whitfield et al., 2003). In fungal cells, glucan and chitin synthases, enzymes responsible for the synthesis of cell wall components, also localize to the plasma membrane (Leal-Morales et al., 1994; Ortiz and Novick, 2006; Valdivia and Schekman, 2003), which supports the idea that chitin and glucan are polymerized at extracellular sites. In contrast to other microbial polysaccharides, GXM is synthesized intracellularly, (Feldmesser et al., 2001; Garcia-Rivera et al., 2004), more specifically inside the Golgi apparatus (Yoneda and Doering, 2006). GXM traffic to the cell surface apparently involves transport by secretion of polysaccharide-containing vesicles (Feldmesser et al., 2001; Garcia-Rivera et al., 2004; Rodrigues et al., 2007), which somehow cross the cell wall, releasing their content into the extracellular space. The released polysaccharide is then connected to the cell wall or incorporated into the growing capsule by putative mechanisms that will be discussed below.

The first evidence that GXM is synthesized intracellularly was presented in a study by Feldmesser et al. (Feldmesser et al., 2001), who noted that monoclonal antibodies to the polysaccharide reacted with cytoplasmic structures of about $100-200 \mathrm{~nm}$ in diameter consistent with vesicles. These results were further supported by subsequent studies using immunogold labeling. Four different monoclonal antibodies to GXM reacted with cytoplasmic vesicles in four strains of C. neoformans (Garcia-Rivera et al., 2004), suggesting that the capsular polysaccharide is synthesized in the cytoplasm and exported to the exterior of the cell in secretory vesicles.

Different genes related to secretion mechanisms in yeast have been described in the last three decades (Lyman and Schekman, 1996). In yeast cells, highly conserved small GTPases are fundamental to exocytic processes (Spang and Schekman, 1998). One of the GTPases regulating exocytosis is Sec4p, a highly conserved molecule that belongs to the Sec4/Rab8 subfamily of Rab GTPases (Lipschutz and Mostov, 2002). This protein has homologs in several eukaryotic systems and, in fact, a Sec4p cryptococcal homolog was recently described (Yoneda and Doering, 2006). A gene encoding for a Sec4p homolog in C. neoformans, SAV1, has been cloned, and disruption of the gene resulted in decreased acid phosphatase secretion, suggesting a role in protein secretion. The most prominent cellular feature of the savl mutant, however, was a marked accumulation of post-Golgi exocytic vesicles in the cytoplasm (Yoneda and Doering, 2006). These vesicles were recognized by an antibody to GXM, confirming that the synthesis of the polysaccharide occurs at intracellular sites. This study also supported the hypothesis that GXM traffic involves secretory vesicles derived from the Golgi apparatus.

The fact that treatment of $C$. neoformans with brefeldin A, an inhibitor of the Golgi-derived transport of molecules, resulted in a significant inhibition of capsule formation (Hu et al., 2007) supports the notion of capsular polysaccharide synthesis in golgi-derived vesicles. However, Golgi-derived vesicles, in the classic secretory pathway, are expected to fuse with the plasma membrane and release their internal content to the extracellular space 
(Mallabiabarrena and Malhotra, 1995). Therefore, such a secretion mechanism could explain how GXM reaches the periplasmic space, but not how the polysaccharide reaches the outer layer of the cell wall to be incorporated into the growing capsule. Late endosomes, the cellular precursors of MVBs, can be connected with structures from the Golgi and the trans-Golgi network (Fevrier and Raposo, 2004). Therefore, one possibility is that the GXM-containing, post-Golgi vesicles of $C$. neoformans connect to the endosomal pathway, resulting in the release of exosome-like structures. In this case, the production of GXM-containing extracellular vesicles by $C$. neoformans would be expected. In fact, different studies supported the hypothesis that $C$. neoformans produce exosome-like vesicles containing the polysaccharide (Rodrigues et al., 2008b; Rodrigues et al., 2007; Rodrigues et al., 2000).

Membrane vesicles that migrate from the plasma membrane to the cell wall of $C$. neoformans, as well as in the region between the cell wall and the capsule, have been described in different studies (Rodrigues et al., 2000; Takeo et al., 1973a, 1973b). The occurrence of vesicles within the cell wall of cryptococci or in its adjacent extracellular microenvironment was also evidenced after in vitro growth, and vesicle-like structures near the edge of the capsule or in the cryptococcal cell wall were also observed in lung sections of mice infected with $C$. neoformans (Rodrigues et al., 2007). These vesicles were isolated from C. neoformans cultures by differential centrifugation and analyzed by transmission electron microscopy (Rodrigues et al., 2007). They corresponded to spheres within the diameter range of 20 to $400 \mathrm{~nm}$ presenting as bilayered membranes. Using morphological criteria, four main vesicle groups were identified, including i) electron dense and ii) electron lucid vesicles, iii) vesicular structures with membrane-associated electron dense regions and iv) vesicles containing hyperdense structures resembling a dark pigment. Vesicle production required cell viability and mass spectrometry analysis of vesicular components revealed the presence of different lipids (Rodrigues et al., 2007) and proteins (Rodrigues et al., 2008b) associated with virulence mechanisms of $C$. neoformans.

Vesicle secretion is apparently not exclusive to encapsulated cells. Although immunogold labeling of vesicles purified from encapsulated cells with an antibody to GXM followed by transmission electron microscopy revealed that the polysaccharide is present in the vesicular matrix, extracellular vesicles are also detectable in culture supernatants of acapsular mutants (Rodrigues et al., 2008b; Rodrigues et al., 2007). The mechanism of vesicular secretion of GXM, however, is putatively relevant for capsule assembly, since induction of capsule expression is accompanied by an enhanced detection of GXM in vesicular fractions (Rodrigues et al., 2007). Acapsular cells were able to extract GXM from vesicular fractions and incorporate the polysaccharide into their cell surfaces, indicating that the fungus has the metabolic apparatus to extract GXM from membrane vesicles. The mechanisms potentially involved in GXM release from vesicles and incorporation into the growing capsule are still not clear.

According to Siafakas and co-workers (Siafakas et al., 2007), the cell wall-associated enzyme phospholipase B could be involved in the release of the molecules transported across cell walls inside membrane-bound vesicles.

The biogenesis of the $C$. neoformans secretory vesicles is still obscure, but several different lines of evidence lead to the hypothesis that they are exosome-like structures. Early studies by Takeo and co-workers described in C. neoformans unusual plasma membrane invaginations containing small vesicles, which would be associated with capsule synthesis (Takeo et al., 1973a, 1973b). Multivesicular compartments in close association with the cell wall were also recently described in C. neoformans (Rodrigues et al., 2008b). Finally, proteomic analysis of the $C$. neoformans vesicles revealed a complex protein composition that included several proteins described in mammalian exosomes (Rodrigues et al., 2008b). These observations, together with morphological data, support the idea that extracellular vesicles produced by $C$. 
neoformans are exosome-like structures. A scheme comprising vesicle formation and GXM traffic in C. neoformans is proposed in Figure 5.

2. Polysaccharide connections at the $\boldsymbol{C}$. neoformans surface-The cell wall of $C$. neoformans is a complex molecular network that includes, chitin and mannoproteins, lipids, pigments, and bioactive enzymes besides well-characterized structural components such as glucans (Nimrichter et al., 2005). This heterogeneous structure is surrounded by multiple layers of capsular polysaccharides, which implies that capsule assembly in $C$. neoformans involves the connection of capsular components to cell wall elements, as well as molecular interactions within the capsule.

Capsule anchoring to the cryptococcal cell wall-Proteins are apparently not involved in the connection of cell wall components to the capsule (Reese and Doering, 2003; Rodrigues et al., 2008a). In contrast, polysaccharides play a key role in capsule attachment to the cell wall. It has been demonstrated that GXM anchoring to the cryptococcal wall requires $\alpha-1,3-$ glucan (Reese and Doering, 2003; Reese et al., 2007). Cryptococcal cells with a disrupted $\alpha$-1,3-glucan synthase gene lost the ability to synthesize $\alpha$-1,3-glucan, (Reese et al., 2007). These cells had the ability to secrete capsular material, although they lacked surface capsule (Reese and Doering, 2003). Interestingly, acapsular mutants of $C$. neoformans treated with glucanase, but not protease, still bound to GXM, but in a defective manner (Reese and Doering, 2003). This result indicated that cell wall molecules other than glucan are required for capsule attachment to the cell wall.

The presence of cell wall chitin-derived molecules in $C$. neoformans has been demonstrated by microscopic and molecular approaches (Baker et al., 2007; Banks et al., 2005; Rodrigues et al., 2008a). Chitosan, the de- $O$-acetylated form of chitin, was demonstrated to be necessary for the correct architecture of the cell wall, melanin and capsule complex (Baker et al., 2007). In addition, chitin-derived oligomers, whose presence at the surface of $C$. neoformans had been suggested a few years ago (Woyke et al., 2002), have been recently shown to be involved in capsule anchoring to the cell wall (Rodrigues et al., 2008a).

The wheat germ agglutinin (WGA) is a lectin that binds to sialic acids and $\beta-1,4-N$ acetylglucosamine (GlcNAc) oligomers. In $C$. neoformans, different techniques revealed that chitin-bound oligomers of GlcNAc, but not sialic acids or intact chitin, are the molecules recognized by the lectin (Rodrigues et al., 2008a). Confocal microscopy demonstrated that the chitin-like oligomers recognized by WGA form projections linking the capsule to the cell wall (Figure 6). Interestingly, some of the molecules recognized by WGA formed unique ring-like structures connecting the capsule to the cell wall during yeast budding (Rodrigues et al., 2008a). The projection of chitin-like oligomers into the capsule, combined with the study of Zaragoza and colleagues showing the occurrence of capsule channels (Zaragoza et al., 2006a) strongly supports the concept that the capsule contains heterogeneous microenvironments despite a relatively homogenous appearance when visualized by India ink suspension and light microscopy. The mechanisms by which this singular architecture is maintained are still not understood.

Treatment of encapsulated $C$. neoformans cells with chitinase released GXM from the cell surface and reduced capsule size (Rodrigues et al., 2008a). The fact that chitinase treatment did not fully remove the cryptococcal capsule may be explained by the ability of cell wall glucans to anchor capsular polysaccharides (Reese and Doering, 2003; Reese et al., 2007). Based on the well documented ability of acapsular mutants to bind GXM to the cell surface (Kozel, 1977), it was demonstrated that chitinase-treated acapsular cells still bound soluble GXM (Rodrigues et al., 2008a). However, in contrast to untreated cells, yeast cells that were pre-incubated with the enzyme bound GXM in a manner that formed a loose polysaccharide 
coat at the surface of $C$. neoformans, as previously described for glucanase-treated acapsular mutants (Reese and Doering, 2003). In combination, these results indicate an association of chitin-derived structures and $\alpha-1,3$-glucan with GXM. However, the hypothesis that other components connect glucans and chitin-derived structures to capsular components cannot be discarded, since loss of cell wall polysaccharides would disturb cell wall assembly and, consequently, capsule anchoring.

\section{Section C Capsule functions in $C$. neoformans. The capsule as a virulence factor. Function during the interaction with the host}

C. neoformans virulence is a complex process and there is evidence that both fungal components and the immune response to infection combine to damage the host (Casadevall and Pirofski, 2003). Concerning fungal factors, the capsule is the major virulence factor involved in the pathogenesis. As stated previously, the polysaccharide from the capsule can be found attached to the cell forming the physical structure, and released to the medium, as exopolysaccharide. Multiple studies indicate that both types of polysaccharide confer beneficial effects for the fungus during its interaction with the host. In general, the capsule virulent function is conveyed by mediation of a protective effect for cryptococcal cells, such as interfering with phagocytosis by macrophages and ameboid environmental predators. However, the capsular polysaccharide also contributes to virulence through multiple deleterious effects on the immune response, which in turn facilitates fungal propagation in tissues and ultimately kills the host.

\section{C.1 Role of the capsule during interaction with the host}

The presence of the capsule confers beneficial effects to C. neoformans during infection, especially during its interaction with phagocytic cells and environmental predators.

Phagocytosis-Phagocytosis is an important process required for the clearance of a large number of pathogens. From the first studies in the early 1970s, it was shown that the capsule had strong antiphagocytic properties, which was the first evidence of its role as virulence factor. As a consequence, the capsule is involved not only in evading killing by phagocytic cells, but also by means of inhibiting a subset of several phenomena which are dependent of phagocytosis. For example, a reduced phagocytosis translates into reduced T-cell proliferation (Syme et al., 1999), and antigen processing and presentation by macrophages, all resulting in an interference with the T-cell response (Vecchiarelli et al., 1994a; Vecchiarelli et al., 1994b). Despite the inhibitory role of the capsule, phagocytosis does occur during infection. During the first hours of infection, a significant proportion of the yeast cells injected in the lungs are found inside phagocytic cells (Feldmesser et al., 2000). This result indicates that during infection, there are mechanisms that overcome the antiphagocytic effect of the capsule. So far two mechanisms for this have been described: 1) the presence of opsonins, 2) direct interaction of the polysaccharide fibers with phagocytic receptors that occur after capsule structure rearrangements.

Opsonins required for phagocytosis-Classically, there have been two types of opsonins that induce $C$. neoformans phagocytosis, which are antibodies and proteins from the complement system. These opsonins bind to the capsular polysaccharide. We will briefly review the interaction that is formed between these opsonins and the polysaccharide fibers.

a) Antibody mediated phagocytosis: A large number of mAbs that recognize GXM have been obtained (Casadevall et al., 1992; Dromer et al., 1987b; Eckert and Kozel, 1987; Kozel et al., 1998; Pirofski et al., 1995; Todaro-Luck et al., 1989). In addition to the protective effect of these antibodies, their binding to the capsule and function as phagocytic opsonins have also 
been tested. IgG antibodies bind the $C$. neoformans capsule, and they induce phagocytosis through binding to the Fc receptors (FcRI and FcRIII). Interestingly, IgM to capsular polysaccharide is opsonic in the absence of complement. IgM opsonic efficacy correlates with the binding pattern of the Abs to the capsule. IgM to GXM can bind in two different patterns to the capsule as shown by immunofluorescence, punctuate and annular (Cleare et al., 1999a; Cleare and Casadevall, 1998; Nussbaum et al., 1997). Annular pattern correlates with a protective effect in mice and with a good opsonic efficacy. In contrast, mAbs that bind to the capsule in a punctuate pattern are not protective and do not induce phagocytosis. Since no FcR has been identified for IgM antibodies, the mechanism by which this isotype induces $C$. neoformans phagocytosis posed a challenging question. Analysis of this phenomenon revealed that phagocytosis of $C$. neoformans in the presence of IgM antibodies occurred through binding of the polysaccharide fibers to the complement receptors, and specifically to CD18 (see below). It was hypothesized that the binding of the $\mathrm{Ab}$ to the capsule produced some structural rearrangements that resulted in the exposure of CD18 binding sites in the polysaccharide, which in turn produced phagocytosis through the complement receptors (CR) (Taborda and Casadevall, 2002). A similar effect was demonstrated for $\mathrm{IgG}$ antibodies and $\mathrm{F}(\mathrm{ab})_{2}$ fragments (Netski and Kozel, 2002; Zaragoza et al., 2003b). In addition to mAbs to the capsule, other opsonic antibodies have been described. Other examples of this phenomenon may exist, such as the report by Merkel and Scofield who described the isolation of an opsonic mAb whose epitope was abundantly found, not in the capsule, but at the level of the cell wall (Merkel and Scofield, 1999).

b) Complement mediated phagocytosis: The other opsonin whose function has been extensively studied in C. neoformans is complement. The capsule of $C$. neoformans is a strong inducer of complement system activation through the alternative pathway, resulting in a large deposition of iC3b on the capsule (Kozel and Pfrommer, 1986; Kozel et al., 1989).

Encapsulated cells and purified GXM induced C3 release from peritoneal cells, and the amount of $\mathrm{C} 3$ released correlated with the degree of encapsulation of the cell (Blackstock and Murphy, 1997). However, binding of $C 3$ to the capsule is not sufficient to induce phagocytosis, because there are many $C$. neoformans strains that are not phagocytosed in the presence of complement. It was later found that there was a negative correlation between the phagocytic index of the strains and the size of the capsule (Yasuoka et al., 1994), suggesting that complement-mediated phagocytosis inhibition correlated with the molecular size of the GXM molecules produced by different strains. Earlier studies had suggested that cells with a large capsule bound a lower amount of C3, also suggesting a mechanism by which cells with a larger capsule were less efficiently phagocytosed (Kozel et al., 1996). More recently, studies using confocal microscopy revealed that $\mathrm{C} 3$ deposition was different in cells with small and large capsules. In cells with large capsule, C3 was located close to the cell wall, away from the capsule edge. This differential localization suggested a mechanism by which capsule enlargement interfered with the interaction of $\mathrm{C} 3$ in the capsule with its corresponding phagocytic receptor (Zaragoza et al., 2003b). Interestingly, C3 proteins from different sources (human, mouse, rat) bound differentially to the capsule, suggesting that the complement pathway from different hosts may have different functions in the defense against $C$. neoformans (Gates and Kozel, 2006), which could explain the differences in susceptibility of the host to $C$. neoformans infection (see comment in (Pirofski, 2006)).

c) Effect of the interaction between the different opsonins with the capsule: During the course of an infection, both complement and antibodies are available, and it has been shown that the presence of both opsonins can result in different outcomes. For example, the presence of Abs to the capsule produces strong complement activation through the classical pathway, leading to a fast deposition of complement on the capsule (Kozel et al., 1998). This effect is largely dependent on the isotype of the $\mathrm{Ab}$. While IgG mAbs have a strong effect, IgM produces a moderate activation. In addition, it has also been shown that addition of mAbs to the capsule 
not only produces $\mathrm{C}$ activation through the classical pathway, but, when added in a sufficient amount, allows complement deposition at the capsule edge, as opposed to deep inside the capsule, resulting in an increase in C-mediated phagocytosis (Zaragoza and Casadevall, 2006).

2) GXM Receptors-Several receptors have been described that interact with the capsular polysaccharide, triggering different responses in phagocytic cells (Ellerbroek et al., 2004c; Levitz, 2002; Monari et al., 2005a; Yauch et al., 2004). These receptors are involved in phagocytosis, either because they directly induce or prevent pathogen engulfment, or because they belong to pattern recognition receptors, which are involved in phagocytosis regulation, such as Toll-like receptors. In the first group, GXM can interact with CD18, which forms part of the complement receptor, and this interaction can trigger CR mediated phagocytosis in the absence of opsonin. GXM can also directly interact with Fc RIIB (Monari et al., 2005a), which has been involved in C. neoformans uptake by phagocytic cells (Monari et al., 2005a; Syme et al., 2002). However, FcR $\gamma$ II engagement produces inhibitory signals that contribute to immune unresponsiveness, as will be reviewed later on. In the second group, it has been described that GXM can interact with CD14 and Toll-like receptors 2 and 4. These receptors are involved in macrophage stimulation, and their functions have been characterized.

The role of other receptors that are known to bind mannose and other polysaccharides has been studied, since the capsular polysaccharide is particularly rich in mannose. These receptors are the mannose receptor and SIGN-R1. In the case of the mannose receptor, it has been shown that it plays a role in C. neoformans uptake by dendritic cells (Syme et al., 2002). In addition, C. neoformans produces immunomodulation through secretion of mannoproteins which interact with the mannose receptor (Levitz and Specht, 2006). The SIGN-R1 receptor binds bacterial polysaccharides, but in the case of $C$. neoformans, it has been shown that it does not bind GXM (De Jesus et al., 2008).

The role of various cellular receptors in phagocytocis and GXM localization has been studied using knock-out mouse strains. None of the receptors were completely required for serum clearance or hepatosplenic polysaccharide degradation (Yauch et al., 2005). In another study, Yauch et al. (Yauch et al., 2004) sought to study the role of the CD14, TLR2, and TLR4 receptors and the function of MyD88, in cryptococcal infection in vitro. The results revealed that MyD88 plays a critical role during cryptococcosiswhile the TLR2 and CD14 receptors play minor roles. That study demonstrated that $\mathrm{MyD} 88^{-/-}$mice succumbed to $C$.

neoformans infection significantly earlier than wild-type mice when infected either i.n. or i.v.

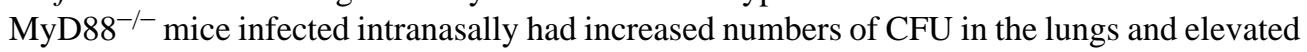
GXM levels in the lungs and sera, which correlated with the reduced survival of these mice. Additionally, mice lacking TLR2 had significantly reduced survival only after pulmonary challenge, while $\mathrm{CD} 14^{-/-}$mice displayed a trend towards reduced survival after intravenous infection. Since the MyD88 ${ }^{-1}$ mice were more susceptible to cryptococcosis than the TLR2 and TLR4 mutant mice, the authors suggested that MyD88 besides serving as an adaptor protein for TLR SIGN-R1 there are other yet-to-be identified receptors for GXM on red pulp macrophages (De Jesus et al., 2008). They also suggested that it does not appear to be involved in macrophage uptake of GXM.

Capsule role during macrophage intracellular parasitism and intracellular GXM accumulation-A key feature of cryptococcal pathogenesis is its ability to evade killing inside phagocytic cells. C. neoformans is considered a facultative intracellular pathogen. This finding was first observed in the early 70s (Diamond and Bennett, 1973) and it has been more carefully studied in the last years in macrophages, microglial cells, and endothelial cells (Coenjaerts et al., 2006; Chretien et al., 2002; Feldmesser et al., 2000; Lee et al., 1995b). C. neoformans can survive inside macrophages, and exploits the intracellular macrophage 
environment for its replication. Furthermore, there are several mechanisms described that allow C. neoformans extrusion from infected macrophages (Alvarez and Casadevall, 2006; Ma et al., 2006) or even cell-to-cell spread (Alvarez and Casadevall, 2007; Ma et al., 2007). Concerning the role of the capsule in this process, it has been shown that acapsular mutants cannot replicate inside phagocytic cells (Feldmesser et al., 2000), which indicates that the capsule plays a key role in intracellular parasitism. Along these lines, acapsular mutants are not extruded by macrophages, and this phenotype is reverted by pre-coating of acapsular cells with GXM (Alvarez and Casadevall, 2006). A typical feature after C. neoformans engulfment is that there is an important accumulation of GXM-containing vesicles (Lee et al., 1995b; Tucker and Casadevall, 2002). These vesicles became permeable during the course of intracellular infection, which suggested a new mechanism by which $C$. neoformans interfered with macrophage functioning (Tucker and Casadevall, 2002). Since phagocytic cells have several receptors for GXM, they can directly engulf this capsular polysaccharide component (Monari et al., 2003). However, binding and internalization differ between phagocytic cells. GXM accumulated constitutively in macrophages, in contrast to neutrophils, in which it was rapidly expelled (Monari et al., 2003). Accumulation of GXM by macrophages was dependent on the cytoskeleton and several macrophage intracellular pathways (Chang et al., 2006b). The presence of intracellular polysaccharide altered the function of the macrophages at multiple levels. For example, once phagocytosed, encapsulated cells do not induce nitric oxide synthase, a phenomenon that does occur when acapsular mutants are ingested (Naslund et al., 1995).

Other mechanisms by which capsular components can interfere with the activity of immune cells will be reviewed below. Finally, it has recently been shown that the capsule confers protection against reactive oxygen species, which are important antifungal molecules produced by macrophages during phagocytosis. In addition, capsule enlargement also increased the survival of the cells in the presence of these radicals and antifungal molecules, such as defensins and Amphotericin B (Zaragoza et al., 2008b). These results suggest mechanisms for how $C$. neoformans evades killing inside the phago-lysosome, and are in agreement with published data in Klebsiella pneumoniae (Campos et al., 2004), which demonstrate that the bacterial capsule confers protection against defensins..

Capsule and dissemination-Extrapulmonary dissemination is a key process for disease causation during fungal pathogenesis (reviewed in (Eisenman et al., 2007; Filler and Sheppard, 2006)). Several microbial factors, such as laccase, phospholipase and the capsule are involved in the dissemination process. The capsule plays an important role in this process, since acapsular mutants have impaired dissemination to the brain (Wilder et al., 2002). Although this effect could be due to the lack of virulence of the strain and rapid clearance by the immune system, there are reports that the polysaccharide capsule plays an active role in this process. For example, a seminal report indicates that during dissemination through the organism, $C$. neoformans manifests important capsule structure changes that may be involved in tissue invasion (Charlier et al., 2005). These authors found that a serotype A strain (H99) that was exclusively reactive with a serotype A-specific $\mathrm{mAb}$ in vitro, became reactive to a serotype $\mathrm{D}$ specific $\mathrm{mAb}$ during endothelial crossing of the blood-brain-barrier. These findings suggest that $C$. neoformans is able to modulate its capsule structure during dissemination, allowing for adaptation to different environments, thereby enhancing dissemination.

During the course of infection and dissemination, $C$. neoformans must cross epithelial and endothelial barriers. C. neoformans can bind to epithelial cells (Merkel and Cunningham, 1992). In this way the capsule contributes to the binding of $C$. neoformans cells to human alveolar epithelial cells (Barbosa et al., 2006). This interaction resulted in a decreased viability of epithelial cells. In a different report the same authors demonstrated that epithelial cells did bind GXM through interaction with CD14, and that this binding resulted in an increased IL-8 production (Barbosa et al., 2007). Other reports, however also suggest that acapsular mutants can efficiently bind to human lung epithelial cell lines (Merkel and Scofield, 1997), implying 
that binding to epithelia can also occur through selective binding of yeast adhesins present in the cell wall.

Concerning endothelial cells, capsular and acapsular C. neoformans cellscross brain microvascular endothelial cells through transcytosis (Chen et al., 2003). Transcytosis was accompanied by disruption of tight junctions and alterations in the cytoskeleton. The role of the capsule in binding endothelial cells is not clear. Binding to endothelial cells occurs for both encapsulated and acapsular strains, although binding, and transcytosis, was more efficient for encapsulated strains (Chen et al., 2003). In agreement with this idea, a mutant defective in CPS1 (encoding a putative glycosyltranferase) manifested a slight decrease in capsule size, and presented a marked reduced adherence to brain endothelial cells (Chang et al., 2006a). However, although this mutant has a smaller capsule size, the structure is still present, which indicates that the capsule is not a complete requirement for $C$. neoformans to bind to endothelial cells. In this sense, Ibrahim et al found that acapsular strains produced damage in umbilical vein endothelial cells and were more efficiently phagocytosed than encapsulated strains, suggesting that the escape from the vasculature and dissemination occurred through acapsular or poorly encapsulated cells (Ibrahim et al., 1995), and that the invasive mechanisms in the BBB are different from other blood vessels. Accordingly, acapsular mutants were recently shown to manifest in vitro invasive growth, a phenomenon not observed in encapsulated strains (Zaragoza et al., 2008a). Mutants defective in inositol phosphosphingolipid-phospholipase C1 are hyperencapsulated and do not disseminate to the brain (Shea et al., 2006). Similar findings have been found with mutants that cannot synthesize GalXM, which are hyperencapsulated, and fail to disseminate to the brain during infection (Moyrand et al., 2007). Such mutants presumably have a capsule with a different structure and lack GalXM, which might play an independent role in dissemination. Thus, the attribution that larger capsules inhibit dissemination must be considered tentative until validated by subsequent studies.

Once the fungal cell has been internalized by the endothelial cell, transcytosis to the abluminal size of the cell occurs. During this process it seems that endothelial cells have antimicrobial mechanisms based on the procuction of free radicals. Coenjaerts et al. found that endothelial cells have the ability to kill $\operatorname{skn} 7$ C. neoformans mutant cells (lacking a transcription factor that regulates oxidative stress response) through production of free radicals (Coenjaerts et al., 2006). The fact that wild-type $C$. neoformans cells can evade this antimicrobial activity suggests that there are mechanisms that protect the cell from killing, enhancing survival, transcytosis and dissemination. We recently described that the capsule and capsular enlargement plays a key role in the protection against free radicals (Zaragoza et al., 2008b), and it is reasonable to think that encapsulated strains are more likely to survive and disseminate than acapsular strains.

\section{C.2. Role of the exopolysaccharides during infection}

The capsular components are released into the surrounding environments, and are found in serum and tissues during infection. In fact, non-cryptococcal cell associated exopolysaccharides have been found freely in various types of tissues (De Jesus et al., 2008; Goldman et al., 1995; Lee et al., 1996; Lendvai et al., 1998; Lee and Casadevall, 1996) . Various approaches have been carried out to study the role of capsular polysaccharides on the immune response. They included investigation of the role of encapsulated and acapsular strains, as well as in vitro or in vivo studies using purified capsular fractions, the latter based on exposure in host models. These approaches have shown that these exopolysaccharides exert a large number of effects inside the host, which will be reviewed in the following sections.

GXM unresponsiveness-Early studies using total polysaccharide from C.neoformans revealed that this antigen had a propensity for inducing immunological paralysis (Blackstock 
and Hall, 1984; Gadebusch, 1958a, 1958b; Robinson et al., 1982). Several reports indicate that the capsular polysaccharide plays an important role in $C$. neoformans-induced immunological unresponsiveness. Murphy et al. showed that the polysaccharide caused a dose-dependent primary immunological response in mice using the hemolytic plaque assay as indicated by the increase in antibody producing cells. However, after a subsequent challenge with capsular polysaccharide, a state of immunological unresponsiveness was induced. There was a diminution of antibody response and the abolition of spleen plaque forming cells rather than neutralization of antibody by excess antigen (Murphy and Cozad, 1972). The results supported the view that tolerance was due to terminal differentiation without proliferation of immunocompetent cells. A second study showed that the induction of unresponsiveness in the host appears to be dependent upon the total amount of polysaccharide to which the host is exposed rather than the duration of exposure. The study suggested that cryptococcal polysaccharide is sequestered until a sufficient amount of polysaccharide is accumulated for the induction of paralysis (Kozel et al., 1977).

In addition to inhibition of $\mathrm{Ab}$ production, $C$. neoformans and capsular polysaccharides interfere with proper inflammatory responses. Mody and Syme found that $C$. neoformans GXM diminished human lymphocyte proliferation (Mody and Syme, 1993). This process was mainly due to the antiphagocytic effect elicited by the capsular polysaccharides (Syme et al., 1999).

Blackstock et al. compared the immune response elicited by two different $C$. neoformans strains, which differed in their ability to induce in vitro capsule enlargement and virulence (Blackstock et al., 1999). The authors found that after infection the strain was unable to induce capsule size, was not associated with GXM accumulation in serum, and was cleared from infected lungs after an early inflammatory response. In contrast, the virulent strain, which was heavily encapsulated, produced a delayed DTH response (after 15 days of infection) and a significant accumulation of polysaccharide in serum. This delayed response correlated with a difference in the cytokine expression pattern. Mice infected with heavily encapsulated strain failed to upregulate Th1 cytokines, such as IL-2 and IFN $\gamma$, and induced a significant accumulation of IL-10, which was not found in mice infected with the hypocapsular mutant. These results suggested that $C$. neoformans and its capsular components, produced anergy through IL10 upregulation and Th1 cytokines downregulation (Blackstock et al., 1999).

Older studies suggest that $C$. neoformans GXM polysaccharide produces some of its immunosuppressive effect by activation of a specific subset of T-supressive cells which secrete T-supressive factors (TsF) (Blackstock, 1996). This factor induced macrophage unresponsiveness and in turn, inhibited phagocytosis (Blackstock et al., 1987; Morgan et al., 1983; Rubinstein et al., 1989). GXM is a type 2 T-cell independent antigen (Sundstrom and Cherniak, 1992). GXM tolerance was T-cell mediated at a low dose, but T-cell independent at high doses. Moreover, the effect seemed to be mediated through CD4+ T-cells. In rat experimental models, it was also shown that $C$. neoformans produced an immunosuppressive state after two and three weeks of infection, which was associated with function of accessory cells (such as macrophages) and inhibition of spleen cell proliferative response to mitogens (Rossi et al., 1998). This unresponsiveness was also induced by purified GXM, and was associated with a decrease in the number of viable spleen mononuclear cells, increased production of IL-10 and IL-4, reduced levels of IL-2, and decreased CD11a surface expression (Chiapello et al., 2001). Addition of GXM to dendritic cells can inhibit T-cell proliferation. Recently, Yauch et al. described that GXM inhibited T-cell proliferation when exposed to dendritic cells. This inhibition occurred not only in the presence of dendritic cells, but also when T-cells were activated by anti-CD3 antibody, concanavalin A, or ionomycin (Yauch et al., 2006).

In addition to modulation of acquired immune system (B and T cells), capsular polysaccharide also interferes with some elements of the innate immune system. For example, the capsule 
inhibits aggregation of $C$. neoformans cells by surfactant protein $\mathrm{D}$, which is an important component of the lung's innate defense system (van de Wetering et al., 2004). Recently, it has been demonstrated that direct engagement of GXM to FcR $\gamma$ II expressed in monocytes, macrophages and dendritic cells, leads to an inhibitory signal that contributes to immune suppression (Monari et al., 2006b).

The immune unresponsiveness resulting from GXM does convey some beneficial effects on the host during other types of inflammatory pathologies. For example, GXM acts as a potent immunosupressor during induced arthritis (Mirshafiey et al., 2004).

GXM immunomodulation-During C. neoformans infection, the expression of a large number of immune mediators are modulated by GXM (reviewed in (Monari et al., 2006a; Vecchiarelli, 2000)). In addition, these immunomodulatory effects vary depending on cell type.

The outcome of the interaction between C. neoformans and monocytes differs depending on whether the yeast cell has a capsule. Acapsular strains elicited higher levels of some proinflammatory cytokines from monocytes, such as TNF- $\alpha$, IL-1- $\beta$ and IFN- $\gamma$ (Vecchiarelli et al., 1995; Walenkamp et al., 1999). This effect of the capsular polysaccharide is largely mediated through GXM, which can influence the expression of many molecules with important functions in the immune response. GXM also induces IL-10 and IL-8 secretion by human monocytes (Walenkamp et al., 1999). Since IL-10 is a potent downregulator of proinflammatory cytokines (such as TNF- $\alpha$ and IL1- $\beta$ ), this finding suggests a mechanism by which C. neoformans polysaccharide interferes with cell mediated immunity (Vecchiarelli et al., 1996). C. neoformans encapsulated cells induced IL-12 poorly when compared to acapsular mutants. It was later described that GXM reduced IL-12 through the increase in IL-10 expression, since neutralization of IL-10 with antibody reversed the GXM suppressive effect (Retini et al., 2001). It has recently been shown in murine macrophage cell lines that GXM induces TNF-beta accumulation (Villena et al., 2008). Cytokine regulation by $C$.

neoformans and GXM is also mediated through the complement pathway (Chaka et al., 1997b). GXM also induces IL-6 in monocytes (Delfino et al., 1997). The same effect was found in rat alveolar macrophages. In this case, the effect was mediated after phagocytosis of encapsulated cells opsonized with specific Abs ( $\mathrm{Li}$ and Mitchell, 1997). The expression of CD4 on monocytes was different when challenged with encapsulated and acapsular strains. Acapsular strains induced higher CD4 levels, and this effect was downregulated by addition of exogenous GXM (Pietrella et al., 1998)

In contrast, the capsule and purified GXM can have different effects on PMN cells. As mentioned above, GXM causes L-selectin shedding from neutrophils, a phenomenon which is accompanied with reduced TNF- $\alpha$ receptor expression, but increased CD15 and CD11b expression in neutrophils (Dong and Murphy, 1996). Furthermore, C. neoformans and purified GXM induce the expression of pro-inflammatory cytokines (TNF- $\alpha$, IL-1 $\beta$, IL-6, and IL-8) in neutrophils. Interestingly, in the case of encapsulated cells, the effect was dependent on the size of the capsule (Retini et al., 1996). However, this effect was not directly mediated through GXM, but through the complement activation pathway by capsule components, especially C3a y C5a, which stimulate PMN to produce pro-inflammatory molecules (Vecchiarelli et al., 1998). Some studies showed higher IL-6 expression in peripheral blood mononuclear cells after prolonged stimulation with acapsular strains (Siddiqui et al., 2006). The capsule also modulates the expression of C5aR (Monari et al., 2002). Exposure of PMN cells to encapsulated cells or acapsular mutants treated with GXM resulted in a drastic decrease of C5aR on the PMN cells membrane, suggesting a mechanism by which GXM interferes with neutrophil function. 
The reason why GXM produces different effects on macrophages and neutrophils is not known, but these cell types interact differently with GXM (see above, (Monari et al., 2003)). While GXM is expulsed from the cells in neutrophils, macrophages show a continuous intracellular accumulation of GXM. This difference may, in turn, produce different effects in cytokine production.

Consistent with the idea of GXM producing different effects in different cell types are findings that GXM from certain serotypes induces IL-8 production in human fetal microglial cells, but not in astrocyte cultures (Lipovsky et al., 1998a). Barluzzi et al. studied the effect of encapsulated and acapsular strains in microglial cell cultures. These authors did not find any difference in the expression of several cytokines, such as TNF- $\alpha$, IL-1 $\beta$, IL-6, IL-12p40 and granulocyte macrophage colony stimulating factor. They did find, however, that lipopolysaccharide-induced TNF $\alpha$ expression was blocked by encapsulated or acapsular yeasts or exposure to purified GXM or GalXM (Barluzzi et al., 1998).

GXM also regulates cytokine expression by CD4+ T cells (Mariano Andrade et al., 2003). GXM does not induce CD4 cell proliferation, but interfered with the immune system, resulting in increased fungal replication through a mechanism that involved enhancement of IL-10 and IL-4 production. These findings were interpreted as indicative that GXM contributes to virulence by interfering with the development of an effective cell-mediated immune response that was unable to inhibit fungal replication.

GalXM immunomodulation-Although most of the immunomodulatory effects of the capsular polysaccharide studies have focused on GXM, GalXM can also contribute to these effects. GXM, GalXM and MP can each elicit an increase in TNF- $\alpha$ in whole blood cultures (Delfino et al., 1996). Another study demonstrated that GXM-induced TNF- $\alpha$ accumulation was dependent on the presence of serum. In the case of GalXM, however, TNF- $\alpha$ was serum independent (Chaka et al., 1997b). GalXM induces IL-6 in monocytes (Delfino et al., 1997). In another study, the cytokine expression profile of human monocytes in the presence of different capsular components was investigated, demonstrating that GalXM and GXM exerted similar effects (Walenkamp et al., 1999). Recent findings in murine macrophages (RAW 264.7 cell line) showed that GalXM and GXM exert different effects on cytokine production, with GalXM having a profound effect on TNF-alpha induction in addition to NO production through ad iNOS expression (Villena et al., 2008). In microglial cells neither the addition of GalXM or GXM was associated with an increase in TNF- $\alpha$ accumulation, but both GXM and GalXM blocked this induction in the presence of LPS (Barluzzi et al., 1998). These results might suggest that GXM and GalXM share immunomodulatory properties.

Effect of GXM on antigen presentation-C. neoformans encapsulation is associated with reduced antigen presentation by macrophages (Collins and Bancroft, 1991). Purified GXM inhibited antigen presentation in monocytes exerted by acapsular cells (Retini et al., 1998). This effect was dependent on phagocytosis and was mediated through an increase in IL-10, resulting in a significant reduction in MHCII. In addition, the capsule was a poor stimulator of co-stimulatory molecule expression required for antigen presentation, such as B7-1 (CD80) and B7-2 (CD86), although encapsulated cells increased expression of ligand CTLA-4 when compared to acapsular cells (Pietrella et al., 2001b). This result is relevant for the host's defense since B7 co-stimulatory molecules are necessary to elicit an efficient T-cell response against C. neoformans (Monari et al., 1999b). Despite the negative effects of GXM on the expression of co-stimulatory and MHC molecules, injection into mice of antigen-presenting cells previously exposed in vitro to GXM inhibited T-suppressive cell responses, a phenomenon that led to enhanced survival of infected mice (Blackstock and Casadevall, 1997). This protective effect of GXM-APC stimulated cells was associated with an early DTH response development, and was mediated through increased production of some cytokines, such as IL-2 
and IFN- $\gamma$ (Blackstock et al., 2000). The authors concluded that during this process, GXMdependent and GXM-independent effects occurred. GXM-specific effects were dependent on MHC class II, while GXM independent effects required B7-1 and B7-2 molecules (Blackstock, 2003).

The capsular polysaccharide also interferes with the normal function of dendritic cells, which are professional antigen presenting cells necessary to initiate T-cell mediated responses.

Acapsular $C$. neoformans mutants are rapidly ingested by dendritic cells, which produces upregulation of maturation markers, such as MHCI and II, CD40, and CD83 (Monari et al., 2002). This maturation was not observed when dendritic cells were exposed to encapsulated cells or purified GXM, and suggested another mechanism by which the capsule interfered with T-cell mediated responses.

GXM induced apoptosis-Several groups have demonstrated that soluble GXM can induce apoptosis in different systems (see figure 7). This phenomenon was first described in rat lymphocytes (Chiapello et al., 2003). GXM-mediated apoptosis was first observed in vitro, and the results were corroborated in animal models, which proved that there was a high proportion of apoptotic cells in rat lungs and spleens during C. neoformans infection. A similar finding was observed when rats where treated with purified GXM (Chiapello et al., 2004). This process correlated with the modulation of some cytokines by GXM, such as IL-10, IL-2, IFN$\gamma$ and TNF- $\alpha$. GXM was also shown to induce expression of the Fas ligand on murine cells. This induction required GXM binding to TLR4 and correlated with GXM accumulation in the macrophages. Moreover, these macrophages induced apoptosis of T-cells or jurkat cells that expressed Fas (Monari et al., 2005b). Recently the mechanism of GXM-induced apoptosis of T-cells was further elucidated. It was found that both in vitro and in vivo systems, the binding of FasL produced by antigen presenting cells, by Fas on T-cells triggers caspase cascades that cause T-cell death (Monari et al., 2008). Caspase 8 was identified to play a central role in apoptosis since it cleaves caspase 3 via the extrinsic and intrinsic apoptotic pathways. It was also found that caspase 9 cleavage can also activate caspase 3 independent of caspase 8 . Therefore, the caspase 8 and caspase 9 pathways co-operate in an amplification loop for efficient cell death. The authors provide evidence that both capsase 8 and 9 are activated in one single cell. Collectively, the data indicate that GXM-induced apoptosis involves, a crosstalk between pathways within a single cell. Recently, GXM was also shown to induce apoptosis in macrophages through a mechanism that involves an increase in both Fas and FasL in the phagocytic cells (Villena et al., 2008).

GalXM induced apoptosis-GalXM inhibited peripheral blood mononuclear cells and Tcell proliferation, increased IFN- $\gamma$ and IL-10 production and induced apoptosis of Tlymphocytes by DNA fragmentation through the activation of caspase 8 (Pericolini et al., 2006). GalXM induces death receptors such as Fas and through subsequent activation of caspase- 8 , it is most likely that the type I apoptotic pathway is involved in this process. These results suggested the possibility of a putative receptor for GalXM on T-cells that may be involved in triggering apoptotic signals. GXM- and GalXM-mediated apoptosis appear to have fundamentally different mechanisms. GXM does not interact directly with T- cells, but rather mediates apoptosis by inducing FasL on antigen-producing cells such as macrophages (Monari et al., 2005b). In contrast, GalXM appears to directly interact with galectins on T-cells to induce apoptosis. However this mechanism needs to be further elucidated (Pericolini et al., 2006).

GalXM is also more potent than GXM at the induction of Fas/FasL expression and apoptosis on macrophages (Villena et al., 2008).

Regulation of chemiotaxis and cellular migration by capsular componentsLeukocyte migration to infected tissues is a complex process that involves chemotaxis of immune cells, binding to endothelial surfaces and movement across the endothelium. The 
capsular components can influence chemotaxis (see review in (Ellerbroek et al., 2004d)). The first evidence suggesting that the capsule interfered with cell migration was provided by the finding that capsular components induced PMN migration through the activation of the complement system by the alternative pathway (Diamond and Erickson, 1982; Laxalt and Kozel, 1979). Consistent with this finding, CSF from rabbits with chronic cryptococcal meningitis contained a host-derived factor with chemotactic activity toward PMN and monocytes (Perfect and Durack, 1985). In addition, encapsulated cells induced chemotaxis of human neutrophils through a direct mechanism (Dong and Murphy, 1993). Acapsular strains also exerted this effect, but in an indirect manner. The direct effect was mediated by GXM, while the other components of the capsule (GalXM and MP) played an indirect role through complement pathway modulation. Interestingly, capsular components from C. gattii did not have any effect on neutrophil migration (Dong and Murphy, 1995a) which suggests a mechanism by which $C$. gattii evades the interaction with this type of phagocytic cells.

The interplay of these chemotactic activities in vivo is very complex. Despite the chemotactic properties of GXM, there is a characteristic inhibition of leukocytes infiltration into infected tissues in cryptococcosis (Baker and Haugen, 1955). Dong and Murphy also showed that elements from the capsule inhibited leukocyte migration (neutrophils, lymphocytes, and monocytes) to infected areas (Dong and Murphy, 1995b). Furthermore, GXM induced shedding of L-selectins from neutrophil membranes as well as reducing TNF receptor expression, but increased CD15 and CD11b (Dong and Murphy, 1996). L-selectins are surface molecules necessary for neutrophil migration into tissues. GalXM and MP did not affect Lselecting shedding by comparison. These findings suggest a mechanism by which GXM may reduce neutrophil migration into infected tissues by preventing neutrophil adhesion to endothelial surfaces. A similar effect was found on T-cells (CD4 and CD8) through a mechanism that required tyrosine kinase (Dong et al., 1999). Some reports have suggested that L-selectin shedding was not the determinant factor that inhibits migration, and the same authors involved E-selectin in the migration process (Ellerbroek et al., 2002). The same authors reported that GXM interfered with rolling and fixed binding of neutrophils on the endothelium using a flow model (not static), and that this interference was mediated through TLR4, CD14 and E-selectin (Ellerbroek et al., 2004c). The effect was dependent on the 6-O-acetylation of mannose residues in GXM (Ellerbroek et al., 2004a). In addition, GXM can bind to CD18, interfering with its role in neutrophil migration (Dong and Murphy, 1997). GXM also interfered with PMN migration in response to IL-8 (Lipovsky et al., 1998a) and in agreement with this finding, it was found that the CSF leukocyte cell count was inversely correlated with the amount of GXM present in the serum (expressed as the GXM proportion in serum related to the amount present in CSF) (Lipovsky et al., 1998b). GXM also inhibited leukocyte migration into CSF in rabbit experimental models of bacterial meningitis (Lipovsky et al., 2000), as well as in some models which induce non-related neutrophil migration, such as rat model of myocardial ischaemia (Ellerbroek et al., 2004b).

Mannoproteins (MPs)—Although it has not been demonstrated that these immunogenic proteins are in fact capsular components, we will briefly review the effect of mannoproteins on the host.

C. neoformans MPs are highly immunogenic (Levitz and Specht, 2006)). Most immunological responses to mannoproteins in C. neoformans are pro-inflammatory (Murphy, 1988), and MPs in general elicit stronger effects than GXM or GalXM. The mannoprotein fraction CneF stimulated delayed-type hypersensitivity whereas the fraction MP4 can desensitize neutrophils toward chemoattractant challenges. MPs produce a strong TNF $\alpha$ accumulation (Delfino et al., 1996), dependent on serum-labile components (Chaka et al., 1997b). MPs also regulated the expression of other cytokines, such as IL-12, IL-6, IL-10, IFNg, and IL-8 in monocytes (Delfino et al., 1997; Pitzurra et al., 2000; Walenkamp et al., 1999). The effect of MPs has also been 
tested in vivo, and these studies have shown that treatment of mice with MP induced IL-12 and IFN- $\gamma$ expression, which was associated with a protective response to $C$. neoformans that included enhanced antifungal activity, early inflammatory responses, and clearance of fungal burden from the brain (Pietrella et al., 2001a). In vivo impairment of IL-12 induction interfered with the protective effect elicited by MPs (Pietrella et al., 2004). Furthermore, these mannoproteins elicit a protective response, not only against $C$. neoformans, but also against other fungal pathogens such as Candida albicans (Pietrella et al., 2002). In addition, MPs induced proliferation of human peripheral blood mononuclear cells (PBMC) (Orendi et al., 1997), a phenomenon not observed with GalXM. This induction resulted in an enhancement of HIV replication in infected PBMC, which suggested a mechanism by which $C$.

neoformans enhanced the viral infection. Later, a specific MP of a molecular size of $105 \mathrm{kDa}$ was demonstrated to be involved in monocyte proliferation induction (Pitzurra et al., 1997).

Mannoproteins also promote maturation and activation of dendritic cells (Pietrella et al., 2005). MP-induced expression of mature DC markers and IL-12, and MP-activated DC efficiently activated both CD4 and CD8 T-cells. MPs also exert a cooperative stimulation of DC with CpG-oligodeoxynucleotides, which induces pro-inflammatory cytokines. (Dan et al., 2008b)

Mannosylation is required for MP-mediated T-cell stimulation (Specht et al., 2007), consistent with the finding that MP stimulatory effect are the result of interactions with human mannose binding protein (Chaka et al., 1997a) or the mannose receptor (Dan et al., 2008b; Mansour et al., 2002). More recently, MP uptake was shown to be similar by dendritic cells from wildtype and mannose receptor KO mice, although MPs only induced CD4 lymphoproliferation in cells from wild-type mice, but not in KO mice (Dan et al., 2008a). This finding indicated that the mannose receptor is required for some of the effects mediated by MPs. There are other mechanisms by which DC can bind MPs, although these other mechanisms were not effective in inducing a protective T-cell response.

Several C. neoformans mannoproteins have been isolated. Mansour et al. identified a specific $98 \mathrm{kDa}$ mannoprotein (MP98) involved in the stimulation of T-cell responses (Levitz et al., 2001). The gene for MP98 was cloned (CDA2), and was found to contain a domain with similarity to chitin deacetylase. The role of chitin deacetylases is to convert chitin to chitosan, the deacetylated form of chitin. Using a collection of putative chitin deacetylase deletion strains cda1, cda2, cda3 and and a polysaccharide deacetylase fpd1, Baker et al. characterized the deacetylases and their biological roles (Baker et al., 2007). The study revealed that a single chitin deacetylase does not adversely affect the ability of $C$. neoformans to produce chitosan. Strains with a $c d a 1 \Delta c d a 2 \Delta$ mutation had increased capsular diameters. The results imply that chitosan produced by $\mathrm{Cda} 1$ and $\mathrm{Cda} 2$ is sufficient to retain normal capsule integrity. However, a quadruple mutation $c d a l c d a 2 c d a 3 f p d l$ abolished chitosan production. Strains lacking the chitosan had incomplete mother daughter cell separation and were sensitive to cell wall inhibitors. Additionally, mutants lacking chitosan were unable to completely retain melanin, another major virulence factor in C. neoformans (Baker et al., 2007).

In 2002, the same group identified a new MP involved in T-cell activation. It had an apparent molecular weight of $88 \mathrm{kDa}$, and was therefore named MP88 (Huang et al., 2002). This protein contained a putative glycosyl phosphatidyl inositol anchor site, and had homology to eleven other C. neoformans proteins, including MP98 (Huang et al., 2002).

Recently new immunogenic MPs have been identified, with molecular weights of 250, 125, 115 , and $84 \mathrm{kDa}$. The genes encoding MP84 and MP115 were cloned and had homology with polysaccharide deacetylases and carboxylesterases, respectively (Biondo et al., 2005). 


\section{C.3. Origin of the capsule as virulence factor}

An intriguing issue in the $C$. neoformans capsule field is how this structure has evolved as a virulence factor in mammals. It is difficult to understand how an environmental yeast that produces infection after inhalation can possess such a specialized structure for virulence in animals while not really requiring an animal host for any aspect of its life cycle.

To properly answer this question, it is important to emphasize that although C. neoformans is an environmental organism, it frequently interacts with a large number of non-conventional hosts widely found throughout nature (Casadevall and Perfect, 1998). For example, $C$. neoformans is known to interact with amoebas, such as Acanthamoeba castellanii and A. polyphaga and the slime mould Dictyostelim discoideum (Bunting et al., 1979; Castellani, 1955; Steenbergen et al., 2003). Some amoebas can phagocytose and kill C. neoformans while this fungus can survive ingestion by others (Steenbergen et al., 2001). In addition, $C$. neoformans has developed some mechanisms that allow phagocytotic inhibition, intracellular fungal replication, and killing evasion (Steenbergen et al., 2001; Zaragoza et al., 2008b).

C. neoformans intracellular pathogenesis in mammalian cells is associated with GXM accumulation in specific vesicles (Tucker and Casadevall, 2002). Remarkably, the interaction of $C$. neoformans with ameboid protozoal cells results in cytopathic changes in the host cell that are strikingly similar to those observed with mammalian cells. In both amoeba and macrophages, the capsular polysaccharide appears to function as an intracellular aggressin whereby polysaccharide-filled vacuoles from phagosomal membrane blebbing and accumulate in the cytoplasm (Steenbergen et al., 2001). In addition, C. neoformans can infect nematodes (Mylonakis et al., 2002), insects (Apidianakis et al., 2004; Mylonakis et al., 2005), toads (Seixas et al., 2008) and goats (Chapman et al., 1990).

In most of these interactions, the capsule plays a critical protective role for $C$. neoformans. Acapsular mutants are more efficiently engulfed by amoebas, and killed to a higher degree than encapsulated fungal cells (Steenbergen et al., 2001). Moreover, capsule enlargement and structural changes induced by starvation can also inhibit $C$. neoformans phagocytosis by amoebas (Zaragoza et al., 2008b). In the case of Caenorhabditis elegans, the capsule is also required for virulence and killing of the nematode, since acapsular mutants were cleared by the worm (Mylonakis et al., 2002). A similar situation was found with the caterpillar Galleria mellonella (the greater wax moth), a model in which acapsular mutants showed a markly reduced virulence (Mylonakis et al., 2005). However, the role of the capsule in the virulence in Drosophila melanogaster was different. In this model, acapsular mutants showed a slightly reduced virulence in comparison to encapsulated cells, but were still able to kill the insect (Apidianakis et al., 2004), indicating that the capsule is dispensible for virulence during $D$. melanogaster infection.

The fact that the capsule plays a protective role during interaction of $C$. neoformans with environmental factors (such as dehydration (Aksenov et al., 1973)) and in the interaction with environmental predators suggests a mechanism by which the $C$. neoformans capsule has adapted to become a virulence factor in multiple hosts. It is hypothesized that during evolution, C. neoformans has adapted the capsule from a protective structure to a feature that confers selective advantage during the interaction with the different hosts that it interacts with. As a consequence, it acquired the ability to produce a large number of deleterious effects on mammalian hosts (Casadevall et al., 2003). This hypothesis provides an explanation for the origin of virulence factors in enviromental microbes that are pathogenic for animals, and allows us to propose how virulence is a feature specifically acquired after numerous exposures and interactions with different types of hosts by natural selection (Casadevall and Pirofski, 2007). 


\section{Section D Use of capsular components as antifungal targets and vaccine}

Given the critical role of the capsule in virulence considerable efforts have been undertaken to develop antibodies and vaccines that target this structure. Two general approaches have been taken. First, many monoclonal antibodies have been developed with the purpose of targeting the capsular components, as a passive immunization. Studies with these mAbs have shown that antibody function against C. neoformans is extremely complex in the sense that some immunoglobulins confer protection, while others do not, and still others may even result in enhancement of disease. In a second approach the use of the capsular polysaccharide or capsulemimetic structures as a protective active vaccine has been proposed. In the following section, we will briefly review the main advances in these two fields.

\section{D.1 Capsule as an antifungal target. Monoclonal antibodies to the capsule as therapeutic alternative}

Although the protective role of the humoral response during C. neoformans infection has historically been questioned and remains uncertain, there have been two main reasons for developing these mAbs: 1) the capsule is the main virulence factor of this fungal pathogen, so blocking it with $\mathrm{mAb}$ theoretically could produce some protective effects; 2 ) it was observed that although the capsule is poorly immunogenic, there are some epitopes that can elicit protective Abs (Cleare et al., 1994).

The binding interactions between mAbs and the capsule and the interactions between $C$. neoformans and the host have been extensively studied. Although the capsule is dispensable for the life of the yeast, binding of mAbs to this structure produces a large number of effects in in vitro and in vivo models. The protective effect of antibodies binding to GXM has been extensively tested in murine models (Dromer et al., 1987a; Feldmesser and Casadevall, 1997; Fleuridor et al., 1998; Mukherjee et al., 1995c; Mukherjee et al., 1992), and the ability to change the outcome of disease has been observed in various infection models (Mukherjee et al., 1993; Mukherjee et al., 1994b). Numerous studies have been performed and a specific $\mathrm{mAb}(18 \mathrm{~B} 7)$ was evaluated in a Phase I/II trial in patients with HIV-associated cryptococcosis as an adjunct to antifungal therapy for cryptococcal meningitis (Larsen et al., 2005). To improve the potential efficacy of antibody therapy in humans, mouse-human chimeric and human Abs have been created. These Abs prolong mouse survival and this effect is dependent on the characteristics of the binding of the mAbs, such as specificity and isotype (Fleuridor et al., 1998; Maitta et al., 2004a; McLean et al., 2002). Moreover, mAbs to GXM enhance antimicrobial effects of some antifungal drugs, such as amphotericin B, fluconazole and flucytosine (Dromer and Charreire, 1991; Feldmesser et al., 1996; Mukherjee et al., 1995b; Mukherjee et al., 1994a).

Passive $\mathrm{Ab}$ administration is not always associated with a protective effect. For example, $\mathrm{mAbs}$ vary in efficacy depending on the infecting C. neoformans strain (Mukherjee et al., 1995d), which suggests that strain differences could be a key determinant in the protective effect of the Abs. Another key factor that determines the effect of mAbs to C. neoformans is the variable region of the $\mathrm{mAb}$. Several studies have demonstrated that Ab efficacy depends on the isotype (Mukherjee et al., 1992; Sanford et al., 1990). IgG1 isotype is generally considered protective, whereas IgM is either protective or neutral, and IgG3 is found to be disease-enhancing in some strains of mice. There are numerous explanations for the different effects according to the $\mathrm{Ab}$ isotype, including differences in distribution in the body, half-life, opsonic capacity and complement activation ability. However, antibodies expressing the same variable regions can differ in terms of their affinity, specifity, and protective efficacy (Torres et al., 2007; Torres et al., 2005). For some antibodies, differences in the binding to the capsule correlate with different in vivo effects (Beenhouwer et al., 2007). There is evidence that the binding pattern of the Abs to the capsule influences the final effect of the Abs. For example, as stated above, IgM Abs, 
which bind to the capsule in a punctuate pattern, are not protective, while IgM mAbs which bind in an annular pattern prolong survival in mice (Cleare and Casadevall, 1998; Nussbaum et al., 1997).

In a recent study, computer modeling to predict pore-hindered diffusion and binding of the GXM-specific antibody within the C. neoformans capsule was modelized (Rakesh et al., 2008). Using the finite element method (FEM), they created a model which represents the in vivo binding of GXM-specific antibody to a $C$. neoformans cell taking into account the intravenous infusion time of antibody, antibody diffusion through capsular pores, and Michaelis-Menten kinetics of antibody binding to capsular GXM (see figure 8). The model predicted rapid diffusion of antibody to all regions of the capsule where pore size was greater than the Stokes diameter of the antibody. Binding occurred primarily at intermediate regions of the capsule. The GXM concentration in each capsular region was the principal determinant of the steady-state antibody-GXM complex concentration, while the forward binding rate constant influenced the rate of complex formation in each region. The concentration profiles predicted by the model closely matched experimental immunofluorescence data (Fig. 8). Inclusion of different antibody isotypes (IgG, IgA and IgM) into the modeling algorithm resulted in similar complex formation in outer capsular regions, but different depth of binding at inner regions. These results have implications for the development of new antibody-based therapies (Rakesh et al., 2008).

Several studies have established that dose is a critical parameter in determing the efficacy of passive antibody administration. A single $\mathrm{mAb}$ can behave as protective, not protective or disease-enhancing depending on the $\mathrm{Ab}$ dose and / or the number of infecting pathogens (Taborda and Casadevall, 2001; Taborda et al., 2003). At high antibody doses, some mAbs lose protective efficacy. This feature, the so-called prozone effect, is an important issue that must be considered when interpreting passive $\mathrm{Ab}$ administration results.

MAbs to the capsule play an important role as opsonins during phagocytosis (see section above), and also in regulating complement activation (Kozel et al., 1998). In addition, mAbs to the capsule can enhance the antifungal activity of macrophages and microglia (Lee et al., 1995a; Mukherjee et al., 1996; Mukherjee et al., 1995e) and also of neutrophils from HIV patients (Monari et al., 1999a). However, the function of mAbs is critically dependent on the host's cell-mediated immunity (Yuan et al., 1997), B-cells (Rivera et al., 2005) and Th1 and Th2 cytokines (Beenhouwer et al., 2001). These studies indicate that mAbs to the capsule exert their in vitro action by modulating the inflammatory response, rather than through a direct antifungal effect. The mechanism by which mAbs binding to the capsule exert their action is therefore very complex, and it seems that binding to the epitope is not sufficient to achieve protection. mAbs to the capsule can regulate the inflammatory response elicited during infection, possibly by altering the release of mediators of inflammation such as cytokines (Feldmesser et al., 1998; Feldmesser et al., 2002). Engagement of Fc receptors appears to be a requirement for efficacy, since mAbs are not protective in $\mathrm{FcRI}^{-/-}$or $\mathrm{FcRIII}^{-1-} \mathrm{KO}$ mice (Yuan et al., 1998). Interestingly, mAbs can be protective in some cases of immunodeficiency, such as the absence of complement component 3 (Shapiro et al., 2002). In addition, the mouse genetic background is an important determinant for the effect of the Abs, which confirms that host elements are important to determine whether a mAb binding to the capsule will have a protective effect or not (Rivera and Casadevall, 2005).

In addition to passive $\mathrm{mAb}$ administration, new strategies based on enhancing the activity of $\mathrm{mAbs}$ to the capsule have been developed to improve their efficacy. For example, radiolabeling of these mAbs converted an antibody into a microbicidal molecule that causes reduction in capsule size, changes in cellular metabolism and an apoptosis-like death in fungal cells (Dadachova et al., 2006). This effect is highly dependent on the antibody isotype and the 
affinity constant of the mAb binding to the polysaccharide capsule (Dadachova et al., 2007). The same dependence of the fungicidal ability of radiolabeled antibodies on the isotype was observed for C. neoformans biofilms which are characterized by massive deposits of exopolysaccharide (Martinez et al., 2006). Administration of radiolabeled GXM-specific mAb 18B7 prolonged survival of $\mathrm{AJ} / \mathrm{Cr}$ mice lethally infected with $C$. neoformans (Dadachova et al., 2003). The success of these studies has led to the emergence of the whole new field of radioimmunotherapy (RIT) of infectious diseases which has been subsequently expanded to treatment of bacterial and viral infections (reviewed (Dadachova and Casadevall, 2008)).

\section{D.2 Use of capsular components as vaccine}

GXM synthesis is different from that of other capsular polysaccharides in that it is a heteropolymer that, in theory, could display an almost infinite number of structural combinations, which could translate into antigenic changes and enhance its structural complexity (McFadden et al., 2007). Fortunately, mAbs that recognize all strains have been identified, suggesting that certain immunudominant epitopes may be conserved across strains. The rationale for GXM-based conjugate vaccines is that they elicit antibodies that are opsonic and bind soluble polysaccharide, promoting its clearance.

The first immunization studies with GXM were done by injecting the polysaccharide with an ion exchange resin or in an emulsion with Freund's adjuvant. This strategy, however, only elicited a weak antibody response mostly of the IgM isotype (Cauley and Murphy, 1979; Gadebusch, 1958a; Kozel et al., 1977). In the late 1960's Goren and Middlebrook generated the first GXM (or cryptococcal polysaccharide)-based glycoconjugate vaccine by coupling unfractionated capsular polysaccharide (which most likely contained all three capsular components) to a bovine gamma globulin by nitrocarbanilation and diazotization (Goren and Middlebrook, 1967). This vaccine was highly immunogenic but did not elicit a protective antibody response. In the 1990's, a second glyconjugate vaccine was developed based on fractionating the GXM component and linking it to tetanus-toxoid (TT) (Devi et al., 1991). Boosting immunization yielded Ab's of the IgG isotype. mAb 18B7 was generated using the GXM-TT conjugate.

An alternative approach in using C. neoformans as a vaccine antigen that is conceptually related to glycoconjugate vaccines in terms of the type of immunity that is elicited, is the development of a peptide that mimics a GXM epitope. A mimetic is a peptide epitope that inhibits the binding of an antibody to its native antigen (Pirofski, 2001). The peptide can elicit a protective antibody response by stimulating the production of protective antibodies that bind to polysaccharide (Pirofski, 2001). The approach used to develop the peptide mimetope vaccine employed a decapeptide phage display library in which peptide epitopes were expressed on the surface protein of the M13 bacteriophage which were then screened by using human IgM monoclonal antibody to C.neoformans GXM, 2E9. This mAb was produced from immortalized lymphocytes from a volunteer who received the GXM-TT vaccine (Valadon et al., 1996). A group of these phage peptide epitopes were isolated and were considered GXM mimetics.

The peptide mimetic P13 was conjugated to TT or BSA and used to vaccinate mice. The vaccine elicited both IgM and IgG antibodies to both GXM and P13, suggesting that P13 is a GXM mimetope. The P13-TT conjugate induced protection in mice that is probably antibody mediated. Despite promising results, mimetope mediated protection and vaccine efficacy is not fully understood.

There have been several attempts to synthesize oligosaccharides that reproduce the structural repeat of GXM (Garegg et al., 1996; Oscarson et al., 2005; Vesely et al., 2008), including a heptasaccharide representing the putative immunodominant motif of serotype A GXM (Oscarson et al., 2005). The heptasaccharide consists of two M2 repeats (see Figure 2 for 
structural interpretation) and one mannose residue. The M2 repeat was selected because it is commonly found in GXM of serotype A strains, although this repeat is also found in other serotypes. The synthetic heptasaccharide was strongly recognized by two different IgMs (Oscarson et al., 2005). Conjugation of the heptasaccharide to human serum albumin resulted in an immunogenic compound that elicited high-titer IgG responses in mice when given with complete Freund's adjuvant. The antibody response elicited by the oligosaccharide conjugate vaccine had characteristics of a T-cell-dependent response (Oscarson et al., 2005). The immunogenic oligosaccharide with the structural motif of GXM therefore represents a potential synthetic vaccine against this fungal pathogen.

\section{Future perspectives}

After 50 years of intensive study that has included serological, biochemical, immunological, microscopic, genetic and physical investigations, much is known about the $C$. neoformans capsule. The capsule is widely acknowledged to be an indispensable virulence factor and continues to occupy much of the investigative attentions of the cryptococcal field. However, despite hundreds of publications detailing capsule-related studies, the capsule remains an enigmatic structure that continues to defy complete understanding. At this time there is probably a reasonably good understanding of the various mechanisms by which the capsule contributes to virulence. While the chemical composition of capsular polysaccharide has been well described, we still do not know the answer to some basic questions concerning capsular biochemistry such as whether some fibrils include branches. There is no current evidence for branched polysaccharides but the biochemical methods do not rule out occasional branched molecules. The areas in which the least is known include the architecture, organization, and synthesis of the capsule. No comprehensive model has yet been proposed for molecular mechanisms responsible for capsular enlargement.

The major problem with regards to studying the architecture of the capsule is a dearth of techniques that yield structural information for a highly hydrated, fragile, and variable polysaccharide fibrilar mesh. Therefore much of what we know about the capsule has been inferred from studies of soluble polysaccharide. A better understanding of how the capsule is assembled may require the development of new approaches that combine approaches from various disciplines.

On the immunological front several important open questions remain. The role of the capsule during intracellular pathogenesis provides the paradoxical finding that a structure that inhibits phagocytosis also functions to undermine the host cell after being ingested. The origin of polysaccharide-containing vesicles that fill the cytoplasm of infected macrophages has not been solved. Similarly, the mechanism by which the capsule contributes to the phenomenon of cryptococcal exocytosis is unknown. Capsular polysaccharides are powerful immunomodulators but their cellular receptors have not been fully characterized.

C. neoformans has the largest, most distinctive and best characterized capsule in the field of medical microbiology and studies of capsular structure, synthesis, and function will continue to occupy the field for many years to come.

\section{Acknowledgements}

We are indebted to Karen Dente for the outstanding review and editing of the manuscript. O.Z. is a "Ramón y Cajal" fellow and is supported by grants 1025/06 and 1142/08 from MICINN and 1181/06 from Instituto de Salud Carlos III. AC is supported by NIH grants AI033774, HL059842, and 5R37AI033142. 


\section{References}

Aksenov SI, Babyeva IP, Golubev VI. On the mechanism of adaptation of micro-organisms to conditions of extreme low humidity. Life Sci Space Res 1973;11:55-61. [PubMed: 12523380]

Alspaugh JA, Perfect JR, Heitman J. Cryptococcus neoformans mating and virulence are regulated by the G-protein alpha subunit GPA1 and cAMP. Genes Dev 1997;11(23):3206-17. [PubMed: 9389652]

Alspaugh JA, Pukkila-Worley R, Harashima T, Cavallo LM, Funnell D, Cox GM, Perfect JR, Kronstad JW, Heitman J. Adenylyl cyclase functions downstream of the Galpha protein Gpa1 and controls mating and pathogenicity of Cryptococcus neoformans. Eukaryot Cell 2002;1(1):75-84. [PubMed: 12455973]

Alvarez M, Casadevall A. Phagosome extrusion and host-cell survival after Cryptococcus neoformans phagocytosis by macrophages. Curr Biol 2006;16(21):2161-5. [PubMed: 17084702]

Alvarez M, Casadevall A. Cell-to-cell spread and massive vacuole formation after Cryptococcus neoformans infection of murine macrophages. BMC Immunol 2007;8:16. [PubMed: 17705844]

Apidianakis Y, Rahme LG, Heitman J, Ausubel FM, Calderwood SB, Mylonakis E. Challenge of Drosophila melanogaster with Cryptococcus neoformans and role of the innate immune response. Eukaryot Cell 2004;3(2):413-9. [PubMed: 15075271]

Bacon BE, Cherniak R, Kwon-Chung KJ, Jacobson ES. Structure of the O-deacetylated glucuronoxylomannan from Cryptococcus neoformans Cap70 as determined by 2D NMR spectroscopy. Carbohydr Res 1996;283:95-110. [PubMed: 8901265]

Bahn YS, Hicks JK, Giles SS, Cox GM, Heitman J. Adenylyl cyclase-associated protein Aca1 regulates virulence and differentiation of Cryptococcus neoformans via the cyclic AMP-protein kinase A cascade. Eukaryot Cell 2004;3(6):1476-91. [PubMed: 15590822]

Baker LG, Specht CA, Donlin MJ, Lodge JK. Chitosan, the deacetylated form of chitin, is necessary for cell wall integrity in Cryptococcus neoformans. Eukaryot Cell 2007;6(5):855-67. [PubMed: 17400891]

Baker RD, Haugen RK. Tissue changes and tissue diagnosis in cryptococcosis; a study of 26 cases. Am J Clin Pathol 1955;25(1):14-24. [PubMed: 14349908]

Banks IR, Specht CA, Donlin MJ, Gerik KJ, Levitz SM, Lodge JK. A chitin synthase and its regulator protein are critical for chitosan production and growth of the fungal pathogen Cryptococcus neoformans. Eukaryot Cell 2005;4(11):1902-12. [PubMed: 16278457]

Bar-Peled M, Griffith CL, Doering TL. Functional cloning and characterization of a UDP- glucuronic acid decarboxylase: the pathogenic fungus Cryptococcus neoformans elucidates UDP-xylose synthesis. Proc Natl Acad Sci U S A 2001;98(21):12003-8. [PubMed: 11593010]

Bar-Peled M, Griffith CL, Ory JJ, Doering TL. Biosynthesis of UDP-GlcA, a key metabolite for capsular polysaccharide synthesis in the pathogenic fungus Cryptococcus neoformans. Biochem J 2004;381 (Pt 1):131-6. [PubMed: 15030319]

Barbosa FM, Fonseca FL, Figueiredo RT, Bozza MT, Casadevall A, Nimrichter L, Rodrigues ML. Binding of glucuronoxylomannan to the CD14 receptor in human A549 alveolar cells induces interleukin-8 production. Clin Vaccine Immunol 2007;14(1):94-8. [PubMed: 17093102]

Barbosa FM, Fonseca FL, Holandino C, Alviano CS, Nimrichter L, Rodrigues ML. Glucuronoxylomannan-mediated interaction of Cryptococcus neoformans with human alveolar cells results in fungal internalization and host cell damage. Microbes Infect 2006;8(2):493-502. [PubMed: 16293436]

Barluzzi R, Brozzetti A, Delfino D, Bistoni F, Blasi E. Role of the capsule in microglial cell-Cryptococcus neoformans interaction: impairment of antifungal activity but not of secretory functions. Med Mycol 1998;36(4):189-97. [PubMed: 9776834]

Beenhouwer DO, Shapiro S, Feldmesser M, Casadevall A, Scharff MD. Both Th1 and Th2 cytokines affect the ability of monoclonal antibodies to protect mice against Cryptococcus neoformans. Infect Immun 2001;69(10):6445-55. [PubMed: 11553589]

Beenhouwer DO, Yoo EM, Lai CW, Rocha MA, Morrison SL. Human immunoglobulin G2 (IgG2) and IgG4, but not IgG1 or IgG3, protect mice against Cryptococcus neoformans infection. Infect Immun 2007;75(3):1424-35. [PubMed: 17220317] 
Belay T, Cherniak R, Kozel TR, Casadevall A. Reactivity patterns and epitope specificities of antiCryptococcus neoformans monoclonal antibodies by enzyme-linked immunosorbent assay and dot enzyme assay. Infect Immun 1997;65(2):718-28. [PubMed: 9009335]

Biondo C, Messina L, Bombaci M, Mancuso G, Midiri A, Beninati C, Cusumano V, Gerace E, Papasergi $\mathrm{S}$, Teti G. Characterization of two novel cryptococcal mannoproteins recognized by immune sera. Infect Immun 2005;73(11):7348-55. [PubMed: 16239533]

Blackstock R. Cryptococcal capsular polysaccharide utilizes an antigen-presenting cell to induce a Tsuppressor cell to secrete TsF. J Med Vet Mycol 1996;34(1):19-30. [PubMed: 8786467]

Blackstock R. Roles for CD40, B7 and major histocompatibility complex in induction of enhanced immunity by cryptococcal polysaccharide-pulsed antigen-presenting cells. Immunology 2003;108 (2):158-66. [PubMed: 12562324]

Blackstock R, Buchanan KL, Adesina AM, Murphy JW. Differential regulation of immune responses by highly and weakly virulent Cryptococcus neoformans isolates. Infect Immun 1999;67(7):3601-9. [PubMed: 10377145]

Blackstock R, Casadevall A. Presentation of cryptococcal capsular polysaccharide (GXM) on activated antigen-presenting cells inhibits the T-suppressor response and enhances delayed-type hypersensitivity and survival. Immunology 1997;92(3):334-9. [PubMed: 9486105]

Blackstock R, Hall NK. Non-specific immunosuppression by Cryptococcus neoformans infection. Mycopathologia 1984;86(1):35-43. [PubMed: 6234468]

Blackstock R, McCormack JM, Hall NK. Induction of a macrophage-suppressive lymphokine by soluble cryptococcal antigens and its association with models of immunologic tolerance. Infect Immun 1987;55(1):233-9. [PubMed: 2947863]

Blackstock R, McElwee N, Neller E, Shaddix-White J. Regulation of cytokine expression in mice immunized with cryptococcal polysaccharide, a glucuronoxylomannan (GXM), associated with peritoneal antigen-presenting cells (APC): requirements for GXM, APC activation, and interleukin-12. Infect Immun 2000;68(9):5146-53. [PubMed: 10948138]

Blackstock R, Murphy JW. Secretion of the C3 component of complement by peritoneal cells cultured with encapsulated Cryptococcus neoformans. Infect Immun 1997;65(10):4114-21. [PubMed: 9317016]

Bose I, Reese AJ, Ory JJ, Janbon G, Doering TL. A yeast under cover: the capsule of Cryptococcus neoformans. Eukaryot Cell 2003;2(4):655-63. [PubMed: 12912884]

Bryan RA, Zaragoza O, Zhang T, Ortiz G, Casadevall A, Dadachova E. Radiological studies reveal radial differences in the architecture of the polysaccharide capsule of Cryptococcus neoformans. Eukaryot Cell 2005;4(2):465-75. [PubMed: 15701808]

Bunting LA, Neilson JB, Bulmer GS. Cryptococcus neoformans: gastronomic delight of a soil ameba. Sabouraudia 1979;17(3):225-32. [PubMed: 394365]

Campos MA, Vargas MA, Regueiro V, Llompart CM, Alberti S, Bengoechea JA. Capsule polysaccharide mediates bacterial resistance to antimicrobial peptides. Infect Immun 2004;72(12):7107-14. [PubMed: 15557634]

Casadevall A, DeShaw M, Fan M, Dromer F, Kozel TR, Pirofski LA. Molecular and idiotypic analysis of antibodies to Cryptococcus neoformans glucuronoxylomannan. Infect Immun 1994;62(9):386472. [PubMed: 8063403]

Casadevall A, Mukherjee J, Devi SJ, Schneerson R, Robbins JB, Scharff MD. Antibodies elicited by a Cryptococcus neoformans-tetanus toxoid conjugate vaccine have the same specificity as those elicited in infection. J Infect Dis 1992;165(6):1086-93. [PubMed: 1583327]

Casadevall, A.; Perfect, JR. Cryptococcus neoformans. Press, A., editor. ASM Press; Washington DC: 1998.

Casadevall A, Pirofski LA. The damage-response framework of microbial pathogenesis. Nat Rev Microbiol 2003;1(1):17-24. [PubMed: 15040176]

Casadevall A, Pirofski LA. Accidental virulence, cryptic pathogenesis, martians, lost hosts, and the pathogenicity of environmental microbes. Eukaryot Cell 2007;6(12):2169-74. [PubMed: 17951515]

Casadevall A, Steenbergen JN, Nosanchuk JD. 'Ready made' virulence and 'dual use' virulence factors in pathogenic environmental fungi--the Cryptococcus neoformans paradigm. Curr Opin Microbiol 2003;6(4):332-7. [PubMed: 12941400] 
Castellani A. [Phagocytic and destructive action of Hartmanella castellanii (Amoeba castellanii) on pathogenic encapsulated yeast-like fungi Torulopsis neoformans (Cryptococcus neoformans).]. Ann Inst Pasteur (Paris) 1955;89(1):1-7. [PubMed: 13403348]

Castle SA, Owuor EA, Thompson SH, Garnsey MR, Klutts JS, Doering TL, Levery SB. The \{beta $\}$ 1,2Xylosyltransferase Cxt1p is solely responsible for xylose incorporation into Cryptococcus neoformans glycosphingolipids. Eukaryot Cell. 2008

Cauley LK, Murphy JW. Response of congenitally athymic (nude) and phenotypically normal mice to Cryptococcus neoformans infection. Infect Immun 1979;23(3):644-51. [PubMed: 313367]

Clancy CJ, Nguyen MH, Alandoerffer R, Cheng S, Iczkowski K, Richardson M, Graybill JR. Cryptococcus neoformans var. grubii isolates recovered from persons with AIDS demonstrate a wide range of virulence during murine meningoencephalitis that correlates with the expression of certain virulence factors. Microbiology 2006;152(Pt 8):2247-55. [PubMed: 16849791]

Cleare W, Brandt ME, Casadevall A. Monoclonal antibody 13F1 produces annular immunofluorescence patterns on Cryptococcus neoformans serotype AD isolates. J Clin Microbiol 1999a;37(9):3080. [PubMed: 10475750]

Cleare W, Casadevall A. The different binding patterns of two immunoglobulin M monoclonal antibodies to Cryptococcus neoformans serotype A and D strains correlate with serotype classification and differences in functional assays. Clin Diagn Lab Immunol 1998;5(2):125-9. [PubMed: 9521132]

Cleare W, Casadevall A. Scanning electron microscopy of encapsulated and non-encapsulated Cryptococcus neoformans and the effect of glucose on capsular polysaccharide release. Med Mycol 1999;37(4):235-43. [PubMed: 10421858]

Cleare W, Cherniak R, Casadevall A. In vitro and in vivo stability of a Cryptococcus neoformans [corrected] glucuronoxylomannan epitope that elicits protective antibodies. Infect Immun 1999b;67 (6):3096-107. [PubMed: 10338526]

Cleare W, Mukherjee S, Spitzer ED, Casadevall A. Prevalence in Cryptococcus neoformans strains of a polysaccharide epitope which can elicit protective antibodies. Clin Diagn Lab Immunol 1994;1(6): 737-40. [PubMed: 8556529]

Coenjaerts FE, Hoepelman AI, Scharringa J, Aarts M, Ellerbroek PM, Bevaart L, Van Strijp JA, Janbon G. The Skn7 response regulator of Cryptococcus neoformans is involved in oxidative stress signalling and augments intracellular survival in endothelium. FEMS Yeast Res 2006;6(4):652-61. [PubMed: 16696662]

Collins HL, Bancroft GJ. Encapsulation of Cryptococcus neoformans impairs antigen-specific T-cell responses. Infect Immun 1991;59(11):3883-8. [PubMed: 1937747]

Cottrell TR, Griffith CL, Liu H, Nenninger AA, Doering TL. The pathogenic fungus Cryptococcus neoformans expresses two functional GDP-mannose transporters with distinct expression patterns and roles in capsule synthesis. Eukaryot Cell 2007;6(5):776-85. [PubMed: 17351078]

Cramer KL, Gerrald QD, Nichols CB, Price MS, Alspaugh JA. Transcription factor Nrg1 mediates capsule formation, stress response, and pathogenesis in Cryptococcus neoformans. Eukaryot Cell 2006;5(7):1147-56. [PubMed: 16835458]

Chaka W, Verheul AF, Vaishnav VV, Cherniak R, Scharringa J, Verhoef J, Snippe H, Hoepelman AI. Induction of TNF-alpha in human peripheral blood mononuclear cells by the mannoprotein of Cryptococcus neoformans involves human mannose binding protein. J Immunol 1997a;159(6):2979_ 85. [PubMed: 9300722]

Chaka W, Verheul AF, Vaishnav VV, Cherniak R, Scharringa J, Verhoef J, Snippe H, Hoepelman IM. Cryptococcus neoformans and cryptococcal glucuronoxylomannan, galactoxylomannan, and mannoprotein induce different levels of tumor necrosis factor alpha in human peripheral blood mononuclear cells. Infect Immun 1997b;65(1):272-8. [PubMed: 8975923]

Chang YC, Jong A, Huang S, Zerfas P, Kwon-Chung KJ. CPS1, a homolog of the Streptococcus pneumoniae type 3 polysaccharide synthase gene, is important for the pathobiology of Cryptococcus neoformans. Infect Immun 2006a;74(7):3930-8. [PubMed: 16790766]

Chang YC, Kwon-Chung KJ. Complementation of a capsule-deficient mutation of Cryptococcus neoformans restores its virulence. Mol Cell Biol 1994;14(7):4912-9. [PubMed: 8007987]

Chang YC, Kwon-Chung KJ. Isolation of the third capsule-associated gene, CAP60, required for virulence in Cryptococcus neoformans. Infect Immun 1998;66(5):2230-6. [PubMed: 9573112] 
Chang YC, Kwon-Chung KJ. Isolation, characterization, and localization of a capsule-associated gene, CAP10, of Cryptococcus neoformans. J Bacteriol 1999;181(18):5636-43. [PubMed: 10482503]

Chang YC, Penoyer LA, Kwon-Chung KJ. The second capsule gene of cryptococcus neoformans, CAP64, is essential for virulence. Infect Immun 1996;64(6):1977-83. [PubMed: 8675296]

Chang ZL, Netski D, Thorkildson P, Kozel TR. Binding and internalization of glucuronoxylomannan, the major capsular polysaccharide of Cryptococcus neoformans, by murine peritoneal macrophages. Infect Immun 2006b;74(1):144-51. [PubMed: 16368967]

Chapman HM, Robinson WF, Bolton JR, Robertson JP. Cryptococcus neoformans infection in goats. Aust Vet J 1990;67(7):263-5. [PubMed: 2393374]

Charlier C, Chretien F, Baudrimont M, Mordelet E, Lortholary O, Dromer F. Capsule structure changes associated with Cryptococcus neoformans crossing of the blood-brain barrier. Am J Pathol 2005;166 (2):421-32. [PubMed: 15681826]

Chen SH, Stins MF, Huang SH, Chen YH, Kwon-Chung KJ, Chang Y, Kim KS, Suzuki K, Jong AY. Cryptococcus neoformans induces alterations in the cytoskeleton of human brain microvascular endothelial cells. J Med Microbiol 2003;52(Pt 11):961-70. [PubMed: 14532340]

Cherniak R, Errol R, Turner S. A galactoxylomannan antigen of Cryptococcus neoformans serotype A. Carbohydrate Research 1982;103:239-250.

Cherniak R, Jones RG, Reiss E. Structure determination of Cryptococcus neoformans serotype A-variant glucuronoxylomannan by 13C-n.m.r. spectroscopy. Carbohydr Res 1988;172(1):113-38. [PubMed: 3280130]

Cherniak R, Morris LC, Belay T, Spitzer ED, Casadevall A. Variation in the structure of glucuronoxylomannan in isolates from patients with recurrent cryptococcal meningitis. Infect Immun 1995;63(5):1899-905. [PubMed: 7729900]

Cherniak R, Sundstrom JB. Polysaccharide antigens of the capsule of Cryptococcus neoformans. Infect Immun 1994;62(5):1507-12. [PubMed: 8168912]

Cherniak R, Valafar H, Morris LC, Valafar F. Cryptococcus neoformans chemotyping by quantitative analysis of $1 \mathrm{H}$ nuclear magnetic resonance spectra of glucuronoxylomannans with a computersimulated artificial neural network. Clin Diagn Lab Immunol 1998;5(2):146-59. [PubMed: 9521136]

Chiapello L, Iribarren P, Cervi L, Rubinstein H, Masih DT. Mechanisms for induction of immunosuppression during experimental cryptococcosis: role of glucuronoxylomannan. Clin Immunol 2001;100(1):96-106. [PubMed: 11414750]

Chiapello LS, Aoki MP, Rubinstein HR, Masih DT. Apoptosis induction by glucuronoxylomannan of Cryptococcus neoformans. Med Mycol 2003;41(4):347-53. [PubMed: 12964728]

Chiapello LS, Baronetti JL, Aoki MP, Gea S, Rubinstein H, Masih DT. Immunosuppression, interleukin-10 synthesis and apoptosis are induced in rats inoculated with Cryptococcus neoformans glucuronoxylomannan. Immunology 2004;113(3):392-400. [PubMed: 15500627]

Chretien F, Lortholary O, Kansau I, Neuville S, Gray F, Dromer F. Pathogenesis of cerebral Cryptococcus neoformans infection after fungemia. J Infect Dis 2002;186(4):522-30. [PubMed: 12195380]

D'Souza CA, Alspaugh JA, Yue C, Harashima T, Cox GM, Perfect JR, Heitman J. Cyclic AMP-dependent protein kinase controls virulence of the fungal pathogen Cryptococcus neoformans. Mol Cell Biol 2001;21(9):3179-91. [PubMed: 11287622]

D'Souza CA, Heitman J. Conserved cAMP signaling cascades regulate fungal development and virulence. FEMS Microbiol Rev 2001;25(3):349-64. [PubMed: 11348689]

Dadachova E, Bryan RA, Apostolidis C, Morgenstern A, Zhang T, Moadel T, Torres M, Huang X, Revskaya E, Casadevall A. Interaction of radiolabeled antibodies with fungal cells and components of the immune system in vitro and during radioimmunotherapy for experimental fungal infection. $\mathrm{J}$ Infect Dis 2006;193(10):1427-36. [PubMed: 16619191]

Dadachova E, Bryan RA, Huang X, Ortiz G, Moadel T, Casadevall A. Comparative evaluation of capsular polysaccharide-specific IgM and IgG antibodies and F(ab')2 and Fab fragments as delivery vehicles for radioimmunotherapy of fungal infection. Clin Cancer Res 2007;13(18 Pt 2):5629s-5635s. [PubMed: 17875799]

Dadachova E, Casadevall A. Host and microbial cells as targets for armed antibodies in the treatment of infectious diseases. Curr Opin Investig Drugs 2008;9(2):184-8. 
Dadachova E, Nakouzi A, Bryan RA, Casadevall A. Ionizing radiation delivered by specific antibody is therapeutic against a fungal infection. Proc Natl Acad Sci U S A 2003;100(19):10942-7. [PubMed: 12930899]

Dan JM, Kelly RM, Lee CK, Levitz SM. Role of the mannose receptor in a murine model of Cryptococcus neoformans infection. Infect Immun 2008a;76(6):2362-7. [PubMed: 18391001]

Dan JM, Wang JP, Lee CK, Levitz SM. Cooperative stimulation of dendritic cells by Cryptococcus neoformans mannoproteins and CpG oligodeoxynucleotides. PLoS ONE 2008b;3(4):e2046. [PubMed: 18446192]

De Jesus M, Park CG, Su Y, Goldman DL, Steinman RM, Casadevall A. Spleen deposition of Cryptococcus neoformans capsular glucuronoxylomannan in rodents occurs in red pulp macrophages and not marginal zone macrophages expressing the C-type lectin SIGN-R1. Med Mycol 2008;46(2): 153-62. [PubMed: 18324494]

Delfino D, Cianci L, Lupis E, Celeste A, Petrelli ML, Curro F, Cusumano V, Teti G. Interleukin-6 production by human monocytes stimulated with Cryptococcus neoformans components. Infect Immun 1997;65(6):2454-6. [PubMed: 9169790]

Delfino D, Cianci L, Migliardo M, Mancuso G, Cusumano V, Corradini C, Teti G. Tumor necrosis factorinducing activities of Cryptococcus neoformans components. Infect Immun 1996;64(12):5199-204. [PubMed: 8945566]

Dembitzer HM, Buza I, Reiss F. Biological and electron microscopic changes in gamma radiated Cryptococcus neoformans. Mycopathol Mycol Appl 1972;47(3):307-15. [PubMed: 4116042]

Devi SJ, Schneerson R, Egan W, Ulrich TJ, Bryla D, Robbins JB, Bennett JE. Cryptococcus neoformans serotype A glucuronoxylomannan-protein conjugate vaccines: synthesis, characterization, and immunogenicity. Infect Immun 1991;59(10):3700-7. [PubMed: 1716613]

Diamond RD, Bennett JE. Growth of Cryptococcus neoformans within human macrophages in vitro. Infect Immun 1973;7(2):231-6. [PubMed: 4697791]

Diamond RD, Erickson NF 3rd. Chemotaxis of human neutrophils and monocytes induced by Cryptococcus neoformans. Infect Immun 1982;38(1):380-2. [PubMed: 6754617]

Doering TL. How does Cryptococcus get its coat? Trends Microbiol 2000;8(12):547-53. [PubMed: 11115750]

Dong ZM, Jackson L, Murphy JW. Mechanisms for induction of L-selectin loss from T lymphocytes by a cryptococcal polysaccharide, glucuronoxylomannan. Infect Immun 1999;67(1):220-9. [PubMed: 9864219]

Dong ZM, Murphy JW. Mobility of human neutrophils in response to Cryptococcus neoformans cells, culture filtrate antigen, and individual components of the antigen. Infect Immun 1993;61(12):506777. [PubMed: 8225584]

Dong ZM, Murphy JW. Effects of the two varieties of Cryptococcus neoformans cells and culture filtrate antigens on neutrophil locomotion. Infect Immun 1995a;63(7):2632-44. [PubMed: 7790079]

Dong ZM, Murphy JW. Intravascular cryptococcal culture filtrate (CneF) and its major component, glucuronoxylomannan, are potent inhibitors of leukocyte accumulation. Infect Immun 1995b;63(3): 770-8. [PubMed: 7868246]

Dong ZM, Murphy JW. Cryptococcal polysaccharides induce L-selectin shedding and tumor necrosis factor receptor loss from the surface of human neutrophils. J Clin Invest 1996;97(3):689-98. [PubMed: 8609224]

Dong ZM, Murphy JW. Cryptococcal polysaccharides bind to CD18 on human neutrophils. Infect Immun 1997;65(2):557-63. [PubMed: 9009313]

Dromer F, Charreire J. Improved amphotericin B activity by a monoclonal anti-Cryptococcus neoformans antibody: study during murine cryptococcosis and mechanisms of action. J Infect Dis 1991;163(5): 1114-20. [PubMed: 2019759]

Dromer F, Charreire J, Contrepois A, Carbon C, Yeni P. Protection of mice against experimental cryptococcosis by anti-Cryptococcus neoformans monoclonal antibody. Infect Immun 1987a;55(3): 749-52. [PubMed: 3546140]

Dromer F, Salamero J, Contrepois A, Carbon C, Yeni P. Production, characterization, and antibody specificity of a mouse monoclonal antibody reactive with Cryptococcus neoformans capsular polysaccharide. Infect Immun 1987b;55(3):742-8. [PubMed: 3546139] 
Dykstra MA, Friedman L, Murphy JW. Capsule size of Cryptococcus neoformans: control and relationship to virulence. Infect Immun 1977;16(1):129-35. [PubMed: 326665]

Eckert TF, Kozel TR. Production and characterization of monoclonal antibodies specific for Cryptococcus neoformans capsular polysaccharide. Infect Immun 1987;55(8):1895-9. [PubMed: 2440810]

Eisenman HC, Casadevall A, McClelland EE. New Insights on the Pathogenesis of Invasive Cryptococcus neoformans Infection. Curr Infect Dis Rep 2007;9(6):457-64. [PubMed: 17999881]

Ellerbroek PM, Hoepelman AI, Wolbers F, Zwaginga JJ, Coenjaerts FE. Cryptococcal glucuronoxylomannan inhibits adhesion of neutrophils to stimulated endothelium in vitro by affecting both neutrophils and endothelial cells. Infect Immun 2002;70(9):4762-71. [PubMed: 12183517]

Ellerbroek PM, Lefeber DJ, van Veghel R, Scharringa J, Brouwer E, Gerwig GJ, Janbon G, Hoepelman AI, Coenjaerts FE. O-acetylation of cryptococcal capsular glucuronoxylomannan is essential for interference with neutrophil migration. J Immunol 2004a;173(12):7513-20. [PubMed: 15585878]

Ellerbroek PM, Schoemaker RG, van Veghel R, Hoepelman AI, Coenjaerts FE. Cryptococcal capsular glucuronoxylomannan reduces ischaemia-related neutrophil influx. Eur J Clin Invest 2004b;34(9): 631-40. [PubMed: 15379763]

Ellerbroek PM, Ulfman LH, Hoepelman AI, Coenjaerts FE. Cryptococcal glucuronoxylomannan interferes with neutrophil rolling on the endothelium. Cell Microbiol 2004c;6(6):581-92. [PubMed: 15104598]

Ellerbroek PM, Walenkamp AM, Hoepelman AI, Coenjaerts FE. Effects of the capsular polysaccharides of Cryptococcus neoformans on phagocyte migration and inflammatory mediators. Curr Med Chem 2004d;11(2):253-66. [PubMed: 14754421]

Feldmesser M, Casadevall A. Effect of serum IgG1 to Cryptococcus neoformans glucuronoxylomannan on murine pulmonary infection. J Immunol 1997;158(2):790-9. [PubMed: 8992996]

Feldmesser M, Kress Y, Casadevall A. Effect of antibody to capsular polysaccharide on eosinophilic pneumonia in murine infection with Cryptococcus neoformans. J Infect Dis 1998;177(6):1639-46. [PubMed: 9607844]

Feldmesser M, Kress Y, Casadevall A. Dynamic changes in the morphology of Cryptococcus neoformans during murine pulmonary infection. Microbiology 2001;147(Pt 8):2355-65. [PubMed: 11496012]

Feldmesser M, Kress Y, Novikoff P, Casadevall A. Cryptococcus neoformans is a facultative intracellular pathogen in murine pulmonary infection. Infect Immun 2000;68(7):4225-37. [PubMed: 10858240]

Feldmesser M, Mednick A, Casadevall A. Antibody-mediated protection in murine Cryptococcus neoformans infection is associated with pleotrophic effects on cytokine and leukocyte responses. Infect Immun 2002;70(3):1571-80. [PubMed: 11854246]

Feldmesser M, Mukherjee J, Casadevall A. Combination of 5-flucytosine and capsule-binding monoclonal antibody in the treatment of murine Cryptococcus neoformans infections and in vitro. J Antimicrob Chemother 1996;37(3):617-22. [PubMed: 9182119]

Fevrier B, Raposo G. Exosomes: endosomal-derived vesicles shipping extracellular messages. Curr Opin Cell Biol 2004;16(4):415-21. [PubMed: 15261674]

Filler SG, Sheppard DC. Fungal invasion of normally non-phagocytic host cells. PLoS Pathog 2006;2 (12):e129. [PubMed: 17196036]

Fleuridor R, Zhong Z, Pirofski L. A human IgM monoclonal antibody prolongs survival of mice with lethal cryptococcosis. J Infect Dis 1998;178(4):1213-6. [PubMed: 9806064]

Frases S, Nimrichter L, Viana NB, Nakouzi A, Casadevall A. Cryptococcus neoformans capsular polysaccharide and exopolysaccharide fractions manifest physical, chemical, and antigenic differences. Eukaryot Cell 2008;7(2):319-27. [PubMed: 18156290]

Fries BC, Goldman DL, Cherniak R, Ju R, Casadevall A. Phenotypic switching in Cryptococcus neoformans results in changes in cellular morphology and glucuronoxylomannan structure. Infect Immun 1999;67(11):6076-83. [PubMed: 10531269]

Fromtling RA, Shadomy HJ, Jacobson ES. Decreased virulence in stable, acapsular mutants of cryptococcus neoformans. Mycopathologia 1982;79(1):23-9. [PubMed: 6750405]

Gadebusch HH. Active immunization against Cryptococcus neoformans. J Infect Dis 1958a;102(3):21926. [PubMed: 13549767] 
Gadebusch HH. Passive immunization against Cryptococcus neoformans. Proc Soc Exp Biol Med 1958b; 98(3):611-4. [PubMed: 13567788]

Garcia-Hermoso D, Dromer F, Janbon G. Cryptococcus neoformans capsule structure evolution in vitro and during murine infection. Infect Immun 2004;72(6):3359-65. [PubMed: 15155641]

Garcia-Rivera J, Chang YC, Kwon-Chung KJ, Casadevall A. Cryptococcus neoformans CAP59 (or Cap59p) is involved in the extracellular trafficking of capsular glucuronoxylomannan. Eukaryot Cell 2004;3(2):385-92. [PubMed: 15075268]

Garegg PJ, Olsson L, Oscarson S. Synthesis of oligosaccharides corresponding to structures found in capsular polysaccharides of Cryptococcus neoformans--II. Bioorg Med Chem 1996;4(11):186771. [PubMed: 9007271]

Gates MA, Kozel TR. Differential localization of complement component 3 within the capsular matrix of Cryptococcus neoformans. Infect Immun 2006;74(6):3096-106. [PubMed: 16714537]

Gates MA, Thorkildson P, Kozel TR. Molecular architecture of the Cryptococcus neoformans capsule. Mol Microbiol 2004;52(1):13-24. [PubMed: 15049807]

Goldman DL, Fries BC, Franzot SP, Montella L, Casadevall A. Phenotypic switching in the human pathogenic fungus Cryptococcus neoformans is associated with changes in virulence and pulmonary inflammatory response in rodents. Proc Natl Acad Sci U S A 1998;95(25):14967-72. [PubMed: 9843999]

Goldman DL, Lee SC, Casadevall A. Tissue localization of Cryptococcus neoformans glucuronoxylomannan in the presence and absence of specific antibody. Infect Immun 1995;63(9): 3448-53. [PubMed: 7642276]

Goren MB, Middlebrook GM. Protein conjugates of polysaccharide from Cryptococcus neoformans. J Immunol 1967;98(5):901-13. [PubMed: 4164846]

Granger DL, Perfect JR, Durack DT. Virulence of Cryptococcus neoformans. Regulation of capsule synthesis by carbon dioxide. J Clin Invest 1985;76(2):508-16. [PubMed: 3928681]

Griffith CL, Klutts JS, Zhang L, Levery SB, Doering TL. UDP-glucose dehydrogenase plays multiple roles in the biology of the pathogenic fungus Cryptococcus neoformans. J Biol Chem 2004;279 (49):51669-76. [PubMed: 15383535]

Gutierrez AL, Farage L, Melo MN, Mohana-Borges RS, Guerardel Y, Coddeville B, Wieruszeski JM, Mendonca-Previato L, Previato JO. Characterization of glycoinositolphosphoryl ceramide structure mutant strains of Cryptococcus neoformans. Glycobiology 2007;17(6):1-11C. [PubMed: 17369287]

Heise N, Gutierrez AL, Mattos KA, Jones C, Wait R, Previato JO, Mendonca-Previato L. Molecular analysis of a novel family of complex glycoinositolphosphoryl ceramides from Cryptococcus neoformans: structural differences between encapsulated and acapsular yeast forms. Glycobiology 2002;12(7):409-20. [PubMed: 12122022]

Hicks JK, Bahn YS, Heitman J. Pde1 phosphodiesterase modulates cyclic AMP levels through a protein kinase A-mediated negative feedback loop in Cryptococcus neoformans. Eukaryot Cell 2005;4(12): 1971-81. [PubMed: 16339715]

Hu G, Steen BR, Lian T, Sham AP, Tam N, Tangen KL, Kronstad JW. Transcriptional regulation by protein kinase A in Cryptococcus neoformans. PLoS Pathog 2007;3(3):e42. [PubMed: 17367210]

Huang C, Nong SH, Mansour MK, Specht CA, Levitz SM. Purification and characterization of a second immunoreactive mannoprotein from Cryptococcus neoformans that stimulates T-Cell responses. Infect Immun 2002;70(10):5485-93. [PubMed: 12228274]

Ibrahim AS, Filler SG, Alcouloumre MS, Kozel TR, Edwards JE Jr. Ghannoum MA. Adherence to and damage of endothelial cells by Cryptococcus neoformans in vitro: role of the capsule. Infect Immun 1995;63(11):4368-74. [PubMed: 7591072]

Jacobson ES. Cryptococcal UDP-glucose dehydrogenase: enzymic control of capsular biosynthesis. J Med Vet Mycol 1987;25(3):131-5. [PubMed: 3302196]

Jain N, Li L, McFadden DC, Banarjee U, Wang X, Cook E, Fries BC. Phenotypic switching in a Cryptococcus neoformans variety gattii strain is associated with changes in virulence and promotes dissemination to the central nervous system. Infect Immun 2006;74(2):896-903. [PubMed: 16428732] 
James PG, Cherniak R. Galactoxylomannans of Cryptococcus neoformans. Infect Immun 1992;60(3): 1084-8. [PubMed: 1541523]

Janbon G. Cryptococcus neoformans capsule biosynthesis and regulation. FEMS Yeast Res 2004;4(8): 765-71. [PubMed: 15450183]

Janbon G, Himmelreich U, Moyrand F, Improvisi L, Dromer F. Cas1p is a membrane protein necessary for the O-acetylation of the Cryptococcus neoformans capsular polysaccharide. Mol Microbiol 2001;42(2):453-67. [PubMed: 11703667]

Jung WH, Sham A, White R, Kronstad JW. Iron regulation of the major virulence factors in the AIDSassociated pathogen Cryptococcus neoformans. PLoS Biol 2006;4(12):e410. [PubMed: 17121456]

Kang YS, Kim JY, Bruening SA, Pack M, Charalambous A, Pritsker A, Moran TM, Loeffler JM, Steinman RM, Park CG. The C-type lectin SIGN-R1 mediates uptake of the capsular polysaccharide of Streptococcus pneumoniae in the marginal zone of mouse spleen. Proc Natl Acad Sci U S A 2004;101(1):215-20. [PubMed: 14694198]

Klutts JS, Doering TL. Cryptococcal xylosyltransferase 1 (Cxt1p) from cryptococcus neoformans plays a direct role in the synthesis of capsule polysaccharides. J Biol Chem. 2008

Klutts JS, Levery SB, Doering TL. A beta-1,2-xylosyltransferase from Cryptococcus neoformans defines a new family of glycosyltransferases. J Biol Chem 2007;282(24):17890-9. [PubMed: 17430900]

Klutts JS, Yoneda A, Reilly MC, Bose I, Doering TL. Glycosyltransferases and their products: cryptococcal variations on fungal themes. FEMS Yeast Res 2006;6(4):499-512. [PubMed: 16696646]

Kozel TR. Non-encapsulated variant of Cryptococcus neoformans. II. Surface receptors for cryptococcal polysaccharide and their role in inhibition of phagocytosis by polysaccharide. Infect Immun 1977;16 (1):99-106. [PubMed: 326680]

Kozel TR, DeJong BCH, Grinsell MM, MacGill RS, Wall KK. Characterization of anticapsular monoclonal antibodies that regulate activation of the complement system by the Cryptococcus neoformans capsule. Infect Immun 1998;66(4):1538-1546. [PubMed: 9529079]

Kozel TR, Gulley WF, Cazin J Jr. Immune response to Cryptococcus neoformans soluble polysaccharide: immunological unresponsiveness. Infect Immun 1977;18(3):701-7. [PubMed: 338489]

Kozel TR, Hermerath CA. Binding of cryptococcal polysaccharide to Cryptococcus neoformans. Infect Immun 1984;43(3):879-86. [PubMed: 6365785]

Kozel TR, Levitz SM, Dromer F, Gates MA, Thorkildson P, Janbon G. Antigenic and biological characteristics of mutant strains of Cryptococcus neoformans lacking capsular $\mathrm{O}$ acetylation or xylosyl side chains. Infect Immun 2003;71(5):2868-75. [PubMed: 12704160]

Kozel TR, Pfrommer GS. Activation of the complement system by Cryptococcus neoformans leads to binding of iC3b to the yeast. Infect Immun 1986;52(1):1-5. [PubMed: 3514450]

Kozel TR, Tabuni A, Young BJ, Levitz SM. Influence of opsonization conditions on C3 deposition and phagocyte binding of large- and small-capsule Cryptococcus neoformans cells. Infect Immun 1996;64(6):2336-8. [PubMed: 8675346]

Kozel TR, Wilson MA, Pfrommer GS, Schlageter AM. Activation and binding of opsonic fragments of C3 on encapsulated Cryptococcus neoformans by using an alternative complement pathway reconstituted from six isolated proteins. Infect Immun 1989;57(7):1922-7. [PubMed: 2525113]

Kwon-Chung KJ, Varma A. Do major species concepts support one, two or more species within Cryptococcus neoformans? FEMS Yeast Res 2006;6(4):574-87. [PubMed: 16696653]

Larsen RA, Pappas PG, Perfect J, Aberg JA, Casadevall A, Cloud GA, James R, Filler S, Dismukes WE. Phase I evaluation of the safety and pharmacokinetics of murine-derived anticryptococcal antibody 18B7 in subjects with treated cryptococcal meningitis. Antimicrob Agents Chemother 2005;49(3): 952-8. [PubMed: 15728888]

Laxalt KA, Kozel TR. Chemotaxigenesis and activation of the alternative complement pathway by encapsulated and non-encapsulated Cryptococcus neoformans. Infect Immun 1979;26(2):435-40. [PubMed: 397927]

Leal-Morales CA, Bracker CE, Bartnicki-Garcia S. Subcellular localization, abundance and stability of chitin synthetases 1 and 2 from Saccharomyces cerevisiae. Microbiology 1994;140(Pt 9):2207-16. [PubMed: 7952171] 
Lee SC, Casadevall A. Polysaccharide antigen in brain tissue of AIDS patients with cryptococcal meningitis. Clin Infect Dis 1996;23(1):194-5. [PubMed: 8816161]

Lee SC, Casadevall A, Dickson DW. Immunohistochemical localization of capsular polysaccharide antigen in the central nervous system cells in cryptococcal meningoencephalitis. Am J Pathol 1996;148(4):1267-74. [PubMed: 8644867]

Lee SC, Kress Y, Dickson DW, Casadevall A. Human microglia mediate anti-Cryptococcus neoformans activity in the presence of specific antibody. J Neuroimmunol 1995a;62(1):43-52. [PubMed: 7499491]

Lee SC, Kress Y, Zhao ML, Dickson DW, Casadevall A. Cryptococcus neoformans survive and replicate in human microglia. Lab Invest 1995b;73(6):871-9. [PubMed: 8558850]

Lendvai N, Casadevall A, Liang Z, Goldman DL, Mukherjee J, Zuckier L. Effect of immune mechanisms on the pharmacokinetics and organ distribution of cryptococcal polysaccharide. J Infect Dis 1998;177(6):1647-59. [PubMed: 9607845]

Levitz SM. Receptor-mediated recognition of Cryptococcus neoformans. Nippon Ishinkin Gakkai Zasshi 2002;43(3):133-6. [PubMed: 12145626]

Levitz SM, Nong S, Mansour MK, Huang C, Specht CA. Molecular characterization of a mannoprotein with homology to chitin deacetylases that stimulates T cell responses to Cryptococcus neoformans. Proc Natl Acad Sci U S A 2001;98(18):10422-7. [PubMed: 11504924]

Levitz SM, Specht CA. The molecular basis for the immunogenicity of Cryptococcus neoformans mannoproteins. FEMS Yeast Res 2006;6(4):513-24. [PubMed: 16696647]

Li RK, Mitchell TG. Induction of interleukin- 6 mRNA in rat alveolar macrophages by in vitro exposure to both Cryptococcus neoformans and anti-C. neoformans antiserum. J Med Vet Mycol 1997;35 (5):327-34. [PubMed: 9402525]

Lian T, Simmer MI, D'Souza CA, Steen BR, Zuyderduyn SD, Jones SJ, Marra MA, Kronstad JW. Ironregulated transcription and capsule formation in the fungal pathogen Cryptococcus neoformans. Mol Microbiol 2005;55(5):1452-72. [PubMed: 15720553]

Lipovsky MM, Gekker G, Hu S, Ehrlich LC, Hoepelman AI, Peterson PK. Cryptococcal glucuronoxylomannan induces interleukin (IL)- 8 production by human microglia but inhibits neutrophil migration toward IL-8. J Infect Dis 1998a;177(1):260-3. [PubMed: 9419203]

Lipovsky MM, Tsenova L, Coenjaerts FE, Kaplan G, Cherniak R, Hoepelman AI. Cryptococcal glucuronoxylomannan delays translocation of leukocytes across the blood-brain barrier in an animal model of acute bacterial meningitis. J Neuroimmunol 2000;111(12):10-4. [PubMed: 11063816]

Lipovsky MM, van Elden LJ, Walenkamp AM, Dankert J, Hoepelman AI. Does the capsule component of the Cryptococcus neoformans glucuronoxylomannan impair transendothelial migration of leukocytes in patients with cryptococcal meningitis? J Infect Dis 1998b;178(4):1231-2. [PubMed: 9806071]

Lipschutz JH, Mostov KE. Exocytosis: the many masters of the exocyst. Curr Biol 2002;12(6):R212-4. [PubMed: 11909549]

Littman ML. Capsule synthesis by Cryptococcus neoformans. Trans N Y Acad Sci 1958;20(7):623-48. [PubMed: 13556861]

Littman ML, Tsubura E. Effect of degree of encapsulation upon virulence of Cryptococcus neoformans. Proc Soc Exp Biol Med 1959;101:773-7. [PubMed: 14417558]

Liu H. Transcriptional control of dimorphism in Candida albicans. Curr Opin Microbiol 2001;4(6):72835. [PubMed: 11731326]

Lyman SK, Schekman R. Polypeptide translocation machinery of the yeast endoplasmic reticulum. Experientia 1996;52(12):1042-9. [PubMed: 8988244]

Ma H, Croudace JE, Lammas DA, May RC. Expulsion of live pathogenic yeast by macrophages. Curr Biol 2006;16(21):2156-60. [PubMed: 17084701]

Ma H, Croudace JE, Lammas DA, May RC. Direct cell-to-cell spread of a pathogenic yeast. BMC Immunol 2007;8:15. [PubMed: 17705831]

MacGill TC, MacGill RS, Casadevall A, Kozel TR. Biological correlates of capsular (quellung) reactions of Cryptococcus neoformans. J Immunol 2000;164(9):4835-42. [PubMed: 10779792]

Maitta RW, Datta K, Chang Q, Luo RX, Witover B, Subramaniam K, Pirofski LA. Protective and nonprotective human immunoglobulin $\mathrm{M}$ monoclonal antibodies to Cryptococcus neoformans 
glucuronoxylomannan manifest different specificities and gene use profiles. Infect Immun 2004a; 72(8):4810-8. [PubMed: 15271943]

Maitta RW, Datta K, Lees A, Belouski SS, Pirofski LA. Immunogenicity and efficacy of Cryptococcus neoformans capsular polysaccharide glucuronoxylomannan peptide mimotope-protein conjugates in human immunoglobulin transgenic mice. Infect Immun 2004b;72(1):196-208. [PubMed: 14688097]

Mallabiabarrena A, Malhotra V. Vesicle biogenesis: the coat connection. Cell 1995;83(5):667-9. [PubMed: 8521481]

Mansour MK, Schlesinger LS, Levitz SM. Optimal T cell responses to Cryptococcus neoformans mannoprotein are dependent on recognition of conjugated carbohydrates by mannose receptors. $\mathrm{J}$ Immunol 2002;168(6):2872-9. [PubMed: 11884457]

Mariano Andrade R, Monteiro Almeida G, Alexandre DosReis G, Alves Melo Bento C. Glucuronoxylomannan of Cryptococcus neoformans exacerbates in vitro yeast cell growth by interleukin 10-dependent inhibition of CD4+ T lymphocyte responses. Cell Immunol 2003;222(2): 116-25. [PubMed: 12826081]

Martinez LR, Bryan RA, Apostolidis C, Morgenstern A, Casadevall A, Dadachova E. Antibody-guided alpha radiation effectively damages fungal biofilms. Antimicrob Agents Chemother 2006;50(6): 2132-6. [PubMed: 16723575]

Maxson ME, Cook E, Casadevall A, Zaragoza O. The volume and hydration of the Cryptococcus neoformans polysaccharide capsule. Fungal Genet Biol 2007a;44(3):180-6. [PubMed: 16963294]

Maxson ME, Dadachova E, Casadevall A, Zaragoza O. Radial mass density, charge, and epitope distribution in the Cryptococcus neoformans capsule. Eukaryot Cell 2007b;6(1):95-109. [PubMed: 17114596]

McClelland EE, Bernhardt P, Casadevall A. Estimating the relative contributions of virulence factors for pathogenic microbes. Infect Immun 2006;74(3):1500-4. [PubMed: 16495520]

McFadden DC, De Jesus M, Casadevall A. The physical properties of the capsular polysaccharides from Cryptococcus neoformans suggest features for capsule construction. J Biol Chem 2006;281(4): 1868-75. [PubMed: 16278213]

McFadden DC, Fries BC, Wang F, Casadevall A. Capsule structural heterogeneity and antigenic variation in Cryptococcus neoformans. Eukaryot Cell 2007;6(8):1464-73. [PubMed: 17601878]

McLean GR, Torres M, Elguezabal N, Nakouzi A, Casadevall A. Isotype can affect the fine specificity of an antibody for a polysaccharide antigen. J Immunol 2002;169(3):1379-86. [PubMed: 12133962]

Merkel GJ, Cunningham RK. The interaction of Cryptococcus neoformans with primary rat lung cell cultures. J Med Vet Mycol 1992;30(2):115-21. [PubMed: 1588461]

Merkel GJ, Scofield BA. The in vitro interaction of Cryptococcus neoformans with human lung epithelial cells. FEMS Immunol Med Microbiol 1997;19(3):203-13. [PubMed: 9453390]

Merkel GJ, Scofield BA. An opsonizing monoclonal antibody that recognizes a noncapsular epitope expressed on Cryptococcus neoformans. Infect Immun 1999;67(10):4994-5000. [PubMed: 10496869]

Mirshafiey A, Ngoc Dzung DT, Murphy JW, Khorramizadeh MR, Saadat F, Mehrabian F, Larsson P. Tolerability and anti-inflammatory effects of glucuronoxylomannan in collagen-induced arthritis. Scand J Immunol 2004;60(3):226-32. [PubMed: 15320878]

Mody CH, Syme RM. Effect of polysaccharide capsule and methods of preparation on human lymphocyte proliferation in response to Cryptococcus neoformans. Infect Immun 1993;61(2):464-9. [PubMed: 8423074]

Mogensen EG, Janbon G, Chaloupka J, Steegborn C, Fu MS, Moyrand F, Klengel T, Pearson DS, Geeves MA, Buck J, Levin LR, Muhlschlegel FA. Cryptococcus neoformans senses CO2 through the carbonic anhydrase Can2 and the adenylyl cyclase Cac1. Eukaryot Cell 2006;5(1):103-11. [PubMed: 16400172]

Monari C, Bistoni F, Casadevall A, Pericolini E, Pietrella D, Kozel TR, Vecchiarelli A. Glucuronoxylomannan, a microbial compound, regulates expression of costimulatory molecules and production of cytokines in macrophages. J Infect Dis 2005a;191(1):127-37. [PubMed: 15593014] 
Monari C, Bistoni F, Vecchiarelli A. Glucuronoxylomannan exhibits potent immunosuppressive properties. FEMS Yeast Res 2006a;6(4):537-42. [PubMed: 16696649]

Monari C, Casadevall A, Retini C, Baldelli F, Bistoni F, Vecchiarelli A. Antibody to capsular polysaccharide enhances the function of neutrophils from patients with AIDS against Cryptococcus neoformans. Aids 1999a;13(6):653-60. [PubMed: 10397559]

Monari C, Kozel TR, Bistoni F, Vecchiarelli A. Modulation of C5aR expression on human neutrophils by encapsulated and acapsular Cryptococcus neoformans. Infect Immun 2002;70(7):3363-70. [PubMed: 12065474]

Monari C, Kozel TR, Casadevall A, Pietrella D, Palazzetti B, Vecchiarelli A. B7 costimulatory ligand regulates development of the T-cell response to Cryptococcus neoformans. Immunology 1999b;98 (1):27-35. [PubMed: 10469230]

Monari C, Kozel TR, Paganelli F, Pericolini E, Perito S, Bistoni F, Casadevall A, Vecchiarelli A. Microbial immune suppression mediated by direct engagement of inhibitory Fc receptor. J Immunol 2006b;177(10):6842-51. [PubMed: 17082598]

Monari C, Paganelli F, Bistoni F, Kozel TR, Vecchiarelli A. Capsular polysaccharide induction of apoptosis by intrinsic and extrinsic mechanisms. Cell Microbiol. 2008

Monari C, Pericolini E, Bistoni G, Casadevall A, Kozel TR, Vecchiarelli A. Cryptococcus neoformans capsular glucuronoxylomannan induces expression of fas ligand in macrophages. J Immunol 2005b; 174(6):3461-8. [PubMed: 15749881]

Monari C, Retini C, Casadevall A, Netski D, Bistoni F, Kozel TR, Vecchiarelli A. Differences in outcome of the interaction between Cryptococcus neoformans glucuronoxylomannan and human monocytes and neutrophils. Eur J Immunol 2003;33(4):1041-51. [PubMed: 12672070]

Morgan MA, Blackstock RA, Bulmer GS, Hall NK. Modification of macrophage phagocytosis in murine cryptococcosis. Infect Immun 1983;40(2):493-500. [PubMed: 6220973]

Moyrand F, Chang YC, Himmelreich U, Kwon-Chung KJ, Janbon G. Cas3p belongs to a seven-member family of capsule structure designer proteins. Eukaryot Cell 2004;3(6):1513-24. [PubMed: 15590825]

Moyrand F, Fontaine T, Janbon G. Systematic capsule gene disruption reveals the central role of galactose metabolism on Cryptococcus neoformans virulence. Mol Microbiol 2007;64(3):771-81. [PubMed: 17462022]

Moyrand F, Janbon G. UGD1, encoding the Cryptococcus neoformans UDP-glucose dehydrogenase, is essential for growth at 37 degrees C and for capsule biosynthesis. Eukaryot Cell 2004;3(6):16018. [PubMed: 15590833]

Mukherjee J, Cleare W, Casadevall A. Monoclonal antibody mediated capsular reactions (Quellung) in Cryptococcus neoformans. J Immunol Methods 1995a;184(1):139-43. [PubMed: 7622865]

Mukherjee J, Feldmesser M, Scharff MD, Casadevall A. Monoclonal antibodies to Cryptococcus neoformans glucuronoxylomannan enhance fluconazole efficacy. Antimicrob Agents Chemother 1995b;39(7):1398-405. [PubMed: 7492075]

Mukherjee J, Nussbaum G, Scharff MD, Casadevall A. Protective and nonprotective monoclonal antibodies to Cryptococcus neoformans originating from one B cell. J Exp Med 1995c;181(1):4059. [PubMed: 7807020]

Mukherjee J, Pirofski LA, Scharff MD, Casadevall A. Antibody-mediated protection in mice with lethal intracerebral Cryptococcus neoformans infection. Proc Natl Acad Sci U S A 1993;90(8):3636-40. [PubMed: 8475112]

Mukherjee J, Scharff MD, Casadevall A. Protective murine monoclonal antibodies to Cryptococcus neoformans. Infect Immun 1992;60(11):4534-41. [PubMed: 1398966]

Mukherjee J, Scharff MD, Casadevall A. Variable efficacy of passive antibody administration against diverse Cryptococcus neoformans strains. Infect Immun 1995d;63(9):3353-9. [PubMed: 7642262]

Mukherjee J, Zuckier LS, Scharff MD, Casadevall A. Therapeutic efficacy of monoclonal antibodies to Cryptococcus neoformans glucuronoxylomannan alone and in combination with amphotericin B. Antimicrob Agents Chemother 1994a;38(3):580-7. [PubMed: 8203858]

Mukherjee S, Feldmesser M, Casadevall A. J774 murine macrophage-like cell interactions with Cryptococcus neoformans in the presence and absence of opsonins. J Infect Dis 1996;173(5):122231. [PubMed: 8627076] 
Mukherjee S, Lee S, Mukherjee J, Scharff MD, Casadevall A. Monoclonal antibodies to Cryptococcus neoformans capsular polysaccharide modify the course of intravenous infection in mice. Infect Immun 1994b;62(3):1079-88. [PubMed: 8112842]

Mukherjee S, Lee SC, Casadevall A. Antibodies to Cryptococcus neoformans glucuronoxylomannan enhance antifungal activity of murine macrophages. Infect Immun 1995e;63(2):573-9. [PubMed: 7822024]

Murphy JW. Influence of cryptococcal antigens on cell-mediated immunity. Rev Infect Dis 1988;10 (Suppl 2):S432-5. [PubMed: 2973118]

Murphy JW, Cozad GC. Immunological unresponsiveness induced by cryptococcal capsular polysaccharide assayed by the hemolytic plaque technique. Infect Immun 1972;5(6):896-901. [PubMed: 4564405]

Mylonakis E, Ausubel FM, Perfect JR, Heitman J, Calderwood SB. Killing of Caenorhabditis elegans by Cryptococcus neoformans as a model of yeast pathogenesis. Proc Natl Acad Sci U S A 2002;99 (24):15675-80. [PubMed: 12438649]

Mylonakis E, Moreno R, El Khoury JB, Idnurm A, Heitman J, Calderwood SB, Ausubel FM, Diener A. Galleria mellonella as a model system to study Cryptococcus neoformans pathogenesis. Infect Immun 2005;73(7):3842-50. [PubMed: 15972469]

Naslund PK, Miller WC, Granger DL. Cryptococcus neoformans fails to induce nitric oxide synthase in primed murine macrophage-like cells. Infect Immun 1995;63(4):1298-304. [PubMed: 7534274]

Netski D, Kozel TR. Fc-dependent and Fc-independent opsonization of Cryptococcus neoformans by anticapsular monoclonal antibodies: importance of epitope specificity. Infect Immun 2002;70(6): 2812-9. [PubMed: 12010967]

Nimrichter L, Cerqueira MD, Leitao EA, Miranda K, Nakayasu ES, Almeida SR, Almeida IC, Alviano CS, Barreto-Bergter E, Rodrigues ML. Structure, cellular distribution, antigenicity, and biological functions of Fonsecaea pedrosoi ceramide monohexosides. Infect Immun 2005;73(12):7860-8. [PubMed: 16299276]

Nimrichter L, Frases S, Cinelli LP, Viana NB, Nakouzi A, Travassos LR, Casadevall A, Rodrigues ML. Self-aggregation of Cryptococcus neoformans capsular glucuronoxylomannan is dependent on divalent cations. Eukaryot Cell 2007;6(8):1400-10. [PubMed: 17573547]

Nosanchuk JD, Casadevall A. Cellular charge of Cryptococcus neoformans: contributions from the capsular polysaccharide, melanin, and monoclonal antibody binding. Infect Immun 1997;65(5): 1836-41. [PubMed: 9125569]

Nussbaum G, Cleare W, Casadevall A, Scharff MD, Valadon P. Epitope location in the Cryptococcus neoformans capsule is a determinant of antibody efficacy. J Exp Med 1997;185(4):685-94. [PubMed: 9034147]

Okabayashi K, Kano R, Watanabe S, Hasegawa A. Expression of capsule-associated genes of Cryptococcus neoformans. Mycopathologia 2005;160(1):1-7. [PubMed: 16160761]

Orendi JM, Verheul AF, De Vos NM, Visser MR, Snippe H, Cherniak R, Vaishnav VV, Rijkers GT, Verhoef J. Mannoproteins of Cryptococcus neoformans induce proliferative response in human peripheral blood mononuclear cells (PBMC) and enhance HIV-1 replication. Clin Exp Immunol 1997;107(2):293-9. [PubMed: 9030866]

Ortiz D, Novick PJ. Ypt32p regulates the translocation of Chs3p from an internal pool to the plasma membrane. Eur J Cell Biol 2006;85(2):107-16. [PubMed: 16303210]

Oscarson S, Alpe M, Svahnberg P, Nakouzi A, Casadevall A. Synthesis and immunological studies of glycoconjugates of Cryptococcus neoformans capsular glucuronoxylomannan oligosaccharide structures. Vaccine 2005;23(30):3961-72. [PubMed: 15917118]

Perfect JR, Durack DT. Chemotactic activity of cerebrospinal fluid in experimental cryptococcal meningitis. Sabouraudia 1985;23(1):37-45. [PubMed: 3992427]

Pericolini E, Cenci E, Monari C, De Jesus M, Bistoni F, Casadevall A, Vecchiarelli A. Cryptococcus neoformans capsular polysaccharide component galactoxylomannan induces apoptosis of human T-cells through activation of caspase-8. Cell Microbiol 2006;8(2):267-75. [PubMed: 16441437]

Pierini LM, Doering TL. Spatial and temporal sequence of capsule construction in Cryptococcus neoformans. Mol Microbiol 2001;41(1):105-15. [PubMed: 11454204] 
Pietrella D, Corbucci C, Perito S, Bistoni G, Vecchiarelli A. Mannoproteins from Cryptococcus neoformans promote dendritic cell maturation and activation. Infect Immun 2005;73(2):820-7. [PubMed: 15664921]

Pietrella D, Cherniak R, Strappini C, Perito S, Mosci P, Bistoni F, Vecchiarelli A. Role of mannoprotein in induction and regulation of immunity to Cryptococcus neoformans. Infect Immun 2001a;69(5): 2808-14. [PubMed: 11292692]

Pietrella D, Lupo P, Bistoni F, Vecchiarelli A. An early imbalance of interleukin 12 influences the adjuvant effect of mannoproteins of Cryptococcus neoformans. Cell Microbiol 2004;6(9):883-91. [PubMed: 15272868]

Pietrella D, Mazzolla R, Lupo P, Pitzurra L, Gomez MJ, Cherniak R, Vecchiarelli A. Mannoprotein from Cryptococcus neoformans promotes T-helper type 1 anticandidal responses in mice. Infect Immun 2002;70(12):6621-7. [PubMed: 12438334]

Pietrella D, Monari C, Retini C, Palazzetti B, Kozel TR, Vecchiarelli A. Cryptococcus neoformans and Candida albicans regulate CD4 expression on human monocytes. J Infect Dis 1998;178(5):146471. [PubMed: 9780269]

Pietrella D, Perito S, Bistoni F, Vecchiarelli A. Cytotoxic T lymphocyte antigen costimulation influences T-cell activation in response to Cryptococcus neoformans. Infect Immun 2001b;69(3):1508-14. [PubMed: 11179320]

Pirofski L, Lui R, DeShaw M, Kressel AB, Zhong Z. Analysis of human monoclonal antibodies elicited by vaccination with a Cryptococcus neoformans glucuronoxylomannan capsular polysaccharide vaccine. Infect Immun 1995;63(8):3005-14. [PubMed: 7622223]

Pirofski LA. Polysaccharides, mimotopes and vaccines for fungal and encapsulated pathogens. Trends Microbiol 2001;9(9):445-51. [PubMed: 11553457]

Pirofski LA. Of mice and men, revisited: new insights into an ancient molecule from studies of complement activation by Cryptococcus neoformans. Infect Immun 2006;74(6):3079-84. [PubMed: 16714535]

Pirofski LA, Casadevall A. Cryptococcus neoformans: paradigm for the role of antibody immunity against fungi? Zentralbl Bakteriol 1996;284(4):475-95. [PubMed: 8899968]

Pitzurra L, Cherniak R, Giammarioli M, Perito S, Bistoni F, Vecchiarelli A. Early induction of interleukin- 12 by human monocytes exposed to Cryptococcus neoformans mannoproteins. Infect Immun 2000;68(2):558-63. [PubMed: 10639417]

Pitzurra L, Vecchiarelli A, Peducci R, Cardinali A, Bistoni F. Identification of a 105 kilodalton Cryptococcus neoformans mannoprotein involved in human cell-mediated immune response. J Med Vet Mycol 1997;35(4):299-303. [PubMed: 9292430]

Pukkila-Worley R, Gerrald QD, Kraus PR, Boily MJ, Davis MJ, Giles SS, Cox GM, Heitman J, Alspaugh JA. Transcriptional network of multiple capsule and melanin genes governed by the Cryptococcus neoformans cyclic AMP cascade. Eukaryot Cell 2005;4(1):190-201. [PubMed: 15643074]

Raetz CR, Whitfield C. Lipopolysaccharide endotoxins. Annu Rev Biochem 2002;71:635-700. [PubMed: 12045108]

Rakesh V, Schweitzer AD, Zaragoza O, Bryan R, Wong K, Datta A, Casadevall A, Dadachova E. FiniteElement Model of Interaction between Fungal Polysaccharide and Monoclonal Antibody in the Capsule of Cryptococcus neoformans. J Phys Chem B 2008;112(29):8514-22. [PubMed: 18588334]

Reese AJ, Doering TL. Cell wall alpha-1,3-glucan is required to anchor the Cryptococcus neoformans capsule. Mol Microbiol 2003;50(4):1401-9. [PubMed: 14622425]

Reese AJ, Yoneda A, Breger JA, Beauvais A, Liu H, Griffith CL, Bose I, Kim MJ, Skau C, Yang S, Sefko JA, Osumi M, Latge JP, Mylonakis E, Doering TL. Loss of cell wall alpha(1-3) glucan affects Cryptococcus neoformans from ultrastructure to virulence. Mol Microbiol 2007;63(5):1385-98. [PubMed: 17244196]

Reiss E, Huppert M, Cherniak R. Characterization of protein and mannan polysaccharide antigens of yeasts, moulds, and actinomycetes. Curr Top Med Mycol 1985;1:172-207. [PubMed: 3916766]

Reiter WD. Biosynthesis and properties of the plant cell wall. Curr Opin Plant Biol 2002;5(6):536-42. [PubMed: 12393017] 
Retini C, Kozel TR, Pietrella D, Monari C, Bistoni F, Vecchiarelli A. Interdependency of interleukin-10 and interleukin-12 in regulation of T-cell differentiation and effector function of monocytes in response to stimulation with Cryptococcus neoformans. Infect Immun 2001;69(10):6064-73. [PubMed: 11553544]

Retini C, Vecchiarelli A, Monari C, Bistoni F, Kozel TR. Encapsulation of Cryptococcus neoformans with glucuronoxylomannan inhibits the antigen-presenting capacity of monocytes. Infect Immun 1998;66(2):664-9. [PubMed: 9453624]

Retini C, Vecchiarelli A, Monari C, Tascini C, Bistoni F, Kozel TR. Capsular polysaccharide of Cryptococcus neoformans induces proinflammatory cytokine release by human neutrophils. Infect Immun 1996;64(8):2897-903. [PubMed: 8757810]

Rivera J, Casadevall A. Mouse genetic background is a major determinant of isotype-related differences for antibody-mediated protective efficacy against Cryptococcus neoformans. J Immunol 2005;174 (12):8017-26. [PubMed: 15944309]

Rivera J, Feldmesser M, Cammer M, Casadevall A. Organ-dependent variation of capsule thickness in Cryptococcus neoformans during experimental murine infection. Infect Immun 1998;66(10):502730. [PubMed: 9746613]

Rivera J, Zaragoza O, Casadevall A. Antibody-mediated protection against Cryptococcus neoformans pulmonary infection is dependent on B cells. Infect Immun 2005;73(2):1141-50. [PubMed: 15664957]

Robinson BE, Hall NK, Bulmer GS, Blackstock R. Suppression of responses to cryptococcal antigen in murine cryptococcosis. Mycopathologia 1982;80(3):157-63. [PubMed: 6219291]

Rodrigues ML, Alvarez M, Fonseca FL, Casadevall A. Binding of the wheat germ lectin to Cryptococcus neoformans suggests an association of chitinlike structures with yeast budding and capsular glucuronoxylomannan. Eukaryot Cell 2008a;7(4):602-9. [PubMed: 18039942]

Rodrigues ML, Nakayasu ES, Oliveira DL, Nimrichter L, Nosanchuk JD, Almeida IC, Casadevall A. Extracellular vesicles produced by Cryptococcus neoformans contain protein components associated with virulence. Eukaryot Cell 2008b;7(1):58-67. [PubMed: 18039940]

Rodrigues ML, Nimrichter L, Oliveira DL, Frases S, Miranda K, Zaragoza O, Alvarez M, Nakouzi A, Feldmesser M, Casadevall A. Vesicular polysaccharide export in Cryptococcus neoformans is a eukaryotic solution to the problem of fungal trans-cell wall transport. Eukaryot Cell 2007;6(1):4859. [PubMed: 17114598]

Rodrigues ML, Travassos LR, Miranda KR, Franzen AJ, Rozental S, de Souza W, Alviano CS, BarretoBergter E. Human antibodies against a purified glucosylceramide from Cryptococcus neoformans inhibit cell budding and fungal growth. Infect Immun 2000;68(12):7049-60. [PubMed: 11083830]

Rossi GR, Cervi LA, Sastre DA, Masih DT. Lack of involvement of nitric oxide in the macrophagemediated inhibition of spleen cell proliferation during experimental cryptococcosis. Clin Immunol Immunopathol 1998;86(1):16-26. [PubMed: 9434793]

Rubinstein HR, Sotomayor CE, Cervi LA, Riera CM, Masih DT. Immunosuppression in experimental cryptococcosis in rats: modification of macrophage functions by $\mathrm{T}$ suppressor cells. Macrophages functions in cryptococcosis. Mycopathologia 1989;108(1):11-9. [PubMed: 2533323]

Salkowski CA, Balish E. Susceptibility of congenitally immunodeficient mice to a nonencapsulated strain of Cryptococcus neoformans. Can J Microbiol 1991;37(11):834-9. [PubMed: 1777860]

Sanford JE, Lupan DM, Schlageter AM, Kozel TR. Passive immunization against Cryptococcus neoformans with an isotype-switch family of monoclonal antibodies reactive with cryptococcal polysaccharide. Infect Immun 1990;58(6):1919-23. [PubMed: 2341184]

Seixas F, Martins Mda L, de Lurdes Pinto M, Travassos PJ, Miranda M, Pires Mdos A. A case of pulmonary cryptococcosis in a free-living toad (Bufo bufo). J Wildl Dis 2008;44(2):460-3. [PubMed: 18436680]

Shapiro S, Beenhouwer DO, Feldmesser M, Taborda C, Carroll MC, Casadevall A, Scharff MD. Immunoglobulin $\mathrm{G}$ monoclonal antibodies to Cryptococcus neoformans protect mice deficient in complement component C3. Infect Immun 2002;70(5):2598-604. [PubMed: 11953401]

Shea JM, Kechichian TB, Luberto C, Del Poeta M. The cryptococcal enzyme inositol phosphosphingolipid-phospholipase $\mathrm{C}$ confers resistance to the antifungal effects of macrophages 
and promotes fungal dissemination to the central nervous system. Infect Immun 2006;74(10):597788. [PubMed: 16988277]

Shen G, Wang YL, Whittington A, Li L, Wang P. The RGS Protein Crg2 Regulates Pheromone and cAMP Signaling in Cryptococcus neoformans. Eukaryot Cell. 2008

Siafakas AR, Sorrell TC, Wright LC, Wilson C, Larsen M, Boadle R, Williamson PR, Djordjevic JT. Cell wall-linked cryptococcal phospholipase B1 is a source of secreted enzyme and a determinant of cell wall integrity. J Biol Chem 2007;282(52):37508-14. [PubMed: 17947228]

Siddiqui AA, Shattock RJ, Harrison TS. Role of capsule and interleukin-6 in long-term immune control of Cryptococcus neoformans infection by specifically activated human peripheral blood mononuclear cells. Infect Immun 2006;74(9):5302-10. [PubMed: 16926424]

Small JM, Mitchell TG. Strain variation in antiphagocytic activity of capsular polysaccharides from Cryptococcus neoformans serotype A. Infect Immun 1989;57(12):3751-6. [PubMed: 2680980]

Sommer U, Liu H, Doering TL. An alpha-1,3-mannosyltransferase of Cryptococcus neoformans. J Biol Chem 2003;278(48):47724-30. [PubMed: 14504286]

Spang A, Schekman R. Reconstitution of retrograde transport from the Golgi to the ER in vitro. J Cell Biol 1998;143(3):589-99. [PubMed: 9813082]

Specht CA, Nong S, Dan JM, Lee CK, Levitz SM. Contribution of glycosylation to T cell responses stimulated by recombinant Cryptococcus neoformans mannoprotein. J Infect Dis 2007;196(5):796800. [PubMed: 17674324]

Steenbergen JN, Nosanchuk JD, Malliaris SD, Casadevall A. Cryptococcus neoformans virulence is enhanced after growth in the genetically malleable host Dictyostelium discoideum. Infect Immun 2003;71(9):4862-72. [PubMed: 12933827]

Steenbergen JN, Shuman HA, Casadevall A. Cryptococcus neoformans interactions with amoebae suggest an explanation for its virulence and intracellular pathogenic strategy in macrophages. Proc Natl Acad Sci U S A 2001;98(26):15245-50. [PubMed: 11742090]

Sundstrom JB, Cherniak R. The glucuronoxylomannan of Cryptococcus neoformans serotype A is a type 2 T-cell-independent antigen. Infect Immun 1992;60(10):4080-7. [PubMed: 1398921]

Syme RM, Bruno TF, Kozel TR, Mody CH. The capsule of Cryptococcus neoformans reduces Tlymphocyte proliferation by reducing phagocytosis, which can be restored with anticapsular antibody. Infect Immun 1999;67(9):4620-7. [PubMed: 10456908]

Syme RM, Spurrell JC, Amankwah EK, Green FH, Mody CH. Primary dendritic cells phagocytose Cryptococcus neoformans via mannose receptors and Fcgamma receptor II for presentation to T lymphocytes. Infect Immun 2002;70(11):5972-81. [PubMed: 12379672]

Taborda CP, Casadevall A. Immunoglobulin M efficacy against Cryptococcus neoformans: mechanism, dose dependence, and prozone-like effects in passive protection experiments. J Immunol 2001;166 (3):2100-7. [PubMed: 11160261]

Taborda CP, Casadevall A. CR3 (CD11b/CD18) and CR4 (CD11c/CD18) Are Involved in ComplementIndependent Antibody-Mediated Phagocytosis of Cryptococcus neoformans. Immunity 2002;16 (6):791-802. [PubMed: 12121661]

Taborda CP, Rivera J, Zaragoza O, Casadevall A. More is not necessarily better: prozone-like effects in passive immunization with IgG. J Immunol 2003;170(7):3621-30. [PubMed: 12646626]

Takeo K, Uesaka I, Uehira K, Nishiura M. Fine structure of Cryptococcus neoformans grown in vitro as observed by freeze-etching. J Bacteriol 1973a;113(3):1442-8. [PubMed: 4347973]

Takeo K, Uesaka I, Uehira K, Nishiura M. Fine structure of Cryptococcus neoformans grown in vivo as observed by freeze-etching. J Bacteriol 1973b;113(3):1449-54. [PubMed: 4570787]

Todaro-Luck F, Reiss E, Cherniak R, Kaufman L. Characterization of Cryptococcus neoformans capsular glucuronoxylomannan polysaccharide with monoclonal antibodies. Infect Immun 1989;57(12): 3882-7. [PubMed: 2680986]

Torres M, Fernandez-Fuentes N, Fiser A, Casadevall A. The immunoglobulin heavy chain constant region affects kinetic and thermodynamic parameters of antibody variable region interactions with antigen. J Biol Chem 2007;282(18):13917-27. [PubMed: 17353196]

Torres M, May R, Scharff MD, Casadevall A. Variable-region-identical antibodies differing in isotype demonstrate differences in fine specificity and idiotype. J Immunol 2005;174(4):2132-42.

[PubMed: 15699144] 
Tucker SC, Casadevall A. Replication of Cryptococcus neoformans in macrophages is accompanied by phagosomal permeabilization and accumulation of vesicles containing polysaccharide in the cytoplasm. Proc Natl Acad Sci U S A 2002;99(5):3165-70. [PubMed: 11880650]

Turner SH, Cherniak R, Reiss E, Kwon-Chung KJ. Structural variability in the glucuronoxylomannan of Cryptococcus neoformans serotype A isolates determined by 13C NMR spectroscopy. Carbohydr Res 1992;233:205-18. [PubMed: 1446309]

Vaishnav VV, Bacon BE, O'Neill M, Cherniak R. Structural characterization of the galactoxylomannan of Cryptococcus neoformans Cap67. Carbohydr Res 1998;306(12):315-30. [PubMed: 9691456]

Valadon P, Nussbaum G, Boyd LF, Margulies DH, Scharff MD. Peptide libraries define the fine specificity of anti-polysaccharide antibodies to Cryptococcus neoformans. J Mol Biol 1996;261(1): 11-22. [PubMed: 8760499]

Valdivia RH, Schekman R. The yeasts Rholp and Pkc1p regulate the transport of chitin synthase III (Chs3p) from internal stores to the plasma membrane. Proc Natl Acad Sci U S A 2003;100(18): 10287-92. [PubMed: 12928491]

van de Moer A, Salhi SL, Cherniak R, Pau B, Garrigues ML, Bastide JM. An anti-Cryptococcus neoformans monoclonal antibody directed against galactoxylomannan. Res Immunol 1990;141(1): 33-42. [PubMed: 2189167]

van de Wetering JK, Coenjaerts FE, Vaandrager AB, van Golde LM, Batenburg JJ. Aggregation of Cryptococcus neoformans by surfactant protein $\mathrm{D}$ is inhibited by its capsular component glucuronoxylomannan. Infect Immun 2004;72(1):145-53. [PubMed: 14688091]

Vartivarian SE, Anaissie EJ, Cowart RE, Sprigg HA, Tingler MJ, Jacobson ES. Regulation of cryptococcal capsular polysaccharide by iron. J Infect Dis 1993;167(1):186-90. [PubMed: 8418165]

Vartivarian SE, Reyes GH, Jacobson ES, James PG, Cherniak R, Mumaw VR, Tingler MJ. Localization of mannoprotein in Cryptococcus neoformans. J Bacteriol 1989;171(12):6850-2. [PubMed: 2687257]

Vecchiarelli A. Immunoregulation by capsular components of Cryptococcus neoformans. Med Mycol 2000;38(6):407-17. [PubMed: 11204878]

Vecchiarelli A, Dottorini M, Pietrella D, Monari C, Retini C, Todisco T, Bistoni F. Role of human alveolar macrophages as antigen-presenting cells in Cryptococcus neoformans infection. Am J Respir Cell Mol Biol 1994a;11(2):130-7. [PubMed: 8049074]

Vecchiarelli A, Pietrella D, Dottorini M, Monari C, Retini C, Todisco T, Bistoni F. Encapsulation of Cryptococcus neoformans regulates fungicidal activity and the antigen presentation process in human alveolar macrophages. Clin Exp Immunol 1994b;98(2):217-23. [PubMed: 7955525]

Vecchiarelli A, Retini C, Casadevall A, Monari C, Pietrella D, Kozel TR. Involvement of C3a and C5a in interleukin-8 secretion by human polymorphonuclear cells in response to capsular material of Cryptococcus neoformans. Infect Immun 1998;66(9):4324-30. [PubMed: 9712784]

Vecchiarelli A, Retini C, Monari C, Tascini C, Bistoni F, Kozel TR. Purified capsular polysaccharide of Cryptococcus neoformans induces interleukin-10 secretion by human monocytes. Infect Immun 1996;64(7):2846-9. [PubMed: 8698522]

Vecchiarelli A, Retini C, Pietrella D, Monari C, Tascini C, Beccari T, Kozel TR. Downregulation by cryptococcal polysaccharide of tumor necrosis factor alpha and interleukin-1 beta secretion from human monocytes. Infect Immun 1995;63(8):2919-23. [PubMed: 7622213]

Vesely J, Rydner L, Oscarson S. Variant synthetic pathway to glucuronic acid-containing di- and trisaccharide thioglycoside building blocks for continued synthesis of Cryptococcus neoformans capsular polysaccharide structures. Carbohydr Res 2008;343(12):2200-8. [PubMed: 18155681]

Villena SN, Pinheiro RO, Pinheiro CS, Nunes MP, Takiya CM, Dosreis GA, Previato JO, MendoncaPreviato L, Freire-de-Lima CG. Capsular polysaccharides galactoxylomannan and glucuronoxylomannan from Cryptococcus neoformans induce macrophage apoptosis mediated by Fas ligand. Cell Microbiol. 2008

Vincken JP, Schols HA, Oomen RJ, McCann MC, Ulvskov P, Voragen AG, Visser RG. If homogalacturonan were a side chain of rhamnogalacturonan I. Implications for cell wall architecture. Plant Physiol 2003;132(4):1781-9. [PubMed: 12913136] 
Walenkamp AM, Chaka WS, Verheul AF, Vaishnav VV, Cherniak R, Coenjaerts FE, Hoepelman IM. Cryptococcus neoformans and its cell wall components induce similar cytokine profiles in human peripheral blood mononuclear cells despite differences in structure. FEMS Immunol Med Microbiol 1999;26(34):309-18. [PubMed: 10575143]

White CW, Cherniak R, Jacobson ES. Side group addition by xylosyltransferase and glucuronyltransferase in biosynthesis of capsular polysaccharide in Cryptococcus neoformans. $\mathrm{J}$ Med Vet Mycol 1990;28(4):289-301. [PubMed: 2125312]

White CW, Jacobson ES. Mannosyl transfer in Cryptococcus neoformans. Can J Microbiol 1993;39(1): 129-33. [PubMed: 8439868]

Whitfield C. Biosynthesis and assembly of capsular polysaccharides in Escherichia coli. Annu Rev Biochem 2006;75:39-68. [PubMed: 16756484]

Whitfield C, Kaniuk N, Frirdich E. Molecular insights into the assembly and diversity of the outer core oligosaccharide in lipopolysaccharides from Escherichia coli and Salmonella. J Endotoxin Res 2003;9(4):244-9. [PubMed: 12935355]

Wilder JA, Olson GK, Chang YC, Kwon-Chung KJ, Lipscomb MF. Complementation of a capsule deficient Cryptococcus neoformans with CAP64 restores virulence in a murine lung infection. Am J Respir Cell Mol Biol 2002;26(3):306-14. [PubMed: 11867339]

Wills EA, Roberts IS, Del Poeta M, Rivera J, Casadevall A, Cox GM, Perfect JR. Identification and characterization of the Cryptococcus neoformans phosphomannose isomerase-encoding gene, MAN1, and its impact on pathogenicity. Mol Microbiol 2001;40(3):610-20. [PubMed: 11359567]

Woyke T, Roberson RW, Pettit GR, Winkelmann G, Pettit RK. Effect of auristatin PHE on microtubule integrity and nuclear localization in Cryptococcus neoformans. Antimicrob Agents Chemother 2002;46(12):3802-8. [PubMed: 12435680]

Xue C, Bahn YS, Cox GM, Heitman J. G protein-coupled receptor Gpr4 senses amino acids and activates the cAMP-PKA pathway in Cryptococcus neoformans. Mol Biol Cell 2006;17(2):667-79. [PubMed: 16291861]

Yasuoka A, Kohno S, Yamada H, Kaku M, Koga H. Influence of molecular sizes of Cryptococcus neoformans capsular polysaccharide on phagocytosis. Microbiol Immunol 1994;38(11):851-6. [PubMed: 7898383]

Yauch LE, Lam JS, Levitz SM. Direct inhibition of T-cell responses by the Cryptococcus capsular polysaccharide glucuronoxylomannan. PLoS Pathog 2006;2(11):e120. [PubMed: 17096589]

Yauch LE, Mansour MK, Levitz SM. Receptor-mediated clearance of Cryptococcus neoformans capsular polysaccharide in vivo. Infect Immun 2005;73(12):8429-32. [PubMed: 16299344]

Yauch LE, Mansour MK, Shoham S, Rottman JB, Levitz SM. Involvement of CD14, toll-like receptors 2 and 4, and MyD88 in the host response to the fungal pathogen Cryptococcus neoformans in vivo. Infect Immun 2004;72(9):5373-82. [PubMed: 15322035]

Yoneda A, Doering TL. A eukaryotic capsular polysaccharide is synthesized intracellularly and secreted via exocytosis. Mol Biol Cell 2006;17(12):5131-40. [PubMed: 17021252]

Yoneda A, Doering TL. Regulation of Cryptococcus neoformans capsule size is mediated at the polymer level. Eukaryot Cell 2008;7(3):546-9. [PubMed: 18156288]

Yuan R, Clynes R, Oh J, Ravetch JV, Scharff MD. Antibody-mediated modulation of Cryptococcus neoformans infection is dependent on distinct $\mathrm{Fc}$ receptor functions and $\mathrm{IgG}$ subclasses. J Exp Med 1998;187(4):641-8. [PubMed: 9463414]

Yuan RR, Casadevall A, Oh J, Scharff MD. T cells cooperate with passive antibody to modify Cryptococcus neoformans infection in mice. Proc Natl Acad Sci U S A 1997;94(6):2483-8. [PubMed: 9122221]

Zaragoza O, Casadevall A. Experimental modulation of capsule size in Cryptococcus neoformans. Biol Proced Online 2004;6:10-15. [PubMed: 15103395]

Zaragoza O, Casadevall A. Monoclonal antibodies can affect complement deposition on the capsule of the pathogenic fungus Cryptococcus neoformans by both classical pathway activation and steric hindrance. Cell Microbiol 2006;8(12):1862-76. [PubMed: 16824038]

Zaragoza O, Cuenca-Estrella M, Regadera J, Rodriguez Tudela JL. The capsule of the fungal pathogen Cryptococcus neoformans paradoxically inhibits invasive growth. The Open Mycology Journal 2008a;2:29-39. 
Zaragoza O, Chrisman CJ, Castelli MV, Frases S, Cuenca-Estrella M, Rodriguez Tudela JL, Casadevall A. Capsule enlargement in Cryptococcus neoformans confers resistance to oxidative stress suggesting a mechanism for intracellular survival. Cell Microbiol. 2008bPubmed ahead of print

Zaragoza O, Fries BC, Casadevall A. Induction of capsule growth in Cryptococcus neoformans by mammalian serum and CO(2). Infect Immun 2003a;71(11):6155-64. [PubMed: 14573631]

Zaragoza O, McClelland EE, Telzak A, Casadevall A. Equatorial ring-like channels in the Cryptococcus neoformans polysaccharide capsule. FEMS Yeast Res 2006a;6(4):662-6. [PubMed: 16696663]

Zaragoza O, Taborda CP, Casadevall A. The efficacy of complement-mediated phagocytosis of Cryptococcus neoformans is dependent on the location of $\mathrm{C} 3$ in the polysaccharide capsule and involves both direct and indirect C3-mediated interactions. Euro. J. Immnunol 2003b;33:19571967.

Zaragoza O, Telzak A, Bryan RA, Dadachova E, Casadevall A. The polysaccharide capsule of the pathogenic fungus Cryptococcus neoformans enlarges by distal growth and is rearranged during budding. Mol Microbiol 2006b;59(1):67-83. [PubMed: 16359319] 

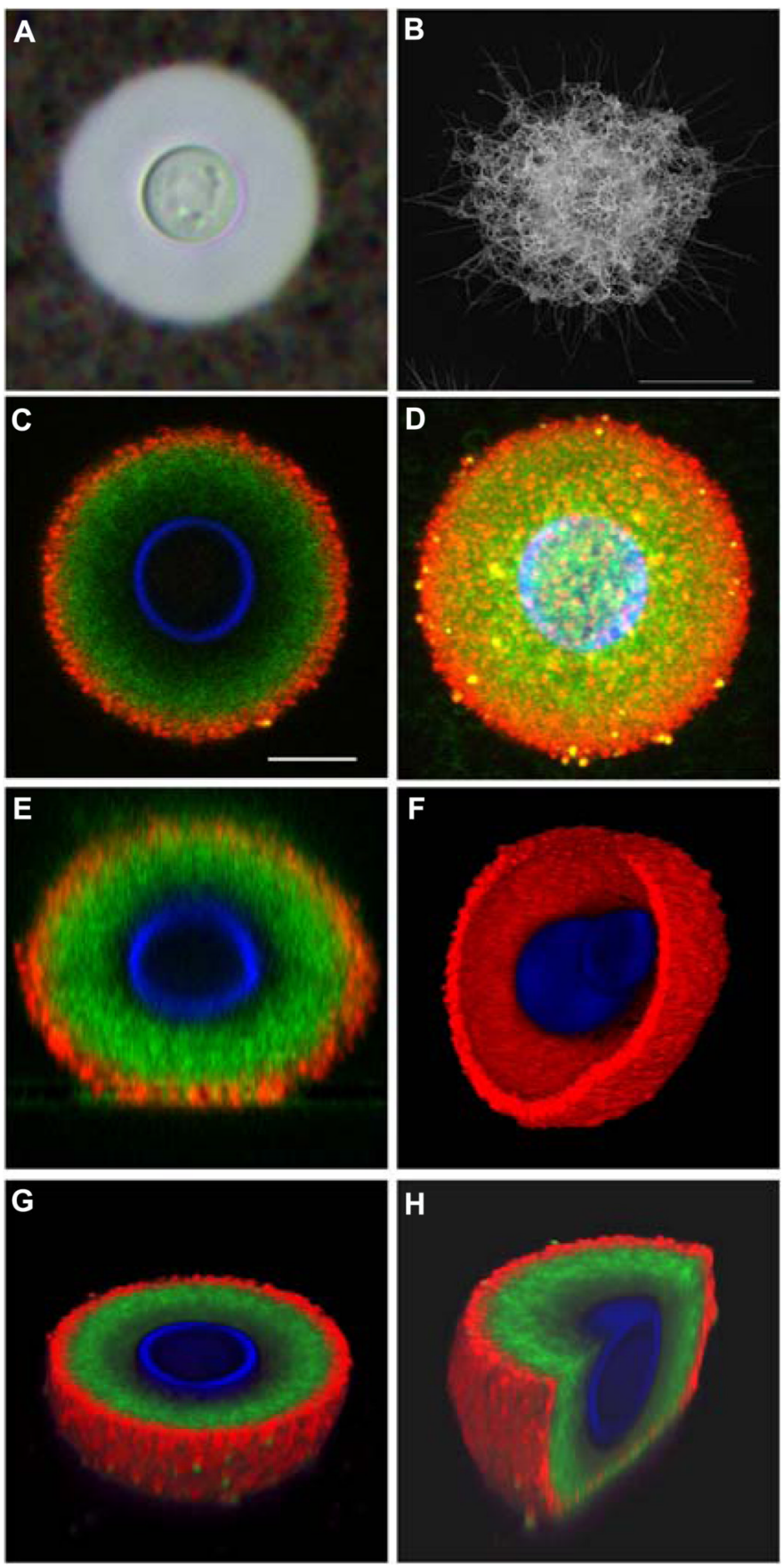

Figure 1.

Different micrographs and compositions showing the polysaccharide capsule of $C$. neoformans. A) Suspension of the cells in India Ink; B) Scanning electron microscopy; C-H) Immunofluorescence using specific $\mathrm{mAbs}$ to the capsule (green and red fluorescence) showing also the cell wall localization (blue flurorescence). D) 3D image composition of a $\mathrm{C}$.

neoformans cell labeled with two different mAbs to the capsule. In blue, the cell wall. E) Side view of a section of cell shown in D. F-H) Sections showing the 3 dimension of the capsule, visualized after staining with mAbs (green and red). Pictures by Oscar Zaragoza, and from (Maxson et al, 2007b). 


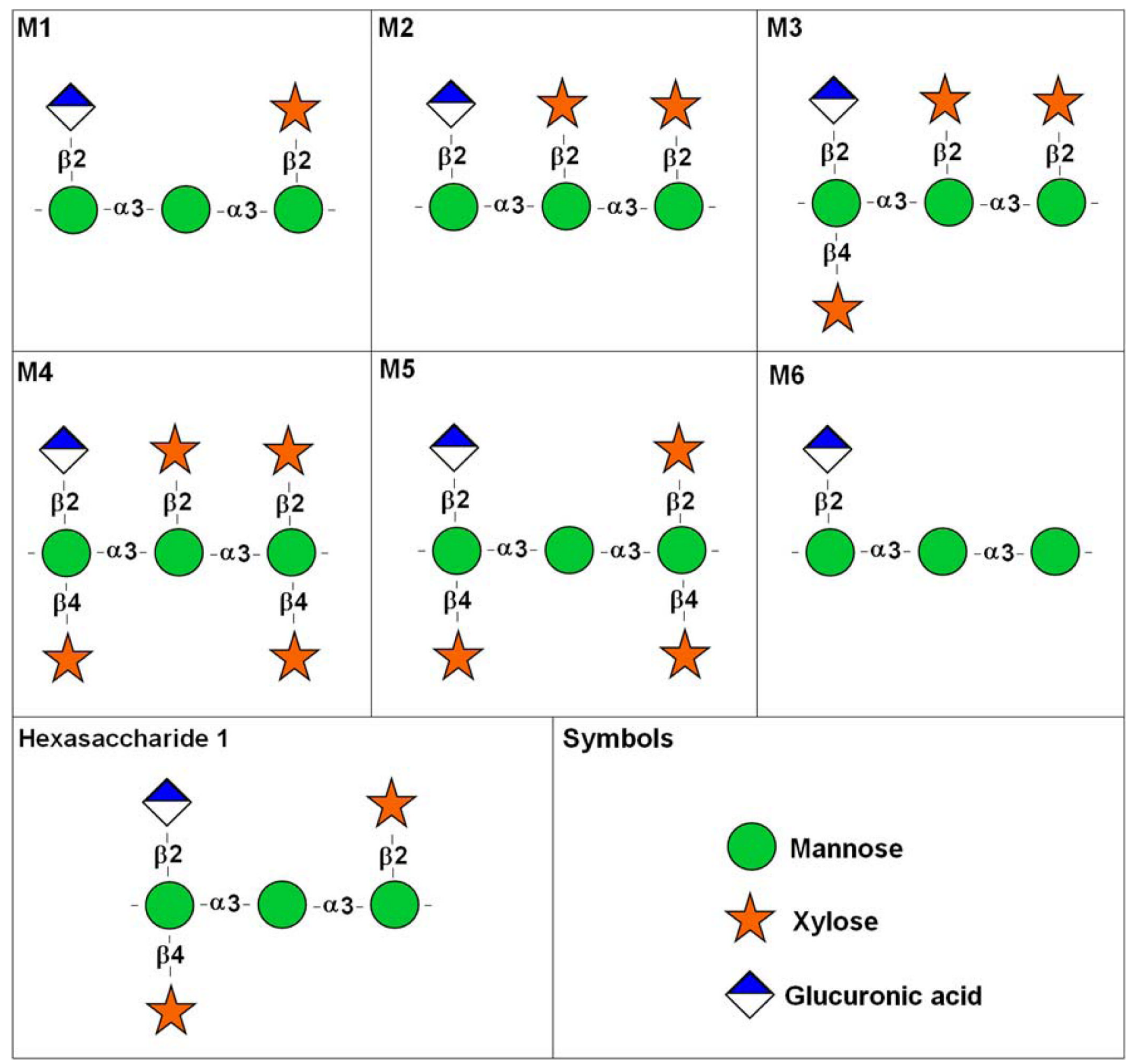

Figure 2. Repeating polysaccharide motifs of GXM

Motifs M1 to M6, which were described by Cherniak and colleagues (1998) as the major structure reporter groups (SRG) of GXM, are shown. Hexasaccharide 1, an additional GXM substituted triad, is also presented. Symbol nomenclature for glycans followed the format available in http://grtc.ucsd.edu/symbol.html. 


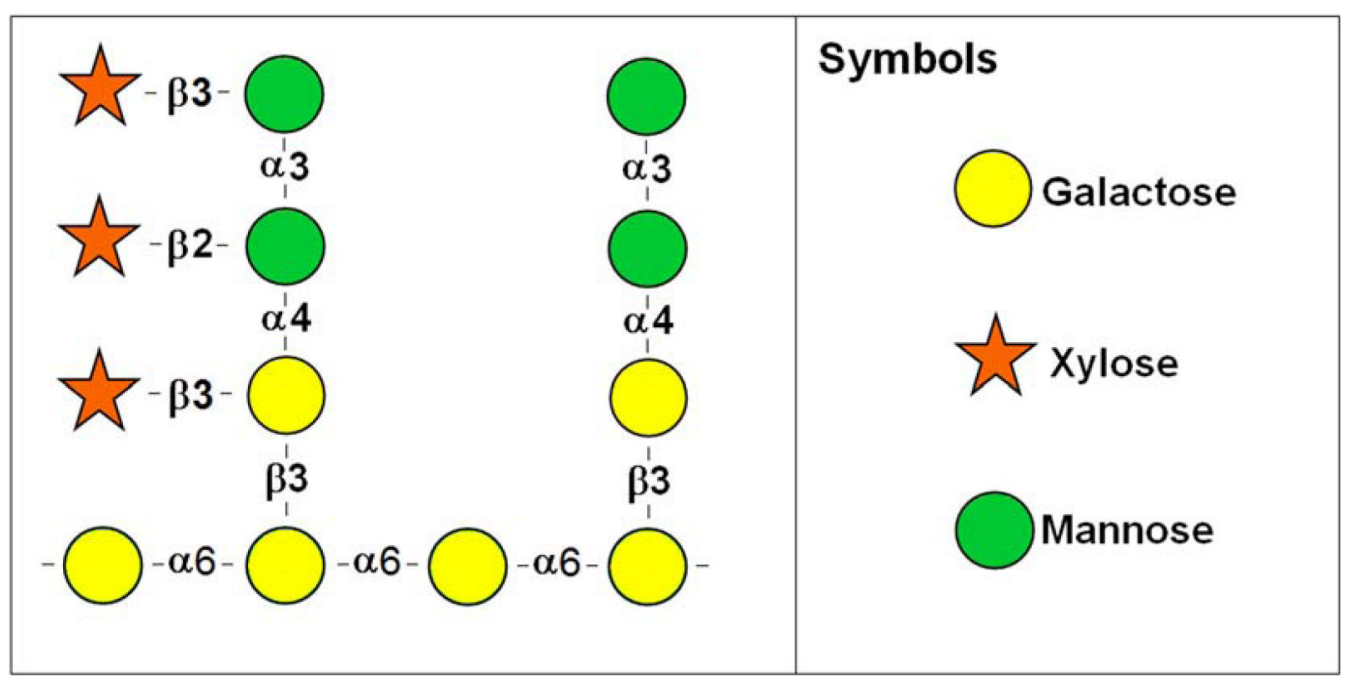

Figure 3. Basic GalXM structure

A GalXM motif has a $\alpha(1 \rightarrow 6)$ galactan backbone. The branches are $\beta$ - 3-O-linked to the backbone and consist of an $\alpha(1 \rightarrow 3)$-Man, $\alpha(1 \rightarrow 4)$-Man, $\beta$-galactosidase trisaccharide with variable amounts of $\beta(1 \rightarrow 2)$ - or $\beta(1 \rightarrow 3)$-xylose side groups. Symbol nomenclature for glycans followed the format available in http://grtc.ucsd.edu/symbol.html. 

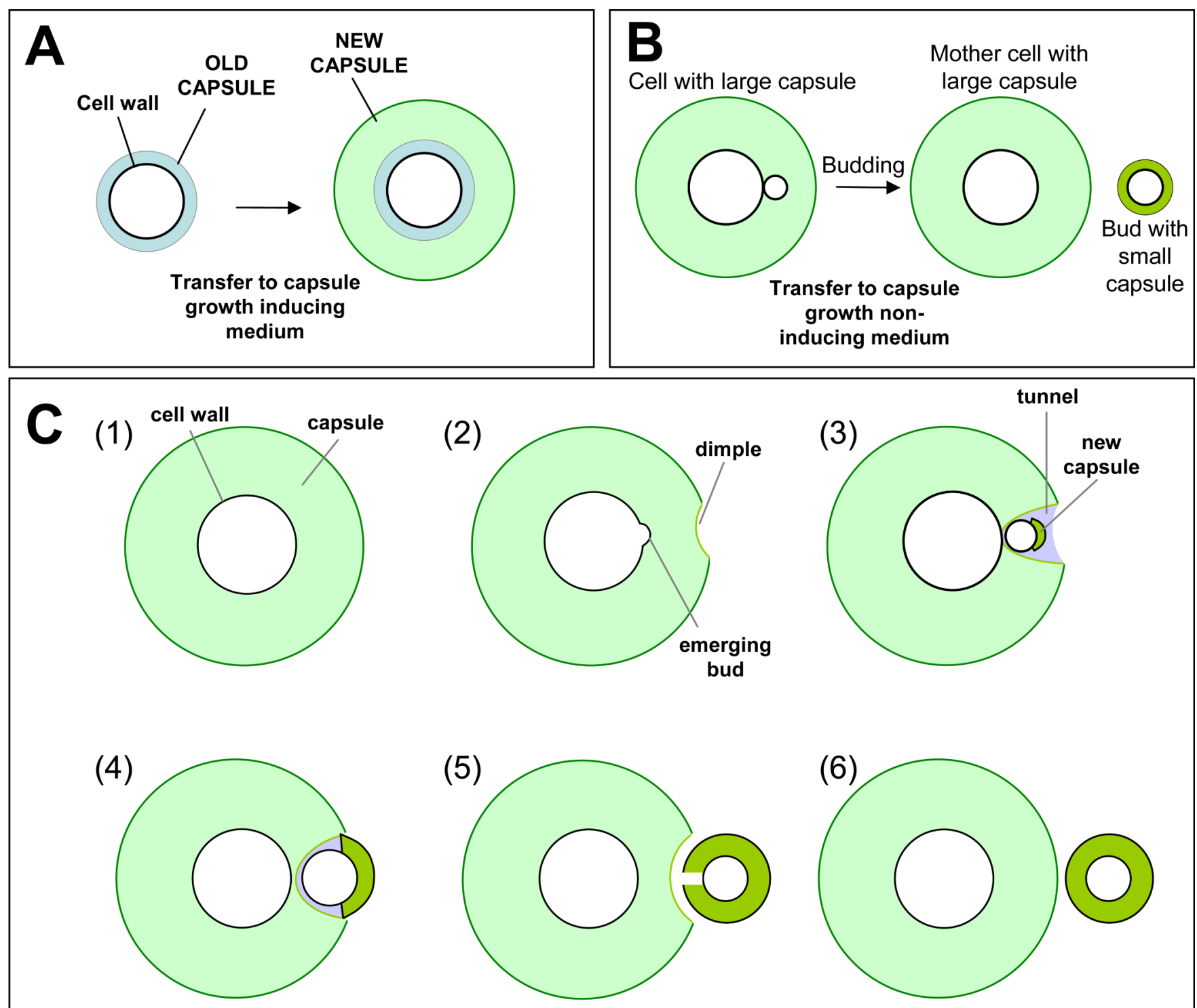

Figure 4.

Model of capsule growth and capsule rearrangements during budding in C. neoformans (From Zaragoza et al, 2006b). A. Model of capsule growth. After capsule enlarges a newly synthesized capsule (light green) accumulates at the edge of the capsule, with the old capsule (light blue) remaining close to the cell wall. B. Model of adaptation to non-capsule growth inducing conditions. Cells with large capsules, when transferred to a medium that does not induce capsule growth, cannot degrade the capsule, but the new emerging buds have a small capsule. C. Rearrangements of the capsule during budding. Panels 1-6 illustrate schematically different stages of budding. When bud arises, a dimple and a tunnel are formed $(2,3)$, which allows the separation of the bud. Bud growth is accompanied by capsule growth in the bud $(3,4)$. Capsule of the mother cell closes as the bud separates from the mother cell, at the same time that the bud completes the capsule without taking any polysaccharide of the mother cell (5), which will allow for the complete separation of the bud (6). 


\section{Capsular polysaccharide}

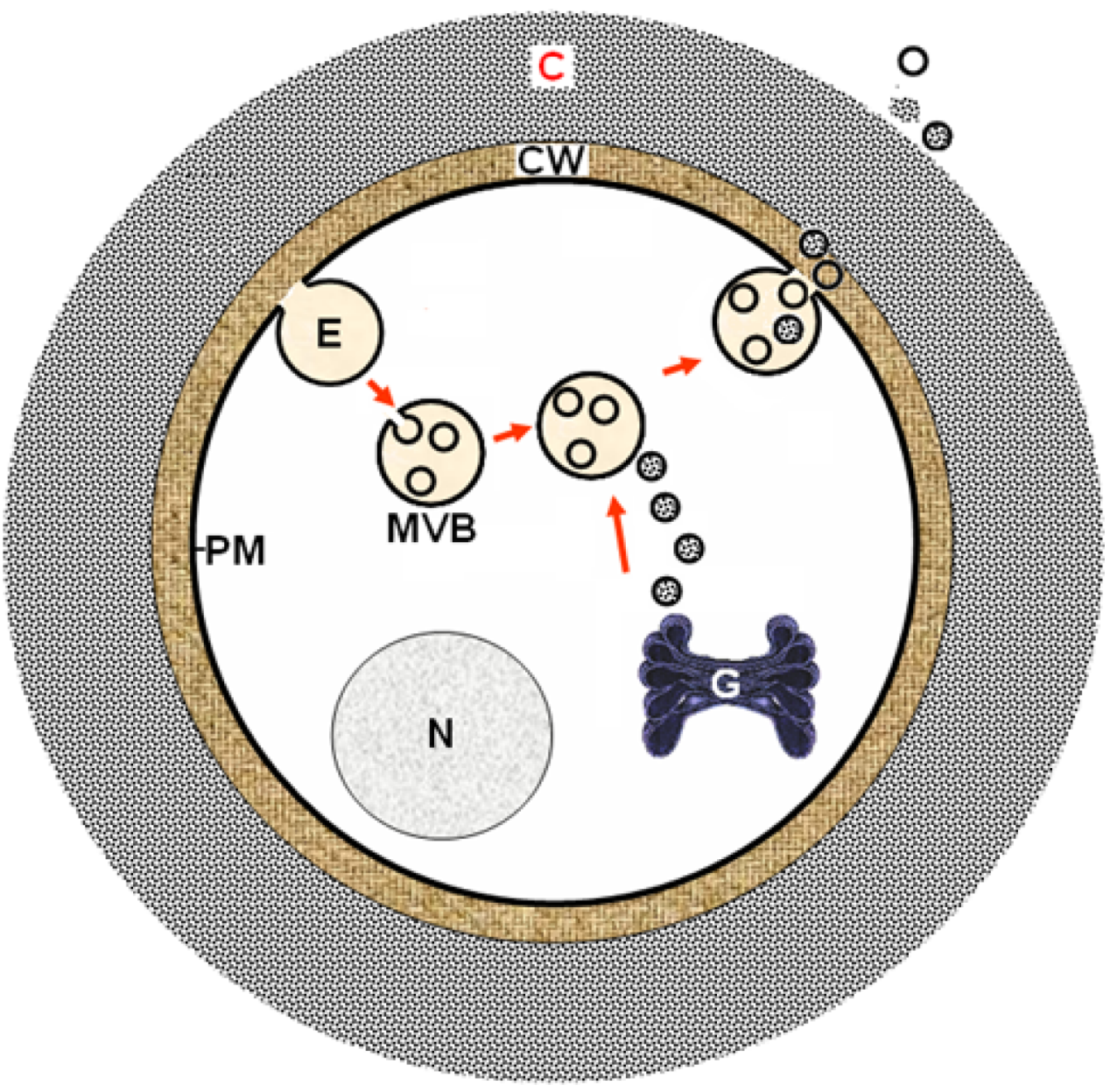

Figure 5. Proposed model for GXM traffic in C. neoformans

GXM is synthesized in the Golgi apparatus and released in post-Golgi vesicles. These vesicles would be integrated into endocytic compartments / multivesicular bodies that are further addressed to the plasma membrane. After fusion of endosome-derived structures with the plasma membrane, small vesicles are released into the periplasmic space to be translocated to the extracellular space. Extracellular vesicles would then release their content, which includes capsular polysaccharides. Abbreviations: N, nucleus; G, Golgi apparatus; PM, plasma membrane; E, endosome; MVB, multivesicular body; CW, cell wall; C, capsule. 
Figure 6. Cell wall-capsule connections in $C$. neoformans

Staining of capsular structures with a monoclonal antibody to GXM (green), cell wall chitin with calcofluor white (blue), and chitin-derived oligomers with WGA (red) followed by confocal analysis reveals that projected structures recognized by WGA connect the cell wall and the capsule. For experimental details, see (Rodrigues et al., 2008a). 


\section{Capsular Polysaccharide Antigens Activate Cell Death.}

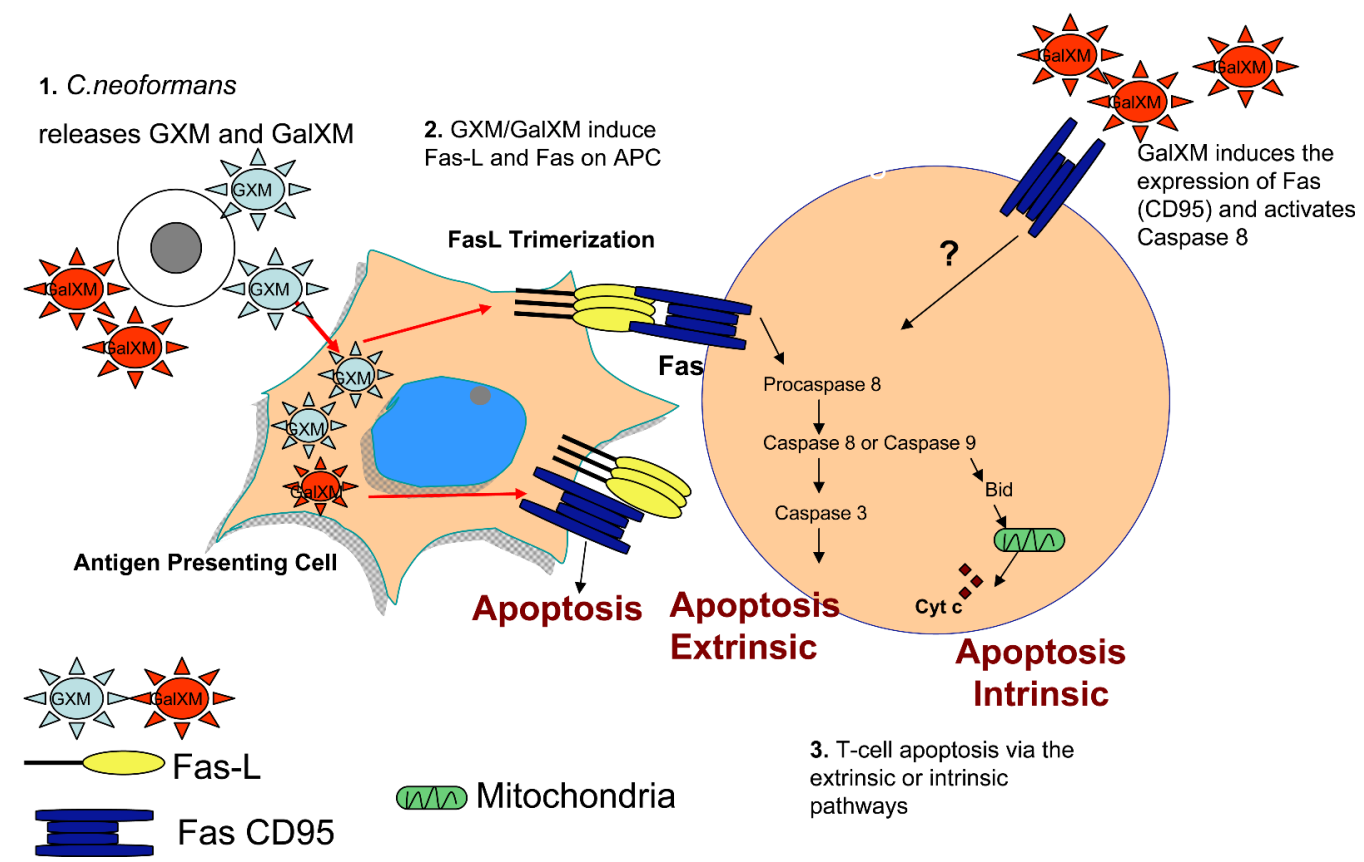

Figure 7.

Scheme summarizing all the levels at which capsular polysaccharides induce apoptosis on antigen presenting cells and T-cells. GXM and GalXM induce apoptosis on antigen presenting cells, such as macrophages, and T-cells. In macrophages, GXM and GalXM induce accumulation of molecules involved in apoptosis induction, such as FasL and Fas. These molecules induce apoptosis in both macrophages and T-cells. In addition, in T-cells, GalXM can directly induce apoptosis through Fas molecules. Apoptosis occurs through caspase pathway. 

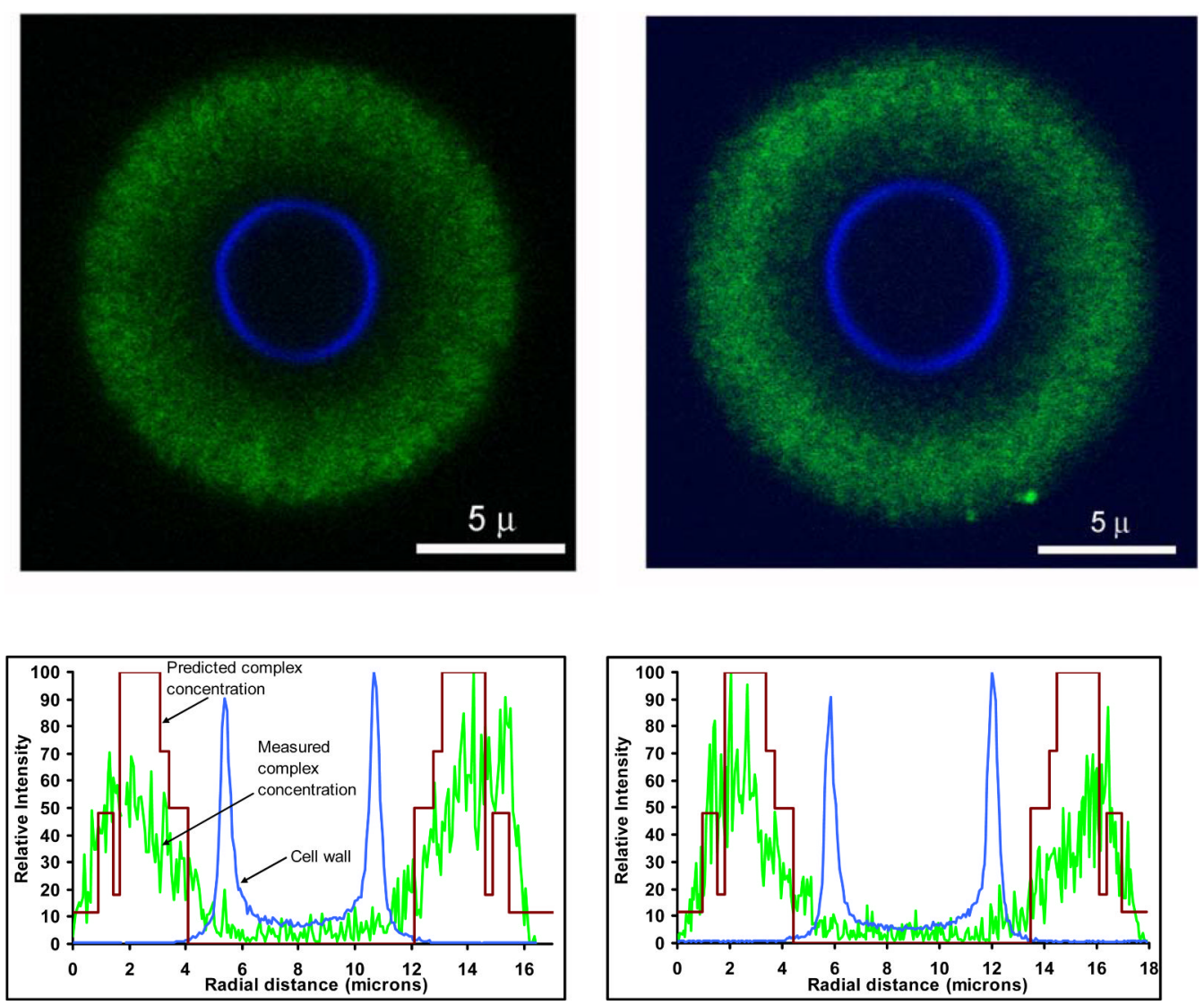

Figure 8.

Comparison of model prediction with experimental results obtained for $C$. neoformans cells using immunofluorescence. Green shows the concentration of complex. The boundaries of the cell wall are shown in blue, detected using calcoflour. Shown are data for two cell sizes (adapted from Rakesh et.al, 2008). 
Table 1

Genes involved in capsule synthesis in $C$. neoformans.

\begin{tabular}{|c|c|c|}
\hline Gene & Putative biochemical functions & Reference \\
\hline CAP59 & $\begin{array}{l}\text { Similar to } C M T 1 \text {, a gene encoding for mannosyltransferase; regulation } \\
\text { of polysaccharide secretion }\end{array}$ & $\begin{array}{l}\text { (Chang and Kwon-Chung, 1994; Garcia- } \\
\text { Rivera et al., 2004; Sommer et al., 2003) }\end{array}$ \\
\hline CAP64 & $\begin{array}{l}\text { Displays similarity to } P R E 1 \text {, a gene encoding the yeast proteasome } \\
\text { subunit }\end{array}$ & (Chang et al., 1996) \\
\hline CAP60 & $\begin{array}{l}\text { Displays similarity to similarity to } C E L 1 \text {, a cellulose growth-specific } \\
\text { gene of } A \text {. bisporus, }\end{array}$ & (Chang and Kwon-Chung, 1998) \\
\hline CAP10 & Similar to $C X T 1$, a gene enconding xylosyltransferase & $\begin{array}{l}\text { (Chang and Kwon-Chung, 1999; Klutts et } \\
\text { al., 2007) }\end{array}$ \\
\hline CIR1 & Iron sensing & (Lian et al., 2005) \\
\hline GPA1 & Protein $\mathrm{G}$ alpha subunit 1 , signal transduction pathways & (Alspaugh et al., 1997) \\
\hline GPR4 & G protein-coupled receptor, signal transduction pathways & (Xue et al., 2006) \\
\hline PKA1 & $\begin{array}{l}\text { cAMP-dependent protein kinase catalytic subunit, signal transduction } \\
\text { pathways }\end{array}$ & (D'Souza et al., 2001) \\
\hline PKR1 & Protein kinase regulatory subunit, signal transduction pathways & (D'Souza et al., 2001) \\
\hline PDE1 & Low-affinity phosphodiesterases; regulation of cAMP levels & (Hicks et al., 2005) \\
\hline$C A C 1$ & Adenylyl cyclase, signal transduction pathways & (Alspaugh et al., 2002) \\
\hline ACAl & Adenylyl cyclase-associated protein 1 , signal transduction pathways & (Bahn et al., 2004) \\
\hline CAN2 & Carbonic anhydrase $2, \mathrm{CO}_{2}$ sensing & (Mogensen et al., 2006) \\
\hline$N R G 1$ & Carbohydrate-regulated transcription factor & (Cramer et al., 2006) \\
\hline MAN1 & GDP-mannose biosynthesis & (Wills et al., 2001) \\
\hline GMT1 & Mannose transporter & (Cottrell et al., 2007) \\
\hline$U G D 1$ & UDP-glucuronic acid biosynthesis & $\begin{array}{l}\text { (Bar-Peled et al., 2004; Griffith et al., 2004; } \\
\text { Jacobson, 1987; Moyrand and Janbon, } \\
\text { 2004) }\end{array}$ \\
\hline UXS1 & UDP-xylose biosynthesis & $\begin{array}{l}\text { (Bar-Peled et al., 2001; Moyrand et al., } \\
\text { 2004) }\end{array}$ \\
\hline CMT1 & Mannosyltransferase & (Sommer et al., 2003) \\
\hline CASI & GXM O-acetylation & (Janbon et al., 2001) \\
\hline CAS3 & GXM O-acetylation & (Moyrand et al., 2004) \\
\hline CAS31 & GXM O-acetylation & (Moyrand et al., 2004) \\
\hline CXT1 & Xylosyltransferase & $\begin{array}{l}\text { (Klutts and Doering, 2008; Klutts et al., } \\
\text { 2007) }\end{array}$ \\
\hline
\end{tabular}

